Document downloaded from:

http://hdl.handle.net/10251/93339

This paper must be cited as:

Toscani, A.; Marín-Hernández, C.; Moragues Pons, ME.; Sancenón Galarza, F.; Dingwall, P.; Brown, NJ.; Martínez-Máñez, R.... (2015). Ruthenium(II) and Osmium(II) Vinyl Complexes as Highly Sensitive and Selective Chromogenic and Fluorogenic Probes for the Sensing of Carbon Monoxide in Air. Chemistry - A European Journal. 21(41):14529-14538. doi:10.1002/chem.201501843

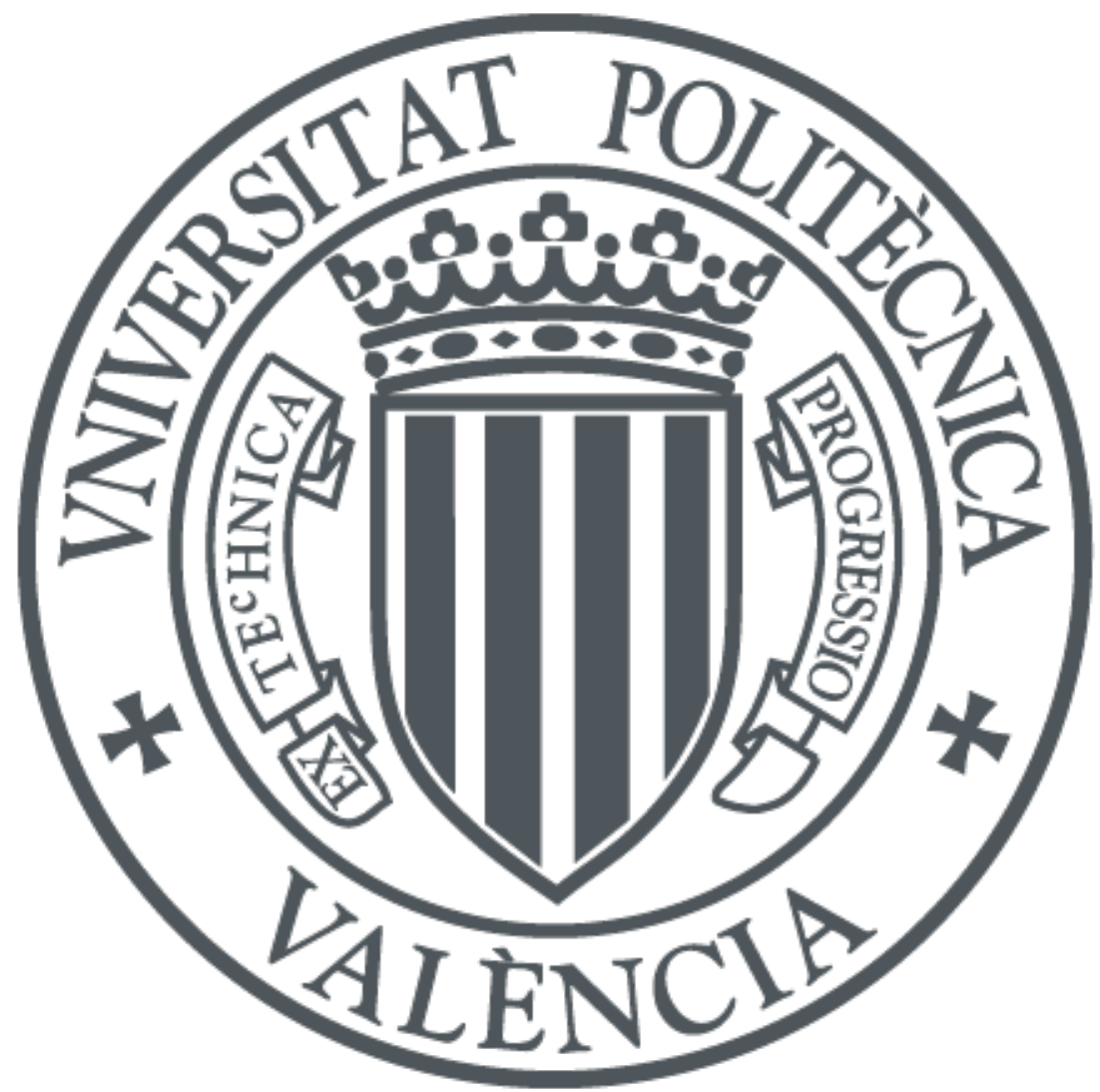

The final publication is available at

http://doi.org/10.1002/chem.201501843

Copyright John Wiley \& Sons

Additional Information 


\title{
Ruthenium(II) and Osmium(II) Vinyl Complexes as Highly Sensitive and Selective Chromogenic and Fluorogenic Probes for the Sensing of Carbon Monoxide in Air
}

\author{
Anita Toscani, ${ }^{[\mathrm{d},+]}$ Cristina Marín-Hernández, ${ }^{[\mathrm{a}, \mathrm{b}, \mathrm{c},+]}$ María E. Moragues, ${ }^{[\mathrm{a}, \mathrm{b}, \mathrm{c}]}$ Félix Sancenón, ${ }^{[\mathrm{a}, \mathrm{b}, \mathrm{c}]}$ Paul \\ Dingwall, ${ }^{[\mathrm{d}]}$ Neil J. Brown, ${ }^{[\mathrm{dd}]}$ Ramón Martínez-Máñez, ${ }^{[\mathrm{a}, \mathrm{b}, \mathrm{c}] \star}$ Andrew J. P. White ${ }^{\left[{ }^{[d]}\right.}$ James D. E. T. Wilton- \\ Ely ${ }^{[\mathrm{d}] *}$
}

Abstract: The detection of carbon monoxide in both solution and air has been achieved using simple, inexpensive systems based on the vinyl complexes $\left[\mathrm{M}(\mathrm{CH}=\mathrm{CHR}) \mathrm{Cl}(\mathrm{CO})(\mathrm{BTD})\left(\mathrm{PPh}_{3}\right)_{2}\right](\mathrm{R}=$ aryl, $\mathrm{BTD}=$ 2,1,3-benzothiadiazole). Depending on the nature of the vinyl group, chromogenic and fluorogenic responses signalled the presence of this odourless, tasteless, invisible and toxic gas. Chloroform solutions of the complexes underwent rapid change between easily differentiated colours when exposed to air samples containing $\mathrm{CO}$. More significantly, adsorbing the complexes on silica produced colorimetric probes for the 'naked eye' detection of $\mathrm{CO}$ in the gas phase. Structural data for key species before and after addition of carbon monoxide were obtained by single X-ray diffraction techniques. In all cases the ruthenium and osmium vinyl complexes studied showed a highly selective response to $\mathrm{CO}$ with exceptionally low detection limits. Naked eye detection of $\mathrm{CO}$ at concentrations as low as $5 \mathrm{ppb}$ in air was achieved with the onset of toxic levels (100 $\mathrm{ppm}$ ) resulting in a remarkably clear colour change. Moreover, complexes bearing pyrene, naphthalene and phenanthrene moieties were fluorescent and greater sensitivities were achieved (through turn-on emission fluorescence) in the presence of carbon monoxide, both in solution and in air. This behaviour was explored computationally using TDDFT experiments. Additionally, the systems were shown to be selective for $\mathrm{CO}$ over all other gases tested, including water vapour and common organic solvents. Supporting the metal complexes on cellulose strips for use in an existing optoelectronic device allows numerical readings for $\mathrm{CO}$ concentration to be obtained and provision of an alarm system.

[a] C. Marín-Hernández, Dr. M. E. Moragues, Dr. F. Sancenón, Prof. R. Martínez-Máñez

Centro de Reconocimiento Molecular y Desarrollo Tecnológico (IDM), Unidad Mixta Universidad Politécnica de Valencia-

Universidad de Valencia. Spain. E-mail: rmaez@qim.upv.es Homepage: http://idm.webs.upv.es/

[b] Departamento de Química, Universidad Politécnica de Valencia, Camino de Vera s/n, E-46022 Valencia, Spain. Fax: (+34) 96-3879349

[c] CIBER de Bioingeniería Biomateriales y Nanomedicina (CIBERBBN)

[d] A. Toscani, Dr. P. Dingwall, Dr. N. J. Brown, Dr. A. J. P. White, Prof. J. D. E. T. Wilton-Ely*

Department of Chemistry, Imperial College London, SW7 2AZ,

London, UK. E-mail: j.wilton-ely@imperial.ac.uk

Homepage: http://imperial.ac.uk/people/j.wilton-ely

Fax: (+44) 207-594-5804

+ Both authors contributed equally to the present work.

Supporting information for this article (including a video) is given via a link at the end of the document.
Introduction

The selective detection of gases which are toxic at low concentrations is one of the most promising applications of optical sensors. Among such gases, carbon monoxide stands out due to its high toxicity and its common presence in both domestic and work settings as well as other environments frequented by the general public. Traditionally, electrochemical cells, solid-state sensors and thermocouples have been used to accomplish routine $\mathrm{CO}$ detection. Electrochemical sensors based on metal-oxide semiconductors generally possess reasonably good resolution and measuring ranges. However, these are very sensitive to temperature and pressure. ${ }^{[1]}$ Indeed, solid-state $\mathrm{CO}$ sensors based on $\mathrm{ZnO}$ and $\mathrm{SnO}_{2}$ require such high working temperatures that their use is restricted to specific laboratory applications. ${ }^{[2]}$ Moreover, the optical sensors which have been reported use either narrowband spectrum lasers ${ }^{[3]}$ or non-dispersive infrared (NDIR $)^{[4]}$ systems. Although currently the most accurate method to measure $\mathrm{CO}$ concentrations in urban air samples, NDIR systems are also sensitive to relatively low concentrations of other common gases (interferents), such as $\mathrm{CO}_{2}, \mathrm{NO}_{\mathrm{x}}$, hydrocarbons or water vapour. In order to avoid false alarms, current commercial $\mathrm{CO}$ detectors have to be sited carefully in environments where water vapour (steam) or particulates (smoke) are generated, such as kitchens and bathrooms. These can also be triggered by the presence of solvents (from cleaning products, hairspray) or fuels (e.g., in mechanical or automotive workshops). Therefore, there is an increasing interest in the development of chemical sensor systems capable of selectively detecting the presence of carbon monoxide in air at low concentrations. In this context, colorimetric methods are especially undemanding, offering several advantages over other analytical procedures, such as real-time monitoring and the use of very simple and inexpensive instrumentation. Additionally, certain colorimetric changes, even at low concentration of analytes, can be observed by the naked eye, making chromogenic approaches unbeatable for certain applications. In the context of these factors, several chromogenic probes for $\mathrm{CO}$ detection have been reported recently. One of the first examples, by Ito and co-workers, uses acetonitrile solutions of an oxo-acetato-bridged triruthenium cluster. In this system, a photosensitizing electron donor (zinc tetraphenylporphyrin) controls the redox state of the metal centre, allowing the exchange of weakly coordinating solvent molecules by $\mathrm{CO}$, resulting in colour changes. ${ }^{[5]}$ Another example involves the selective optical monitoring of $\mathrm{CO}$ by covalently immobilized bimetallic rhodium complexes on glass substrates. Despite the poorly resolved changes in colour, a detection limit as low as $2.5 \mathrm{ppm}$ of $\mathrm{CO}$ can be determined by 
UV-Vis measurements on this monolayer-based sensor. ${ }^{[6]}$ Kirchner and co-workers prepared a penta-coordinate iron diisopropylphosphino diaminopyridine pincer complex that gives rise to a clear colour change (from yellow to red) in the solid state upon exposure to $\mathrm{CO}$, but only with high concentrations of the gas (1 atm). However, the generation of the resultant hexacoordinate derivative is stereospecific and the $\mathrm{CO}$ binding is fully reversible. ${ }^{[7]}$ Redox polymers functionalized with porphyrins have also been used for the recognition of $\mathrm{CO}$. Polypyrrole can be functionalized with tetraphenylporphyrin iron(III) chloride units and the polymer formed is able to detect $\mathrm{CO}$ in water/methanol solutions with a detection limit as low as 100 ppm. ${ }^{[8]}$ Very recently, sensitive and selective $\mathrm{CO}$ detection in air was accomplished by some of us via the use of binuclear rhodium complexes. Silica probes of these rhodium(II) complexes allowed the 'naked eye' detection of $\mathrm{CO}$ concentrations of around $50 \mathrm{ppm}$, resulting from a colour change on axial coordination of the $\mathrm{CO}$ to the metal complexes. ${ }^{[9]}$ Finally, a P-S$\mathrm{N}$ iron(II) complex was reported recently which achieves the chromogenic sensing of $\mathrm{CO}$ (albeit only in solution). Purple acetonitrile solutions of the complex become orange on exposure to high concentrations of $\mathrm{CO}$ (passing a $1 \mathrm{~atm}$ stream of $\mathrm{CO}$ through the solution for 5 mins). The colour change observed is ascribed to the reversible binding of $\mathrm{CO}$ to form the corresponding octahedral iron monocarbonyl complex. ${ }^{[10]}$

In spite of the significant progress made during the past decade, developing a readily applicable and highly sensitive molecular visual detection system for $\mathrm{CO}$ in air remains a challenge. The design of such systems requires not only selectivity and sensitivity towards a given analyte but, in the case of highly poisonous gases such as $\mathrm{CO}$, the detection process must be both rapid and reliable (stable). While the systems described above display novel and ingenious approaches to $\mathrm{CO}$ sensing, some of them have drawbacks such as detecting $\mathrm{CO}$ only in solution, requiring expensive, nonportable instrumentation or showing limits of detection unsuitable for the early warning of the presence of sub-acute levels of $\mathrm{CO}$ in air. In addition, the relative cost, synthetic difficulty and stability of these systems are also potential issues. Lastly, in order to compete with current electronic systems, a molecular probe must be readily integrated into a device which can display a reading and sound an alarm.

In order to understand the extent of the issues surrounding human exposure to carbon monoxide, it is helpful to describe its occurrence. Carbon monoxide is produced as a result of the incomplete burning of carbon-based fuels (i.e., propane, gasoline, kerosene, wood, coal, charcoal etc.) in inadequately vented heaters and furnaces. Carbon monoxide levels can vary widely within an enclosed or semi-enclosed area such as a domestic room, office, garage or workshop; and can also fluctuate enormously over a short period of time as conditions change. For this reason, the level of $\mathrm{CO}$ concentration in air is often measured using the Time-Weighted Average (TWA). This determines an average exposure to $\mathrm{CO}$ over time (usually expressed in parts per million, ppm). Carbon monoxide poisoning symptoms vary widely between individuals. A person exposed to relatively low carbon monoxide levels over a longer period can display only mild symptoms while actually becoming seriously poisoned. Normal fresh air contains 0-0.2 ppm carbon monoxide. The American Society of Heating Refrigeration and Air Conditioning Engineers (ASHRAE) lists a maximum allowable short term limit of $9 \mathrm{ppm}$ CO. The Environmental Protection Agency $(\mathrm{EPA})^{[11]}$ has set two national health protection standards for CO: a 1-hour TWA of $35 \mathrm{ppm}$, and an 8hour TWA of $9 \mathrm{ppm}$. These standards make it clear that any carbon monoxide reading over $9 \mathrm{ppm}$ should be investigated and acted upon. The UK Department of Health reported in 2013 that 50 people die each year from carbon monoxide poisoning in the UK ${ }^{[12]}$ Many factors play a role in the severity of symptoms while in the body. Some health effects due to prolonged exposure to various concentrations of $\mathrm{CO}$ are summarized in Table 1. From mild to extreme $\mathrm{CO}$ exposure; passing through medium exposure, symptoms evolve as stated to result in headache, nausea, dizziness, fatigue, collapse, loss of consciousness and danger of death. Significantly, the less severe of these symptoms can often be mistaken for other ailments, such as mild food poisoning or dehydration, leading to prolonged exposure.

Table 1. Health effects ${ }^{[a]}$ of $\mathrm{CO}$ upon exposure to levels ${ }^{[b]}$ of $\mathrm{CO}$ considered dangerous.

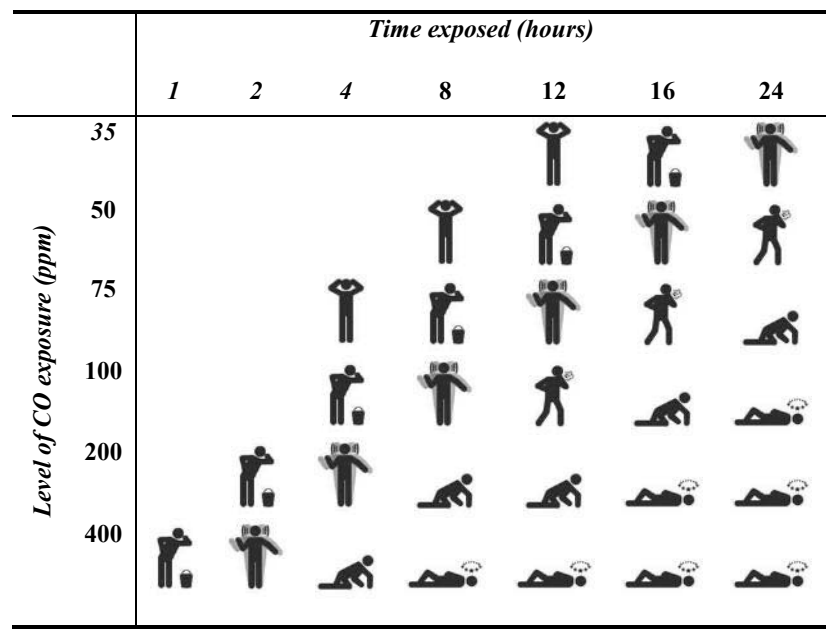

[a] The images typify the following symptoms in order of severity: headache, nausea, dizziness, fatigue, collapse and loss of consciousness. [b] US Environmental Protection Agency (EPA) standards.

Taking into account the facts mentioned above and following our interest in the design of novel chromo-fluorogenic systems,${ }^{[13]}$ we present here the application of ruthenium(II) and osmium(II) vinyl complexes as sensitive, selective, colorimetric and fluorimetric probes for the sensing of $\mathrm{CO}$ using their wellknown ability to react with small molecules, such as carbon monoxide. ${ }^{[14]}$ We have recently reported preliminary data on the development of a chromo-fluorogenic probe based on the ruthenium(II) pyrenylvinyl complex 1 of formula $[\mathrm{Ru}(\mathrm{CH}=\mathrm{CHPyr}-$ 1) $\left.\mathrm{Cl}(\mathrm{CO})(\mathrm{BTD})\left(\mathrm{PPh}_{3}\right)_{2}\right]^{\left[{ }^{[15]}\right.}$ Based on the initial sensing results obtained for this ruthenium complex in terms of selectivity and 
sensitivity, we report herein an extended study using a set of synthetically accessible and relatively inexpensive ruthenium(II) and osmium(II) vinyl complexes of general formula $\left[\mathrm{M}(\mathrm{CH}=\mathrm{CHR}) \mathrm{Cl}(\mathrm{CO})(\mathrm{BTD})\left(\mathrm{PPh}_{3}\right)_{2}\right]$ containing the 2,1,3benzothiadiazole (BTD) chromophore and various different vinyl ligands. For these compounds the colour modulations observed in the presence of carbon monoxide, induced by the displacement of the BTD ligand upon coordination of the $\mathrm{CO}$ group, have been studied spectroscopically and computationally. Also the changes in the emission of the complexes bearing pyrene, naphthalene and phenanthrene fluorophores induced by $\mathrm{CO}$ in solution and in air were studied.

\section{Results and Discussion}

Design of the probe complexes: The design of the chromofluorogenic probes involves the use of brightly coloured $\sigma$-vinyl 18-electron complexes and their well-documented ability to react with neutral, two-electron donors, such as carbon monoxide. The vinyl ligand is an important member of the $\sigma$-organyl ligand family, and is believed to be present as an intermediate in many catalytic reactions. Well-established synthetic routes such as hydrometallation and the reaction of coordinated alkynes with electrophiles or nucleophiles are known to yield vinyl complexes of many metals, often those belonging to group $8 .{ }^{[16]}$ Since the discovery of hydrometallation of alkynes by the compounds $\left[\mathrm{RuHCl}(\mathrm{CO})\left(\mathrm{PPr}_{3}^{\mathrm{i}}\right)_{2}\right]$ and $\left[\mathrm{RuHCl}(\mathrm{CO})\left(\mathrm{PPh}_{3}\right)_{3}\right]$, the resulting vinyl complexes have been studied extensively by many researchers (see examples by Werner, ${ }^{[17]}$ Esteruelas, ${ }^{[18]}$ Santos, ${ }^{[19]}$ Caulton, ${ }^{[20]}$ Winter ${ }^{[21]}$ and Hill $\left.{ }^{[22]}\right)$, as well as by some of us; ${ }^{[23]}$ covering functional-group transformation, ligand exchange and theoretical calculations.

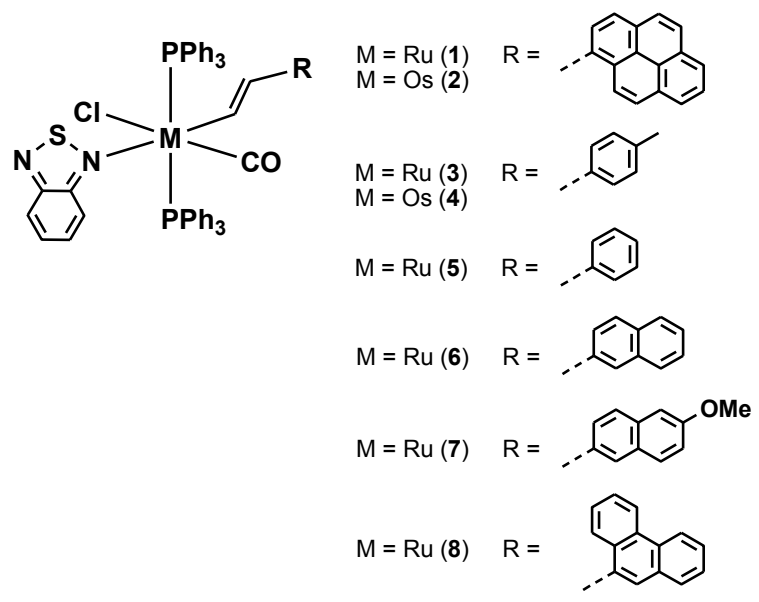

Scheme 1. Structures of the ruthenium and osmium vinyl complexes (1-8) used in this work.

The effect of nitrogen donor ligands on the reactivity of ruthenium hydrides ${ }^{[24]}$ and vinyl ruthenium complexes ${ }^{[21 c]}$ has been examined in detail. Yet, the most common triphenylphosphine-stabilised vinyl complexes to be used as starting materials are those of the form $\left[\mathrm{M}(\mathrm{CR}=\mathrm{CHR}) \mathrm{Cl}(\mathrm{CO})\left(\mathrm{PPh}_{3}\right)_{2}\right] \quad(\mathrm{M}=\mathrm{Ru} \text { only })^{[25]}$ or $\left[\mathrm{M}(\mathrm{CR}=\mathrm{CHR}) \mathrm{Cl}(\mathrm{CO})(\mathrm{BTD})\left(\mathrm{PPh}_{3}\right)_{2}\right] \quad(\mathrm{M}=\mathrm{Ru}$, Os). The BTD heterocycle confers both high crystallinity and enhanced visible properties on the materials and competes successfully with any excess triphenylphosphine present to avoid contamination by tris(phosphine) byproducts. Moreover, the lability of the BTD ligand in these complexes is remarkably well balanced, being displaced by better donors but resisting exchange with potentially coordinating solvents such as alcohols, tetrahydrofuran or even high concentrations of acetonitrile. As a result, substantial chemistry has been developed using vinyl complexes bearing this heterocycle. ${ }^{[22 c]}$

Based on the potential for modulation of the sensing features via changes in the metal centre and the donor-acceptor properties of the vinyl ligands, a set of ruthenium and osmium vinyl complexes was prepared (structures 1-8 in Scheme 1) of general formula $\left[\mathrm{M}(\mathrm{CH}=\mathrm{CHR}) \mathrm{Cl}(\mathrm{CO})(\mathrm{BTD})\left(\mathrm{PPh}_{3}\right)_{2}\right]$. These compounds contain two different metals as central atoms (Ru or Os) and six different vinyl ligands ( $R=$ Pyr-1, Phen-9, Nap-2, Nap-2-OMe-6, $\mathrm{C}_{6} \mathrm{H}_{4} \mathrm{Me}-4$ or $\left.\mathrm{C}_{6} \mathrm{H}_{5}\right)$ trans to the 2,1,3benzothiadiazole (BTD) chromophore. Two triphenylphosphine ligands, a chloride and a carbonyl unit complete the coordination sphere of the 18-electron octahedral complexes. The synthesis and chromo-fluorogenic features of complex $[\mathrm{Ru}(\mathrm{CH}=\mathrm{CHPyr}-$ 1) $\left.\mathrm{Cl}(\mathrm{CO})(\mathrm{BTD})\left(\mathrm{PPh}_{3}\right)_{2}\right]$ (1) have been recently reported by us in a preliminary communication and the additional complexes described here were prepared in similarly high yield and purity (Supporting Information). ${ }^{[15]}$

Table 2. UV-Vis and diffuse reflectance spectral data at room temperature for complexes 1-8 in chloroform solutions and supported on silica.

\begin{tabular}{|c|c|c|c|}
\hline \multirow{3}{*}{ Compound } & \multicolumn{2}{|c|}{$\mathrm{CHCl}_{3}$ solution } & \multirow{3}{*}{$\begin{array}{c}\text { Solid } \\
\text { Absence of } \\
\text { CO } \\
\lambda_{\max }(\mathrm{nm})\end{array}$} \\
\hline & Absence of $\mathrm{CO}$ & Presence of CO & \\
\hline & $\lambda_{\max }(\mathrm{nm})$ & $\lambda_{\max }(\mathrm{nm})$ & \\
\hline 1 & $\begin{array}{c}500 ; 402 ;(361 ; \\
345)^{[\mathrm{a}]}\end{array}$ & $(361 ; 345)^{[a, b]}$ & 499 \\
\hline 2 & $547 ;(418 ; 402)^{[\mathrm{a}]}$ & $(395 ; 377)^{[\mathrm{a}]}$ & 547 \\
\hline 3 & $487 ; 400$ & - & 513 \\
\hline 4 & 540 & - & 558 \\
\hline 5 & $483 ; 400$ & - & 500 \\
\hline 6 & $\begin{array}{c}487 ;(311 ; 297 ; \\
277 ; 255)^{[c]}\end{array}$ & $\begin{array}{c}(309 ; 297 ; 271 \\
255)^{[c]}\end{array}$ & 478 \\
\hline 7 & $\begin{array}{c}492 ;(299 ; 287 \\
279 ; 251)^{[c]}\end{array}$ & $\begin{array}{c}(299 ; 287 ; 279 \\
251)^{[\mathrm{c}\}}\end{array}$ & 489 \\
\hline 8 & $478 ;(301 ; 255)^{[d]}$ & $(306 ; 260)^{[\mathrm{d}]}$ & 477 \\
\hline
\end{tabular}

The data in brackets are assigned as: [a] pyrene signals, [b] enhanced signals [c] naphthalene signals, [d] phenanthrene signals. Due to saturation of the UV region after addition of $\mathrm{CO}$, diffuse reflectance data were not obtained for the silica-supported solid after $\mathrm{CO}$ addition. 
Reactivity with carbon monoxide in solution: Once the set of ruthenium and osmium derivatives had been prepared, UV-Vis spectrophotometric studies were performed for the coordination of $\mathrm{CO}$ to compounds 1-8. Chloroform solutions of the ruthenium complexes 1, 3, 5-8 displayed an orange colour that changed to yellow when CO-containing air samples were bubbled through their solutions (see Table 2 and video in Supporting Information) In contrast, the osmium complexes $\mathbf{2}$ and $\mathbf{4}$ displayed a COinduced colour change from purple to light yellow (see Table 2). The observed colour modulations are consistent with the formation of the corresponding dicarbonyl complexes, through displacement of the BTD ligand (Scheme 2). The stoichiometry of the reaction was confirmed by titration experiments (Figures S21-23 in the Supporting Information) using compound 7, which confirmed 7.CO as the final product (no evidence of acyl formation was observed).

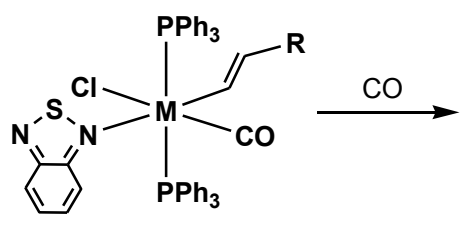

PR<smiles>[R]C=CC(=O)N(C(=O)[O-])c1ccccc1</smiles>

PR.CO
Scheme 2. Reactivity of the complexes acting as probes, simplified as PR, with carbon monoxide to give the corresponding dicarbonyl products (PR-CO).

Characterization of the dicarbonyl complexes: Crystal structures of numerous transition metal complexes containing phosphines and vinyl ligands have been reported. ${ }^{[16]}$ The molecular structures of complexes $\mathbf{1}$ to $\mathbf{8}$ are very similar with all containing one metal centre bonded to two triphenylphosphine ligands, one chloride, a CO molecule and a BTD heterocycle trans to the vinyl ligand. This results in a slightly distorted octahedral arrangement around the metal centres. A significant structural feature of these complexes is the coplanar orientation of the vinyl and carbonyl ligands. Participation of the empty $\pi^{*}$ orbitals of the vinyl ligands in back-bonding interactions result in a strengthened metal-carbon bond. When a vinyl complex contains other $\pi$-acceptor ligands (e.g., the $\mathrm{CO}$ molecule), competition for back-donation, and therefore the relative orientation of the vinyl ligand, is believed to have an impact on the stability of the complex. ${ }^{[26]}$

In order to understand the ability of carbon monoxide to bind to these divalent metal vinyl complexes, it is helpful to draw a comparison between related structures reported previously and those of the corresponding BTD and CO-substituted complexes. Suitable crystals for single $\mathrm{X}$-ray diffraction were obtained (Figure 1) by diffusion of ethanol into (in the case of 5.CO, CO-infused) dichloromethane solutions of the complexes. The crystal structures of BTD complexes with three different vinyl ligands have been obtained ( 1 reported in a recent communication $^{[15]}$ and 4 and 6 reported here) as well as two dicarbonyl examples, formed after addition of carbon monoxide (1.CO and 5.CO reported in previous and present work, respectively).
The molecular structure of compound 4 (Figure 1a) consists of an osmium centre with two triphenylphosphine ligands, while the labile BTD unit is situated trans to the tolylvinyl ligand. A chloride and a $\mathrm{CO}$ molecule complete the coordination sphere. Relevant crystallographic data for all structures are collected in the Supporting Information.

The structures reported here, together with the ones reported previously, ${ }^{[15]}$ allow comparison between a series of analogous $\left[\mathrm{M}(\mathrm{CH}=\mathrm{CHR}) \mathrm{Cl}(\mathrm{CO})(\mathrm{L})\left(\mathrm{PPh}_{3}\right)_{2}\right] \quad(\mathrm{L}=\mathrm{BTD}, \mathrm{CO})$ compounds differing only in the metal $(\mathrm{M}=\mathrm{Ru}$ or $\mathrm{Os})$ and in the vinyl substituents $\left(\mathrm{R}=\mathrm{Pyr}-1, \mathrm{Nap}-2\right.$ or $\left.\mathrm{C}_{6} \mathrm{H}_{4} \mathrm{Me}-4\right)$. Table 3 collects the main metal-ligand structural data.

a)

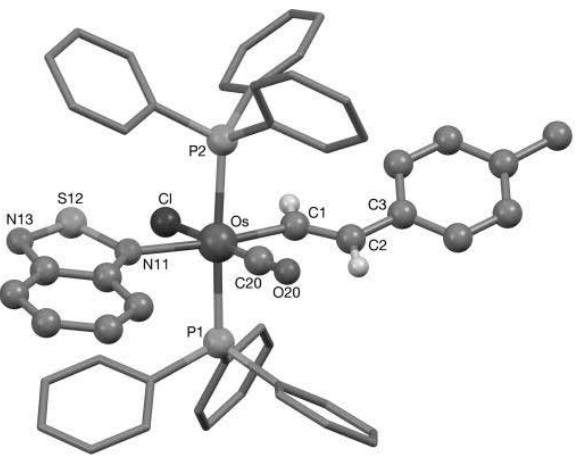

b)

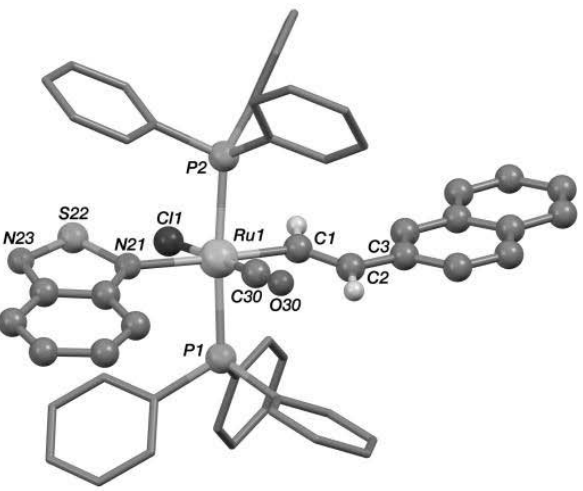

c)

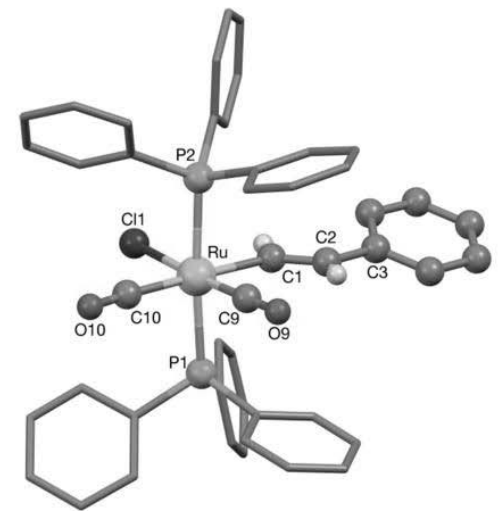

Figure 1. Crystal structures of a) $\left[\mathrm{Os}\left(\mathrm{CH}=\mathrm{CHC}_{6} \mathrm{H}_{4} \mathrm{Me}-4\right) \mathrm{Cl}(\mathrm{CO})(\mathrm{BTD})\left(\mathrm{PPh}_{3}\right)_{2}\right]$ (4) b) $\quad\left[\mathrm{Ru}(\mathrm{CH}=\mathrm{CHNap}-2) \mathrm{Cl}(\mathrm{CO})(\mathrm{BTD})\left(\mathrm{PPh}_{3}\right)_{2}\right] \quad$ (6) and c) $\left[\mathrm{Ru}\left(\mathrm{CH}=\mathrm{CHC}_{6} \mathrm{H}_{5}\right) \mathrm{Cl}(\mathrm{CO})_{2}\left(\mathrm{PPh}_{3}\right)_{2}\right](\mathbf{5} \cdot \mathbf{C O})$.

In structures 4, 6 and 5.CO (Figure 1), an approximate octahedral arrangement is adopted. Somewhat surprisingly 
given their use over a number of decades, the structures of 1, 4 and 6 are the first examples of structurally characterised vinyl complexes bearing the BTD ligand. The trans relationship adopted by $\mathbf{4}$ and $\mathbf{6}$ (and also $\mathbf{1}$ ) is in contrast to the mutually cis disposition of the BTD ligand and the hydride ligand in the complex $\left[\mathrm{RuHCl}(\mathrm{CO})(\mathrm{BTD})\left(\mathrm{PPh}_{3}\right)_{2}{ }_{2}\right.$, ${ }^{[27]}$ which is a precursor to the compounds $\left[\mathrm{Ru}(\mathrm{CH}=\mathrm{CHR}) \mathrm{Cl}(\mathrm{CO})(\mathrm{BTD})\left(\mathrm{PPh}_{3}\right)_{2}\right]$. This indicates that substantial reorganisation occurs on hydrometallation of the alkyne by the hydride precursor. Also, noteworthy is the fact that the $\mathrm{M}-\mathrm{C}_{\mathrm{co}}$ bond distances for the two carbonyl ligands in the dicarbonyl complex (5.CO) differ substantially. This can be taken as evidence of the substantial trans influence exerted by the vinyl group, resulting in an elongation of the $\mathrm{M}-\mathrm{C}_{\mathrm{co}}$ bond trans to the vinyl ligand. This effect is also observed in the pyrenylvinyl complex 1.CO. Comparing the structure of the BTD complex 1 with that of the dicarbonyl $1 \cdot \mathrm{CO}$, a greater $\mathrm{M}-\mathrm{C}_{\text {vinyl }}$ distance is observed also for the vinyl ligand in the dicarbonyl structure. In the absence of significantly greater steric congestion, this must also be taken as evidence of the greater trans influence of the $\mathrm{CO}$ ligand compared to that of the BTD ligand. It would be expected that the Os-N distance (2.2073(19) $\AA$ ) in 4 would be similar if not slightly longer than the Ru-N bond length in the analogous ruthenium complex (1). However, it is in fact substantially shorter $\left(d_{\text {Ru-N }}\right.$ in 1 is $2.238(3) \AA$ ). This could be due to a release of steric congestion on replacing the pyrenylvinyl in 1 with the less bulky tolylvinyl in 4. Otherwise, the structures are as expected and the bond data are in agreement with those reported previously for comparable compounds with monodentate $\mathrm{N}$-donors such as $\left[\mathrm{Ru}\left(\mathrm{CH}=\mathrm{CHBu}{ }^{t}\right) \mathrm{Cl}(\mathrm{CO})\left(\mathrm{Me}_{2} \mathrm{Hpz}\right)\left(\mathrm{PPh}_{3}\right)_{2}\right] \quad\left(\mathrm{Me}_{2} \mathrm{Hpz}=3,5-\right.$ dimethylpyrazole). ${ }^{[28]}$ Further details and bond data can be found in the Supporting Information.

Table 3. Relevant bond distances $(\AA)$ for the divalent vinyl complexes used in this work.

\begin{tabular}{lccccc}
\hline & $\mathbf{1}^{[15]}$ & $\mathbf{1 \cdot \mathbf { C O } ^ { [ 1 5 ] }}$ & $\mathbf{4}$ & $\mathbf{6}$ & $\mathbf{5} \cdot \mathbf{C O}$ \\
\hline$d_{\mathrm{M}-\mathrm{Cco}}$ & $1.824(3)$ & $1.857(2)$ & $1.831(2)$ & $1.827(3)$ & $1.858(6)$ \\
$d_{\mathrm{M}-\mathrm{Cl}}$ & $2.4663(7)$ & $2.4472(5)$ & $2.4591(6)$ & $2.4673(8)$ & $2.4688(14)$ \\
$d_{\mathrm{M}-\mathrm{Cvinyl}}$ & $2.048(3)$ & $2.104(2)$ & $2.068(2)$ & $2.061(3)$ & $2.115(5)$ \\
$d_{\mathrm{M}-\mathrm{N}}$ & $2.238(3)$ & - & $2.2073(19)$ & $2.248(3)$ & - \\
$d_{\mathrm{M}-\mathrm{Cc0} 2}$ & - & $1.957(2)$ & - & - & $1.971(6)$ \\
$d_{\mathrm{M}-\mathrm{P} 1}$ & $2.4064(7)$ & $2.4126(5)$ & $2.3878(6)$ & $2.3920(9)$ & $2.4061(14)$ \\
$d_{\mathrm{M}-\mathrm{P} 2}$ & $2.4099(6)$ & $2.4060(5)$ & $2.4158(6)$ & $2.4114(9)$ & $2.4037(14)$ \\
\hline
\end{tabular}

Carbon monoxide sensing behaviour in air: Despite the encouraging spectrophotometric response of the ruthenium and osmium vinyl complexes 1-8 in chloroform solution, the detection of $\mathrm{CO}$ in the gas phase was of paramount importance in the design of a probe to be used in air. In order to address this aim, the eight complexes were adsorbed on an inorganic matrix (thus greatly increasing the surface area exposed to the gas) and their chromogenic response toward $\mathrm{CO}$ in air studied (Figure 2). Adsorption of probes 1-8 on silica was achieved by dissolution of each complex in a minimum amount of chloroform followed by the addition of conventional lab silica (particle size $40-63 \mu \mathrm{m}$ ) at a weight ratio of 250 times. This resulted in orange $(\mathbf{1}, \mathbf{3}, \mathbf{5}, \mathbf{6}, \mathbf{7}$ and $\mathbf{8}$ ) and purple (2 and 4 ) solids after solvent removal on a rotary evaporator. The resulting solids were left to stand for at least $1 \mathrm{~h}$ before use to ensure a stable initial colour. Diffuse reflectance UV-Vis spectra were recorded (Figure 2a) and the maxima for the complexes are included in Table 2. This illustrates that the probes show intense absorption bands in the 470-560 $\mathrm{nm}$ range.

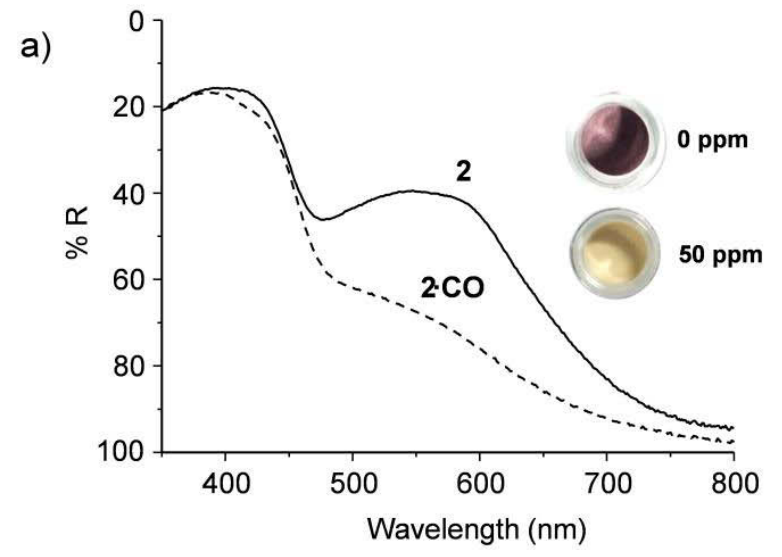

b)

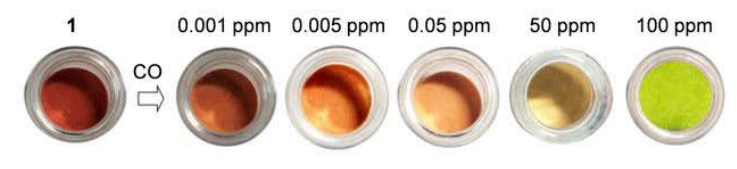

c)

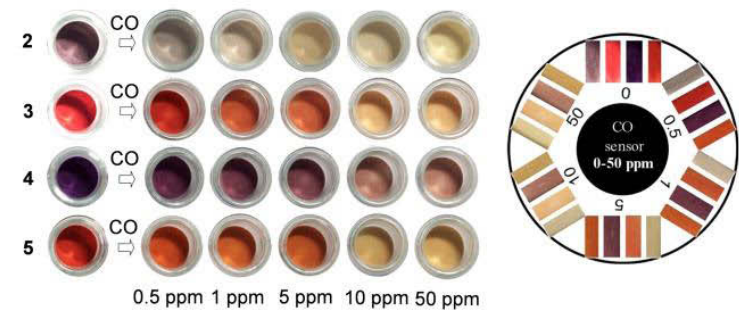

Figure 2. a) Diffuse reflectance UV-Vis spectrum of complex 2 on silica with the changes observed in the presence of air containing $50 \mathrm{ppm}$ of $\mathrm{CO}$; b) Colour changes observable to the naked eye for complex 1 on silica gel upon exposure to $0.001,0.005,0.05,50,100 \mathrm{ppm}$ CO in air; c) Sensing array of probes 2-5 for $\mathrm{CO}$ detection in air showing naked eye colour changes upon exposure of $0.5,1,5,10,50 \mathrm{ppm}$ CO.

Using simple titration profiles of the eight sensor materials with $\mathrm{CO}$, the limits of detection (LODs) were evaluated and the results are displayed in Table 4 . Together with the values measured using a conventional UV-visible spectrophotometer (see Figure S5 in Supporting Information), Table 4 shows the estimated detection limit to the naked eye for complexes 1-8 in the presence of $\mathrm{CO}$; i.e. the minimum amount of $\mathrm{CO}$ necessary to observe a clear colour change in the materials. As examples of the CO response, the reduction of the intensity of the band centred at $535 \mathrm{~nm}$ vs. the log of the concentration of $\mathrm{CO}$ in air for 2 adsorbed on silica is shown in Figure 3, whereas images of 
the colour changes observed for 1 on silica gel upon exposure to $0.001,0.005,0.05,50$ and $100 \mathrm{ppm} \mathrm{CO}$ in air are shown in Figure 2b.

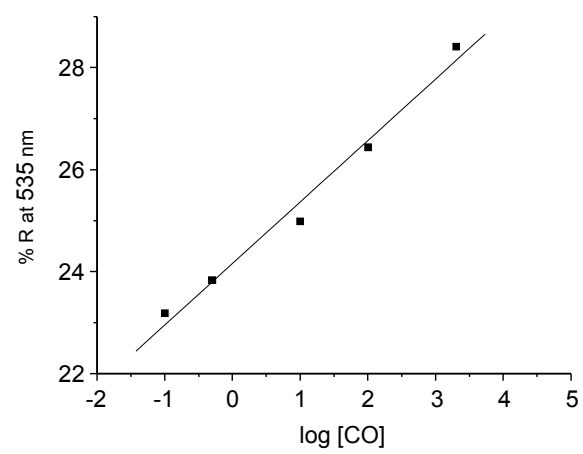

Figure 3. Reduction of the intensity of the band centred at $535 \mathrm{~nm}$ vs. the log of the concentration of $\mathrm{CO}$ in air for $\mathbf{2}$ adsorbed on silica.

One of the most remarkable aspects of the behaviour of complexes 1-8 is the clear chromogenic response observed at relatively low concentrations of carbon monoxide. In particular, and notably, for silica-supported complexes 2-5, a chromogenic change to the naked eye was observed at concentrations as low as $0.5 \mathrm{ppm}$. When complexes 6-8 were used, a chromogenic naked eye response was observed for higher $\mathrm{CO}$ concentrations (ca. $5 \mathrm{ppm}$ ). However, of all the compounds investigated, complex 1 performs best, due not only to its marked colour modulation observed at concentrations at which $\mathrm{CO}$ becomes toxic; but also to its ability to detect extremely low $\mathrm{CO}$ concentrations $(0.005 \mathrm{ppm})$. However, the high cost of the 1ethynylpyrene precursor compared to inexpensive ethynylbenzene makes $\mathbf{5}$ a more attractive option for sensing carbon monoxide in air in the $10-50 \mathrm{ppm}$ range needed for a domestic alarm. Indeed, the high sensitivity of 1 could even be a drawback in applications where low concentrations of $\mathrm{CO}$ are present as part of the background (e.g., in factories).

Figure 4. Turn-on fluorescence response $\left(\lambda_{\mathrm{ex}}=492 \mathrm{~nm}\right)$ of a $1 \times 10^{-4} \mathrm{~mol} \mathrm{dm}^{-3}$ chloroform solution of 7 upon addition of increasing quantities of $\mathrm{CO}(0,1.0 \mathrm{x}$ $10^{-7}, 1.0 \times 10^{-5}, 1.0 \times 10^{-3}, 0.01,1,100,500$ and $\left.1000 \mathrm{ppm}\right)$.

Another very significant feature observed in $\mathbf{1}$ was that the displacement of the BTD ligand by $\mathrm{CO}$ also results in the recovery of the previously quenched fluorescence emission of the pyrene group. This effect was observed both in solution and in air. For instance methanolic solutions of $\mathbf{1}$ were poorly fluorescent $\left(\lambda_{\mathrm{exc}}=355 \mathrm{~nm}, \lambda_{\mathrm{em}}=458 \mathrm{~nm}\right)$ but addition of $\mathrm{CO}$ and formation of 1.CO resulted in a remarkable 36-fold increase in emission. Moreover, 1 was also found to display a turn-on emission enhancement in the presence of carbon monoxide when the probe was adsorbed on strips of cellulose paper (column silica gel was also tested as support but the emission changes of adsorbed complex 1 were negligible). Using this support, a remarkable LOD for CO of $0.7 \mathrm{ppb}$ was calculated. In addition to this, a clear optical response to the naked eye was also found for concentrations of ca. 90 ppm using a conventional UV lamp. Detection of carbon monoxide using a fluorescence response has been described in a number of reports, though, previous to this work, only in solution. ${ }^{[29]}$

Encouraged by the remarkable emission enhancement observed for $\mathbf{1}$, the fluorescence behaviour of complex 7 and 8 was studied upon addition of $\mathrm{CO}$ in solution and in the gas phase. Chloroform solutions of complex 7 were only weakly emissive with an emission band centred at $538 \mathrm{~nm}\left(\lambda_{\mathrm{exc}}=492\right.$ $\mathrm{nm})$. When different concentrations of $\mathrm{CO}$ air were bubbled into the chloroform solutions of 7 a substantial 10 -fold enhancement of the emission band at $538 \mathrm{~nm}$ was observed (see Figure 4). Nearly the same behaviour, upon addition of increasing quantities of $\mathrm{CO}$, was observed for chloroform solutions of complex 8 with a close to 20 -fold enhancement of the emission at $586 \mathrm{~nm}\left(\lambda_{\mathrm{exc}}=478 \mathrm{~nm}\right.$ ) (see Figure S6 in Supporting Information). As for complex 1, the enhancement in emission intensity observed upon addition of increasing quantities of $\mathrm{CO}$ was ascribed to the displacement of the BTD ligand that results in the recovery of the naphthalene and phenanthrene fluorescence. The emission response of silica gel-containing complexes $\mathbf{7}$ and 8 to $\mathrm{CO}$ was also tested. After exposing the solids to air containing different $\mathrm{CO}$ concentrations, a clear emission enhancement at 599 and $586 \mathrm{~nm}$ for 7 and 8 , respectively, was observed. From the corresponding titration profiles, LODs of 1.1 and $10 \mathrm{ppb}$ were calculated for $\mathrm{CO}$ detection using emission data for $\mathbf{7}$ and $\mathbf{8}$ (Table 4).

Table 4. Limits of detection (ppm) for complexes 1-8 in the presence of $\mathrm{CO}$. Limits calculated from UV-Visible, emission spectral data and the naked eye.

\begin{tabular}{cccc} 
& \multicolumn{2}{c}{ Detection limits (ppm) of CO } & \\
Compound & UV-Visible & Fluorescence & Naked eye \\
\hline $\mathbf{1}$ & 0.0006 & 0.001 & 0.005 \\
$\mathbf{2}$ & 0.19 & - & 0.5 \\
$\mathbf{3}$ & 0.1 & - & 0.5 \\
$\mathbf{4}$ & 0.015 & - & 0.5 \\
$\mathbf{5}$ & 0.084 & - & 0.5 \\
$\mathbf{6}$ & 0.65 & - & 5 \\
$\mathbf{7}$ & 4.07 & 0.0011 & 5 \\
$\mathbf{8}$ & 0.60 & 0.01 & 5 \\
\hline
\end{tabular}


Based on the observation that naked-eye colour changes for probes 2-8 are found at different $\mathrm{CO}$ concentrations it is possible to design systems for semi-quantitative visual sensing of $\mathrm{CO}$ in air. As an example, a sensing array containing compounds 2-5 and the colour changes observed at concentrations of $\mathrm{CO}$ of $0,0.5,1,5,10$ and $50 \mathrm{ppm}$ in air is shown in Figure 2c.

Selectivity: Once the sensitivity of the eight silica-supported vinyl complexes towards $\mathrm{CO}$ had been established, the chromogenic and fluorogenic response in the presence of steam, other gases $\left(\mathrm{CO}_{2}, \mathrm{~N}_{2}, \mathrm{O}_{2}, \mathrm{Ar}, \mathrm{SO}_{2}, \mathrm{NO}_{\mathrm{x}}\right.$ and $\left.\mathrm{H}_{2} \mathrm{~S}\right)$ and vapours (acetone, chloroform, ethanol, formaldehyde, hexane, toluene and acetonitrile) was studied. In all cases the ruthenium and osmium vinyl complexes displayed a remarkably selective response for carbon monoxide in air. For instance, no reaction was observed in the presence of $\mathrm{CO}_{2}, \mathrm{~N}_{2}, \mathrm{O}_{2}$ or $\mathrm{Ar}$ at very high concentrations (up to $50000 \mathrm{ppm}$ ). Similarly, no colour or emission changes were observed in the presence of volatile organic compounds such as acetone, chloroform, ethanol, formaldehyde, hexane or toluene (up to $30000 \mathrm{ppm}$ in air). However, some change in colour was observed for all complexes (emission changes only were observed for complex 7 and 8 ) in the presence of acetonitrile vapour, although only at concentrations of 600-5000 ppm (see Figure $\mathrm{S} 18$ for an example). Such levels are considered toxic to humans and are unlikely to be encountered where $\mathrm{CO}$ sensing is required. Studies with other potentially coordinating gaseous species, such as $\mathrm{SO}_{2}, \mathrm{NO}_{x}$ and $\mathrm{H}_{2} \mathrm{~S}$ were also carried out. No noticeable colour and fluorescence changes were observed with any of the complexes adsorbed on silica in the presence of $\mathrm{SO}_{2}$ (up to $38000 \mathrm{ppm}$ ) or $\mathrm{H}_{2} \mathrm{~S}$ (up to $200 \mathrm{ppm}$, well above the level toxic to humans).

Table 5. Summary of the observed behaviour for acetonitrile and $\mathrm{NO}_{x}$ with complexes 1-8. Responses are shown with the concentration (in ppm) necessary to induce a colour change.

\begin{tabular}{ccccc}
\hline \multicolumn{2}{c}{ UV-Visible } & \multicolumn{2}{c}{ Interferent } & Fluorescence \\
Solid & $\begin{array}{c}\text { Acetonitrile } \\
(\mathrm{ppm})\end{array}$ & $\begin{array}{c}\mathrm{NO}_{\mathrm{x}} \\
(\mathrm{ppm})\end{array}$ & $\begin{array}{c}\text { Acetonitrile } \\
(\mathrm{ppm})\end{array}$ & $\begin{array}{c}\mathrm{NO}_{\mathrm{x}} \\
(\mathrm{ppm})\end{array}$ \\
\hline $\mathbf{1}$ & 5000 & {$[\mathrm{a}]$} & {$[\mathrm{b}]$} & [b] \\
$\mathbf{2}$ & 2090 & 2570 & - & - \\
$\mathbf{3}$ & 2146 & 2287 & - & - \\
$\mathbf{4}$ & 3020 & 2582 & - & - \\
$\mathbf{5}$ & 1574 & 2213 & - & 2290 \\
$\mathbf{6}$ & 2853 & 870 & - & 8709 \\
\hline $\mathbf{7}$ & 1460 & 1449 & 4168 & 1584 \\
\hline
\end{tabular}

[a] No visible spectroscopic changes even at 4000 ppm. [b] Complex 1 adsorbed on silica gel exhibited negligible changes even at $4000 \mathrm{ppm}$.

Exposure to $\mathrm{NO}_{x}$ produced colour changes to orange for all complexes except for 1 (that was already orange) and emission enhancements for $\mathbf{7}$ and $\mathbf{8}$. However, this reactivity was again only observed at very high concentrations of nitrogen oxides (around $2200 \mathrm{ppm}$ ). The reactivity towards acetonitrile and $\mathrm{NO}_{\mathrm{x}}$, together with relevant concentrations, are summarised in Table 5. Experiments were also carried out to show that a representative complex (7) was unaffected in its ability to detect $10 \mathrm{ppm}$ of $\mathrm{CO}$ in the presence of either low $(5 \mathrm{ppm})$ or moderate levels (50 ppm) of $\mathrm{NO}_{x}$ and $\mathrm{MeCN}$ (Figure S19).

Of particular significance in the context of potential application in domestic settings is the lack of reactivity with water vapour (steam). Even at elevated temperatures, the complexes are insoluble in water (Figure S17) and do not undergo colour changes.

Reversibility: Coordination of $\mathrm{CO}$ with this set of vinyl complexes was found to be essentially irreversible both in solution and in air. Therefore the probes can be defined (and used) as chemodosimeters which will reflect the cumulative response towards the concentration of $\mathrm{CO}$ present in air during a prolonged period of time.

In an attempt to design probes that could be used for the reversible sensing of $\mathrm{CO}$, the focus turned to the phosphavinyl ruthenium complex $\left[\mathrm{Ru}\left(\mathrm{P}=\mathrm{CHBu}{ }^{t}\right) \mathrm{Cl}(\mathrm{CO})\left(\mathrm{PPh}_{3}\right)_{2}\right](9) .{ }^{\left[{ }^{[0]}\right.}$ At first glance, complex 9 appears closely related to the conventional vinyl complexes $\left[\mathrm{Ru}(\mathrm{CH}=\mathrm{CHR}) \mathrm{Cl}(\mathrm{CO})\left(\mathrm{PPh}_{3}\right)_{2}\right]$. However, analogously to nitrosyl ligands, the phosphavinyl ligand can act as either a one-electron or a three-electron donor. There is evidence that the phosphavinyl ligand demonstrates behaviour similar to that of a 3-electron donor, rendering the coordination sphere of the metal coordinatively-saturated. For example, the analogue $\left[\mathrm{Ru}\left(\mathrm{P}=\mathrm{CHBu}{ }^{t}\right) \mathrm{Cl}(\mathrm{CO})(\mathrm{BTD})\left(\mathrm{PPh}_{3}\right)_{2}\right]$ cannot be prepared as the BTD ligand is ejected after reaction between $\left[\mathrm{RuHCl}(\mathrm{CO})(\mathrm{BTD})\left(\mathrm{PPh}_{3}\right)_{2}\right]$ and $\mathrm{P} \equiv \mathrm{CBu}^{\mathrm{t}}$ to form 9 exclusively. It has been shown that coordination of carbon monoxide to 9 is reversible (Scheme 3) and even solid samples of $\mathbf{9 \cdot C O}$ precipitated under an atmosphere of $\mathrm{CO}$ lose carbon monoxide over a period of hours to reform $9 .^{[30 b]}$<smiles></smiles>

9

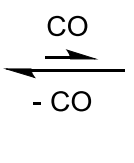

Scheme 3. Reversible reaction of phosphavinyl compound $\mathbf{9}$ with CO

In order to explore the possibility of exploiting this in the current study, solutions of $\mathbf{9}$ in dichloromethane were exposed to a mixture of carbon monoxide in air, resulting in a colour change from yellow-orange to colourless. The colour could be regenerated by purging the solution with air (see video in Supporting Information). In the solid state, addition of pure carbon monoxide led to a colour change from orange to pale yellow, which was reversed on removal of the carbon monoxide 
atmosphere. However, supporting complex 9 on silica under the same conditions used for the other complexes led to the orange colour being lost (through interaction with the substrate) and so the use of $\mathbf{9}$ as a probe for the detection of $\mathrm{CO}$ in air was not pursued further.

Density functional theory (DFT) study: To further investigate the colour change observed on exposure of the vinyl complexes to carbon monoxide, a computational study was performed using a high level of theory. Three ruthenium vinyl complexes containing pyrenyl (1), phenyl (5) or naphthyl (6) substituents on the vinyl ligand were modelled, both as the BTD precursor $(1,5$ and $\mathbf{6})$ and with $\mathrm{CO}$ bound (1.CO, 5.CO and 6.CO). Calculations were conducted using the B3LYP functional with explicit inclusion of dispersion corrections using the D3 procedure by Grimme, employing the MW28 pseudopotential and basis set for $\mathrm{Ru}$ and the TZVP basis set for all other atoms. Solvent effects were included via CPCM. Time-dependent Density Functional Theory (TD-DFT) experiments were conducted at the same level of theory for the first 100 states.
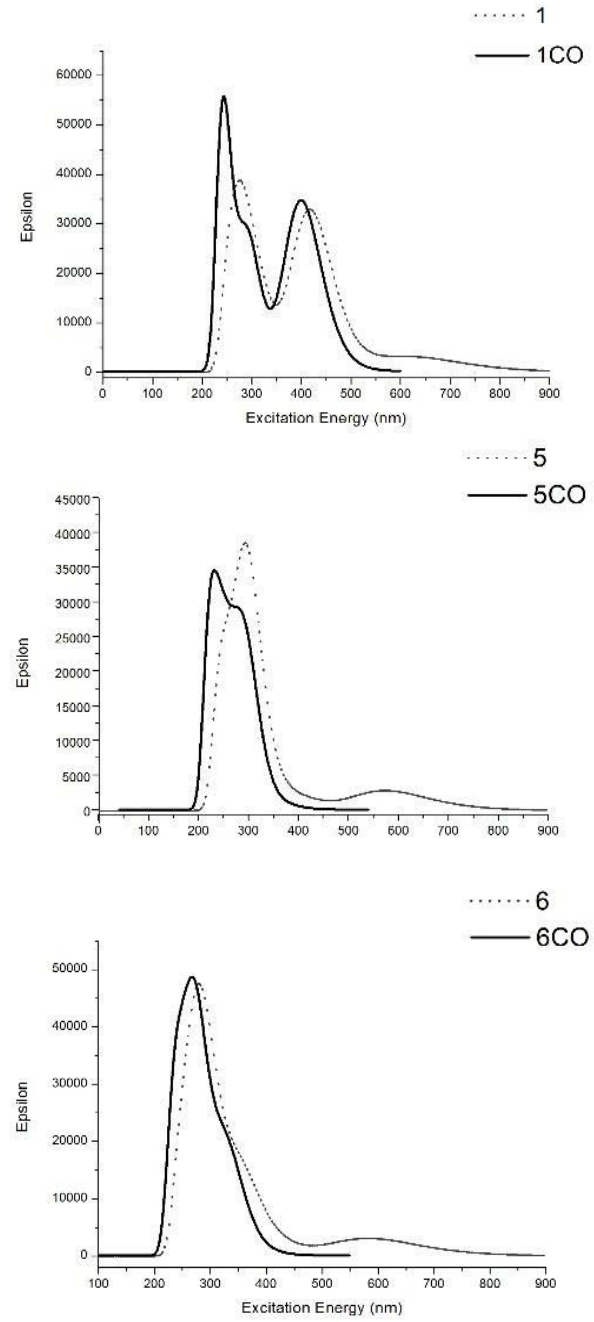

Figure 5. TD-DFT UV spectra for 1, 5, 6 and their carbon monoxide adducts, $1 \cdot \mathrm{CO}, 5 \cdot \mathrm{CO}$ and $6 \cdot \mathrm{CO}$
In all three BTD probes 1, 5 and $\mathbf{6}$ (before CO is added), the strong colour of the complexes originate from a low intensity $\pi-\pi^{*}$ transition between the aromatic vinyl group and the BTD chromophore (at around $624 \mathrm{~nm}$ for 1, $576 \mathrm{~nm}$ for 5 and $585 \mathrm{~nm}$ for 6) and a more intense $\pi-\pi^{*}$ aromatic vinyl transition (at ca. $300-400 \mathrm{~nm}$ ). Predicted UV-Vis spectra are shown in Figure 5 and selected MOs can be found in the Supporting Information (Tables S2-S7). Upon coordination of $\mathrm{CO}$ the transitions change depending on the nature of the vinyl group, but all compounds lose their distinct coloured transitions $>500 \mathrm{~nm}$. For the electron rich pyrene system, the visible colour of the complex is maintained by a pyrene $\pi-\pi^{*}$ transition at ca. $410 \mathrm{~nm}$. In addition, the UV absorbance at ca. $245 \mathrm{~nm}$ increases with coordination of CO. For the comparatively electron poor phenyl group the transition in the visible region is blue-shifted to ca. $240 \mathrm{~nm}$, increasing the UV absorbance of the compound. These results are in good agreement with DFT studies performed by Winter et $\mathrm{al}^{[21 \mathrm{c}]}$ on related 5 -coordinate vinyl model structures and a pyridine adduct.

\section{Conclusions}

Ruthenium(II) and osmium(II) vinyl complexes (1-8) of general formula $\left[\mathrm{M}(\mathrm{CH}=\mathrm{CHR}) \mathrm{Cl}(\mathrm{CO})(\mathrm{BTD})\left(\mathrm{PPh}_{3}\right)_{2}\right]$ containing two different metal centres (Ru or Os) and six different vinyl ligands $\left(\mathrm{R}=\right.$ Pyr-1, Phen-9, Nap-2, Nap-2-OMe-6, $\mathrm{C}_{6} \mathrm{H}_{4} \mathrm{Me}-4$ or $\left.\mathrm{C}_{6} \mathrm{H}_{5}\right)$ trans to a 2,1,3-benzothiadiazole (BTD) chromophore have been investigated as chromo-fluorogenic probes for $\mathrm{CO}$ detection. Spectroscopic studies (UV-Vis and fluorescence) were carried out on the complexes, both in solution and immobilized on silica, showing colour changes in the visible region and enhancement in emission intensity due to coordination of $\mathrm{CO}$ and displacement of BTD ligand. Remarkable colour modulations from orange to yellow (in the case of ruthenium complexes 1, 3 and 5-8) and from purple to yellow (for osmium complexes 2 and 4) were observed. Further information on these modulations in colour was provided by a TD-DFT computational study. Examples of the probes before ( $\mathbf{4}$ and $\mathbf{6})$ and after $\mathrm{CO}$ additions $(5 \cdot \mathbf{C O})$ were also investigated structurally using single crystal $X-$ ray diffraction techniques. In all cases the ruthenium and osmium vinyl complexes studied showed a highly selective response to $\mathrm{CO}$ with remarkably low detection limits. Of all VOCs and gases tested as possible interferents, only acetonitrile and $\mathrm{NO}_{x}$ gave any indication of colour and emission changes, yet in both cases this was only observed at extremely high (and well above toxic) concentrations unlikely to be encountered in any setting requiring $\mathrm{CO}$ sensing. Most notably, the exceptional selectivity for $\mathrm{CO}$ over water vapour and all organic solvents tested is of crucial importance in the potential application of this system in domestic or workplace settings where steam, cleaning products or fuel fumes are present (thus addressing this particular shortcoming in commercial devices).

While this very high selectivity is vital for a viable $\mathrm{CO}$ detector, good sensitivity and a clear indication of the presence of this odourless, tasteless, toxic gas are both critical attributes. These requirements are met by all the complexes tested (1-8), 
which display very clear and significant colour changes, easily visible to the naked eye, at very low concentrations of $\mathrm{CO}$. In particular, complex 1 demonstrates distinct changes in colour at $\mathrm{CO}$ concentrations as low as $0.005 \mathrm{ppm}$, even allowing the visual quantification of $\mathrm{CO}$ in air. Critically, the chromogenic responses observed cover a wide spectrum of concentrations, encompassing the toxicity range for humans (Table 1). This would allow the system described here to be employed in its current form to monitor acute or cumulative exposure to $\mathrm{CO}$ in the home or workplace (using a comparison colour chart for various amounts of $\mathrm{CO}$ ). Cellulose strips impregnated with the complexes $^{[15]}$ also allow the colour change to be converted to a numerical reading (and hence alarm) using a simple, portable optoelectronic device, such as the one described by some of us previously. ${ }^{[31]}$ The attributes described above for the colorimetric probes 2-6 complement the more sophisticated dual chromofluorogenic detection of carbon monoxide by complexes 1, 7 and 8 but using simpler and less expensive reagents. Furthermore, the high-yielding and straightforward synthetic procedure used to prepare 1-8 in air, coupled with the commercial availability and relatively low cost of ruthenium and other reagents (especially ethynylbenzene) render the metal complexes both accessible and inexpensive. Complexes 1 and 5 offer subtly contrasting sensitivities, which can suit different applications and environments where different background levels of carbon monoxide are present. Complex 1 costs around $€ 34 / g$ for the materials but less than a cent for the amount on a cellulose strip, while $\mathbf{5}$ is three times less expensive. The combination of sensitivity, selectivity, simple synthesis and low cost make the system described here a very attractive and efficient chemosensor for the simple chromogenic (and for 1, 7 and 8, fluorogenic) detection of this colourless, odourless and highly toxic gas.

\section{Acknowledgements}

The authors wish to express their gratitude to the Spanish Government (project MAT2012-38429-C04) and Generalitat Valenciana (project PROMETEOII/2014/047) for their support. M.E.M. is grateful to the Spanish Ministerio de Ciencia e Innovación for an FPU grant as well as for the short-stay fellowship, which allowed this profitable collaboration. C.M-H. thanks the Spanish Ministry of Economy and Competitiveness for her grant. A.T. gratefully acknowledges the support of the Leverhulme Trust (Grant RPG-2012-634) for a studentship. The authors thank Prof. C. K. Williams, Prof. N. J. Long and Dr P. Hunt (Imperial College) for the use of apparatus and assistance.

Keywords: Ruthenium • Osmium • Carbon monoxide • Sensors - Gas detection

\section{References}

[1] a) D. Gutmacher, C. Foelmli, W. Vollenweider, U. Hoefer, J. Wöllenstein, Procedia Eng., 2011, 25, 1121-1124; b) C. Kaminski, A. Poll, Electrochemical or Solid State $\mathrm{H}_{2} \mathrm{~S}$ Sensors: Which is Right for You? InTech, USA, 1985.

[2] a) G. Korotcenkov, V. Brynzari, S. Dmitriev, Mater. Sci. Eng. B 1999, 63, 195-204; b) N. Yamazoe, Y. Kurokawa, T. Seiyama, Sens. Actuators, 1983, 4, 283-289.

[3] J. Wolfrum, Proc. Combust. Inst. 1998, 27, 1, 1-41.

[4] K. -H. Cho, S. -W. Lee, J. -H. Lee, K. -S. Choi, Anal. Sci. Technol. 2000, 13, 222-228.

[5] M. Itou, Y. Araki, O. Ito, H. Kido, Inorg. Chem. 2006, 45, 61146116.

[6] A. Giulino, T. Gupta, M. Altman, S. Lo Schiavo, P. G. Mineo, I. L. Fragalà, G. Evmenenko, P. Dutta, M. E. van der Boom, Chem Commun. 2008, 2900-2902.

[7] D. Benito-Garagorri, M. Puchberger, K. Mereiter, K. Kirchner, Angew. Chem. Int. Ed. 2008, 47, 9142-9145; Angew. Chem. 2008, 120, 9282-9285.

[8] S. Paul, F. Amalraj, S. Radhakrishnana, Synt. Met. 2009, 159, 1019-1023.

[9] a) M. E. Moragues, J. Esteban, J. V. Ros-Lis, R. Martínez-Máñez M.D. Marcos, M. Martínez, J. Soto, F. Sancenón, J. Am. Chem. Soc. 2011, 133, 15762-15772; b) J. Esteban, J. V. Ros-Lis, R. Martínez-Máñez, M. D. Marcos, M. Moragues, J. Soto, F Sancenón, Angew. Chem. Int. Ed. 2010, 49, 4934-4937; Angew. Chem. 2010, 122, 5054-5057.

[10] C. W. Tate, A. deMello, A. D. Gee, S. Kealey, R. Vilar, A. J. P. White, N. J. Long, Dalton Trans. 2012, 41, 83-89.

[11] US Environmental Protection Agency, Air Quality Criteria for Carbon Monoxide, EPA/600/P-99/001. National Center for Environmental Assessment, Research Triangle Park, NC, 1999.

[12] https://www.gov.uk/government/publications/carbon-monoxidepoisoning.

[13] See for instance: a) L. E. Santos-Figueroa, C. Giménez, A Agostini, E. Aznar, M. D. Marcos, F. Sancenón, R. MartínezMáñez, P. Amorós, Angew. Chem. Int. Ed. 2013, 52, 13712 13716; Angew. Chem. 2013, 125, 13957-13961.; b) E. Climent, M.D. Marcos, R. Martínez-Máñez, F. Sancenón, J. Soto, K. Rurack, P. Amorós, Angew. Chem. Int. Ed. 2009, 48, 8519-8522 Angew. Chem. 2009, 121, 8671-8674. c) E. Climent, A. Bernardos, R. Martínez-Máñez, A. Maquieira, M.D. Marcos, N Pastor-Navarro, R. Puchades, F. Sancenón, J. Soto, P. Amorós, J. Am. Chem. Soc. 2009, 131, 14075-14080; d) Comes, E. Aznar M. Moragues, M.D. Marcos, R. Martínez-Máñez, F. Sancenón, J. Soto, L.A. Villaescusa, L. Gil, P. Amorós, Chem. Eur. J. 2009, 15, 9024-9033; e) T. Ábalos, S. Royo, R. Martínez-Máñez, F. Sancenón, J. Soto, A.M. Costero, S. Gil, M. Parra, New. J. Chem 2009, 33, 1641-1645; f) E. Aznar, C. Coll, M.D. Marcos, R. Martínez-Máñez, F. Sancenón, J. Soto, P. Amorós, J. Cano, E. Ruiz, Chem. Eur. J. 2009, 15, 6877-6888; g) E. Climent, P Calero, M.D. Marcos, R. Martínez-Máñez, F. Sancenón, J. Soto, Chem. Eur. J. 2009, 15, 1816-1820.

[14] a) H. Loumrhari, J. Ros, M. R. Torres, A. Santos, A. M. Echavarren, J. Organomet. Chem. 1991, 411, 255-261; b) M. C. J. Harris, A. F. Hill, Organometallics 1991, 10, 3903-3906.

[15] M. E. Moragues, A. Toscani, F. Sancenón, R. Martínez-Máñez, A J. P. White, J. D. E. T. Wilton-Ely, J. Am. Chem. Soc. 2014, 136, 11930-11933.

[16] For an overview of vinyl chemistry of ruthenium(II), see: a) M. K Whittlesey in Comprehensive Organometallic Chemistry III, Eds.: R. H. Crabtree, D. M. P. Mingos, M. I. Bruce, Elsevier: Oxford U.K., 2006; Vol. 6; b) A. F. Hill in Comprehensive Organometallic 
Chemistry II, Eds.: E. W. Abel, F. G. A. Stone, G. Wilkinson, Pergamon Press: Oxford, U.K., 1995; Vol. 7

a) S. Jung, K. Ilg, C. D. Brandt, J. Wolf, H. Werner, Eur. J. Inorg. Chem. 2004, 469-480; b) S. Jung, C. D. Brandt, J. Wolf, H Werner, Dalton Trans. 2004, 375-383; c) H. Werner, S. Jung, P. Gonzalez-Herrero, K. Ilg, J. Wolf, Eur. J. Inorg. Chem. 2001 1957-1961; d) S. Jung, K. Ilg, J. Wolf, H. Werner, Organometallics 2001, 20, 2121-2123; e) H. Werner, W. Stüer, S Jung, B. Weberndörfer, J. Wolf, Eur. J. Inorg. Chem. 2002, 10761080; f) H. Werner, A. Stark, P. Steinert, C. Grunwald, J. Wolf, Chem. Ber. 1995, 128, 49-62.

[18] a) M. A. Esteruelas, A. M. López, E. Oñate, Organometallics 2007, 26, 3260-3263; b) T. Bolano, R. Castarlenas, M. A Esteruelas, E. Oñate, J. Am. Chem. Soc. 2006, 128, 3965-3973 c) B. Eguillar, M. A. Esteruelas, M. Oliván, E. Oñate, Organometallics 2005, 24, 1428-1438; d) R. Castarlenas, M. A Esteruelas, E. Oñate, Organometallics 2001, 20, 3283-3292; e) R. Castarlenas, M. A. Esteruelas, E. Oñate, Organometallics 2001, 20, 2294-2302; f) M. A. Esteruelas, C. García-Yebra, M Oliván, E. Oñate, M. Tajada, Organometallics 2000, 19, 50985106; g) R. Castarlenas, M. A. Esteruelas, E. Oñate, Organometallics 2000, 19, 5454-5463; h) M. L. Buil, M. A Esteruelas, C. García-Yebra, E. Gutiérrez-Puebla and M. Oliván Organometallics 2000, 19, 2184-2193; i) C. Bohanna, M. L. Buil, M. A. Esteruelas, E. Oñate, C. Valero, Organometallics 1999, 18 5176-5179; j) C. Bohanna, B. Callejas, A. Edwards, M. A Esteruelas, F. J. Lahoz, L. A. Oro, N. Ruiz, C. Valero, Organometallics 1998, 17, 373-381; k) M. A. Esteruelas, A. V. Gómez, A. M. López, E. Oñate, Organometallics 1998, 17, $3567-$ 3573; I) M. A. Esteruelas, F. Liu, E. Oñate, E. Sola, B. Zeier, Organometallics 1997, 16, 2919-2928; m) M. L. Buil, S. Elipe, M. A. Esteruelas, E. Oñate, E. Peinado, N. Ruiz, Organometallics 1997, 16, 5748-5755; n )M. A. Esteruelas, F. J. Lahoz, E. Oñate L. A. Oro, E. Sola, J. Am. Chem. Soc. 1996, 118, 89-99; o) C Bohanna, M. A. Esteruelas, J. Herrero, A. M. López, L. A. Oro, J. Organomet. Chem. 1995, 498, 199-206; p) C. Bohanna, M. A Esteruelas, F. J. Lahoz, E. Oñate, L. A. Oro, E. Sola, Organometallics 1995, 14, 4825-4831; q) C. Bohanna, M. A Esteruelas, F. J. Lahoz, E. Oñate, L. A. Oro, Organometallics 1995, 14, 4685-4696.

[19] a) B. Gómez-Lor, A. Santos, M. Ruiz, A. M. Echavarren, Eur. J. Inorg. Chem. 2001, 2305-2310; b) A. M. Castaño, A. M. Echavarren, J. López, A. Santos, J. Organomet. Chem. 1989, 379, 171-175; c) J. Montoya, A. Santos, A. M. Echavarren, J. Ros, J. Organomet. Chem. 1990, 390, C57-C60; d) J. Montoya, A. Santos, J. López, A. M. Echavarren, J. Ros, A. Romero, J. Organomet. Chem. 1992, 426, 383-398; e) J. López, A. Romero, A. Santos, A. Vegas, A. M. Echavarren, P. Noheda, J. Organomet. Chem. 1989, 373, 249-258; f) A. M. Echavarren, J. López, A. Santos, J. Montoya, J. Organomet. Chem. 1991, 414, 393-400; g) M. R. Torres, A. Vegas, A. Santos, J. Ros, J. Organomet. Chem. 1987, 326, 413-421; h) M. R. Torres, A. Santos, J. Ros, X. Solans, Organometallics 1987, 6, 1091-1095.

[20] a) D. J. Huang, K. B. Renkema, K. G. Caulton, Polyhedron 2006, 25, 459-468; b) A. V. Marchenko, H. Gérard, O. Eisenstein, K. G. Caulton, New J. Chem. 2001, 25, 1382-1388; c) A. V. Marchenko, H. Gérard, O. Eisenstein, K. G. Caulton, New J. Chem. 2001, 25, 1244-1255; d) J. N. Coalter, W. E. Streib, K. G. Caulton, Inorg. Chem. 2000, 39, 3749-3756; e) A. Pedersen, M. Tilset, K. Folting, K. G. Caulton, Organometallics 1995, 14, 875888.

[21] a) J. Maurer, R. F. Winter, B. Sarkar, J. Fiedler, S. Z. liš, Chem. Commun. 2004, 1900-1901; b) J. Maurer, B. Sarkar, W. Kaim, R.
F. Winter, S. Záliš, Chem. Eur. J. 2007, 13, 10257-10272; c) J. Maurer, M. Linseis, B. Sarkar, B. Schwederski, M. Niemeyer, W Kaim, S. Záliš, C. Anson, M. Zabel, R. F. Winter, J. Am. Chem. Soc. 2008, 130, 259-268; d) M. Linseis, R. F. Winter, B. Sarkar W. Kaim, S. Záliš, Organometallics, 2008, 27, 3321-3324; e) M Pichlmaier, R. F. Winter, M. Zabel, S. Záliš, J. Am. Chem. Soc 2009, 131, 4892-4903; f) K. Kowalski, M. Linseis, R. F. Winter, M Zabel, S. Záliš, H. Kelm, H.-J. Krüger, B. Sarkar, W. Kaim Organometallics 2009, 28, 4196-4209; g) F. Pevny, R. F. Winter, B. Sarkar, S. Záliš, Dalton Trans., 2010, 39, 8000-8011; h) S Záliš, R. F. Winter, W. Kaim, Coord. Chem. Rev. 2010, 254, 1383-1396; i) P. Mucke, M. Linseis, S. Záliš, R. F. Winter, Inorg. Chim. Acta 2011, 374, 36-50; j) P. Mücke, M. Zabel, R. Edge, D. Collison, S. Clément, S. Záliš, R. F. Winter, J. Organomet. Chem 2011, 696, 3186-3197; k) J. Chen, R. F. Winter, Chem. Eur. J. 2012, 18, 10733-10741; I) E. Wuttke, F. Pevny, Y.-M. Hervault, L. Norel, M. Drescher, R. F. Winter, S. Rigaut, Inorg. Chem. 2012, 51, 1902-1915; m) M. Linseis, S. Záliš, M. Zabel, R. F. Winter, J. Am. Chem. Soc. 2012, 134, 16671-16692; n) W. Polit, P. Mücke, E. Wuttke, T. Exner, R. F. Winter, Organometallics 2013, 32, 5461-5472; o) E. Wuttke, Y.-M. Hervault, W. Polit, M. Linseis, P. Erler, S. Rigaut, R. F. Winter, Organometallics 2014, 33, 4672-4686.

[22] a) A. F. Hill, R. P.Melling, J. Organomet. Chem. 1990, 396, C22C24; b) A. F. Hill, M. C. J. Harris, R. P. Melling, Polyhedron 1992 11, 781-787; c) M. C. J. Harris, A. F. Hill, Organometallics 1991 10, 3903-3906; d) A. F. Hill, A. J. P. White, D. J. Williams, J. D. E. T. Wilton-Ely, Organometallics 1998, 17, 4249-4258; e) J. C. Cannadine, A. F. Hill, A. J. P. White, D. J. Williams, J. D. E. T. Wilton-Ely, Organometallics 1996, 15, 5409-5415; f) A. F. Hill, C. T. Ho and J. D. E. T. Wilton-Ely, Chem. Commun. 1997, 22072208; g) A. F. Hill, J. D. E. T. Wilton-Ely, J. Chem. Soc., Dalton Trans. 1999, 3501-3510.

[23] a) J. D. E. T. Wilton-Ely, M. Wang, D. Benoit, D. A. Tocher, Eur. J. Inorg. Chem. 2006, 3068-3078; b) J. D. E. T. Wilton-Ely, P. J. Pogorzelec, S. J. Honarkhah, D. A. Tocher, Organometallics 2005, 24, 2862-2874; c) J. D. E. T. Wilton-Ely, S. J. Honarkhah M. Wang, D. A. Tocher, Dalton Trans. 2005, 1930-1939; d) J. D. E. T. Wilton-Ely, M. Wang, S. J. Honarkhah, D. A. Tocher, Inorg. Chim. Acta 2005, 358, 3218-3226.

[24] A. Santos, J. López, A. Galán, J. J. González, P. Tinoco, A. M. Echavarren, Organometallics 1997, 16, 3482-3488.

[25] M. R. Torres, A. Vegas, A. Santos, J. Ros, J. Organomet. Chem. 1986, 309, 169-177.

[26] S.-H. Choi, I. Bytheway, Z. Lin, G. Jia, Organometallics 1998, 17 3974-3980.

[27] N. W. Alcock, A. F. Hill, M. S. Roe, J. Chem. Soc., Dalton Trans. 1999, 1737-1740

[28] A. Romero, A. Santos, A. Vegas, Organometallics 1988, 7, 19881993.

[29] a) B. W. Michel, A. R. Lippert, C. J. Chang, J. Am. Chem. Soc 2012, 134, 15668-15671; b) J. Wang, J. Karpus, B. S. Zhao, Z Luo, P. R. Chen, C. He, Angew. Chem. Int. Ed. 2012, 51, 96529656 .

[30] a) R. B. Bedford, A. F. Hill, C. Jones, Angew. Chem. Int. Ed. 1996, 35, 547-549; Angew. Chem. 1996, 108, 587-589; b) R. B. Bedford, A. F. Hill, C. Jones, A. J. P. White, D. J. Williams, J. D. E. T. Wilton-Ely, Organometallics 1998, 17, 4744-4753.

[31] M. E. Moragues, R. Montes-Robles, J. V. Ros-Lis, M. Alcañíz, J. Ibañez, T. Pardo, R. Martínez-Máñez, Sens. Actuators B 2014, 191, 257-263. 
The chromo-fluorogenic detection of carbon monoxide in both solution and air has been achieved using simple, inexpensive ruthenium and osmium complexes.

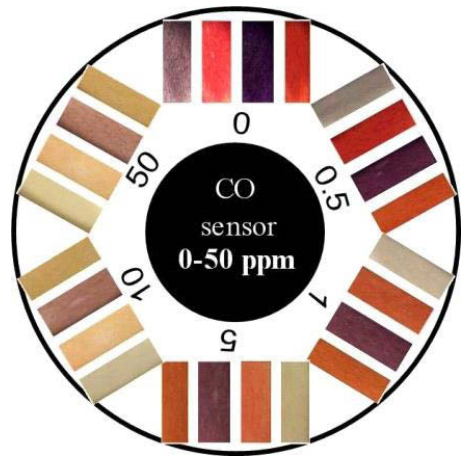

A. Toscani, C. Marín-Hernández, M. E. Moragues, F. Sancenón, P. Dingwall, N. J. Brown, R. Martínez-Máñez, ${ }^{*} A$. J. P. White and J. D. E. T. Wilton-Ely*

Ruthenium(II) and Osmium(II) Vinyl Complexes as Highly Sensitive and Selective Chromogenic and Fluorogenic Probes for the Sensing of Carbon Monoxide in Air 


\title{
Electronic Supporting Information
}

\author{
1. Experimental procedures
}

2. Crystallography

3. Carbon monoxide sensing studies

4. DFT Studies

5. Calculated UV-Vis Spectra

6. Interferents

7. Detection limits

8. Stoichiometry of the reaction and Job plot

9. Binding constants

\section{Experimental procedures}

\section{Reagents}

The compounds 1-ethynylpyrene, 4-ethynyltoluene, 4-ethynylbenzene, 9-ethynylphenanthrene, 2ethynylnaphthalene, 2-ethynyl-6-methoxynaphthalene and 2,1,3-benzothiadiazole (BTD) were used as purchased. All solvents were of analytical grade. Solvents used for UV-Vis measurements were thoroughly degassed with $\mathrm{N}_{2}$. Petroleum ether refers to the fraction boiling between $40-60^{\circ} \mathrm{C}$. All experiments and manipulations of compounds were conducted in air, unless otherwise specified. Carbon monoxide was provided by commercially available $\mathrm{CO}$ cylinders. Mixtures of different concentrations of CO were prepared by mixing $\mathrm{CO}$ with CO-free synthetic air. The rest of gases used in this work were generated in situ, carbon dioxide (by adding hydrochloric acid to sodium carbonate), nitrogen oxides (by oxidation of copper with nitric acid), sulfur dioxide (by copper oxidation with sulfuric acid) and $\mathrm{H}_{2} \mathrm{~S}$ (by adding hydrochloric acid to sodium sulphide). Geduran Silica gel for chromatographic use (particle size 40-63 $\mu \mathrm{m}$ ) was purchased from Millipore (Merck) and employed as solid support for the immobilisation of the compounds. The procedures given provide materials of sufficient purity for synthetic and spectroscopic purposes. 


\section{Instrumentation}

NMR spectroscopy was performed at $25^{\circ} \mathrm{C}$ using a Bruker AV400 spectrometer, operating at $400.32 \mathrm{MHz}$ for ${ }^{1} \mathrm{H}$ nuclei and $162.05 \mathrm{MHz}$ for ${ }^{31} \mathrm{P}$ nuclei. Spectra were recorded in $\mathrm{CDCl}_{3}$ unless stated otherwise. Chemical shifts are reported in ppm and coupling constants $(J)$ are in Hertz. Infrared data were obtained using a PerkinElmer Spectrum 100 FT-IR spectrophotometer. Elemental analysis data were obtained by London Metropolitan University. Solvates were confirmed by integration of the ${ }^{1} \mathrm{H}$ NMR spectrum. Electrospray (ES) mass analyses were performed at Imperial College London on a Micromass LCT Premier spectrometer. UV-Vis spectra were recorded using a Jasco V-650 spectrophotometer equipped with a diffuse reflectance sphere (model ISV-722) for measurements on solids. In the latter case, measurements were conducted at room temperature over a wavelength range of 350-800 $\mathrm{nm}$ with a wavelength step of $1 \mathrm{~nm}$. Carbon monoxide concentrations were measured using an ambient carbon monoxide analyser (Testo 315-2 model 0632 0317), properly validated with an ISO calibration certificate issued by Instrumentos Testo, Cabrils, Spain. Computational calculations were performed using the B3LYP functional, dispersion corrections were added using the empirical dispersion keyword and Grimme's D3 procedure. MWB28 was used as the pseudo potential and basis set for Ru. Initially, all other atoms were calculated at 6-31G(d) and then refined using the TZVP basis set. Solvent (methanol) was included in all calculations using the CPCM methodology. An ultrafine grid and tight convergence criteria, $\operatorname{scf}=9$, was employed throughout. TD-DFT calculations were carried out on fully optimised structures for the first 100 states using the same functional and basis sets. Molecular orbital diagrams were generated using Gauss view. Full crystallographic data have been deposited in the Cambridge Crystallographic Data Centre for 4, 6 and 5.CO with the numbers CCDC 1011581, 1048863 and 1011582, respectively.

\section{Synthesis}

General Comments. The compounds $\quad\left[\mathrm{RuHCl}(\mathrm{CO})\left(\mathrm{PPh}_{3}\right)_{3}\right],{ }^{\mathrm{S} 1} \quad\left[\mathrm{OsHCl}(\mathrm{CO})(\mathrm{BTD})\left(\mathrm{PPh}_{3}\right)_{2}\right],{ }^{\mathrm{S} 2}$ $\left[\mathrm{Os}\left(\mathrm{CH}=\mathrm{CHC}_{6} \mathrm{H}_{4} \mathrm{Me}-4\right) \mathrm{Cl}(\mathrm{CO})(\mathrm{BTD})\left(\mathrm{PPh}_{3}\right)_{2}\right] \quad(\mathbf{4}),{ }^{\mathrm{S} 2} \quad\left[\mathrm{Os}\left(\mathrm{CH}=\mathrm{CHC}{ }_{6} \mathrm{H}_{4} \mathrm{Me}-4\right) \mathrm{Cl}(\mathrm{CO})_{2}\left(\mathrm{PPh}_{3}\right)_{2}\right] \quad(\mathbf{4} \cdot \mathbf{C O}),{ }^{\mathrm{S} 2}$ $\left[\mathrm{Ru}\left(\mathrm{P}=\mathrm{CH}^{\mathrm{t}} \mathrm{Bu}\right) \mathrm{Cl}(\mathrm{CO})\left(\mathrm{PPh}_{3}\right)_{2}\right] \quad(\mathbf{9}),{ }^{\mathrm{S} 3} \quad\left[\mathrm{Ru}\left(\mathrm{P}=\mathrm{CH}^{\mathrm{t}} \mathrm{Bu}\right) \mathrm{Cl}(\mathrm{CO})_{2}\left(\mathrm{PPh}_{3}\right)_{2}\right] \quad(\mathbf{9} \cdot \mathbf{C O})^{\mathrm{S} 3} \quad$ and $\left[\mathrm{Ru}\left(\mathrm{CH}=\mathrm{CHC}_{6} \mathrm{H}_{5}\right) \mathrm{Cl}(\mathrm{CO})_{2}\left(\mathrm{PPh}_{3}\right)_{2}\right](\mathbf{5} \cdot \mathbf{C O})^{\mathrm{S} 4}$ were prepared according to published procedures. Further data are provided for the compounds $\left[\mathrm{Ru}(\mathrm{CH}=\mathrm{CHPyr}-1) \mathrm{Cl}(\mathrm{CO})(\mathrm{BTD})\left(\mathrm{PPh}_{3}\right)_{2}\right] \quad(\mathbf{1}){ }^{\mathrm{S} 5} \quad[\mathrm{Ru}(\mathrm{CH}=\mathrm{CHPyr}-$ 1) $\left.\mathrm{Cl}(\mathrm{CO})_{2}\left(\mathrm{PPh}_{3}\right)_{2}\right](\mathbf{1} \cdot \mathbf{C O}) .{ }^{\mathrm{S} 5}$
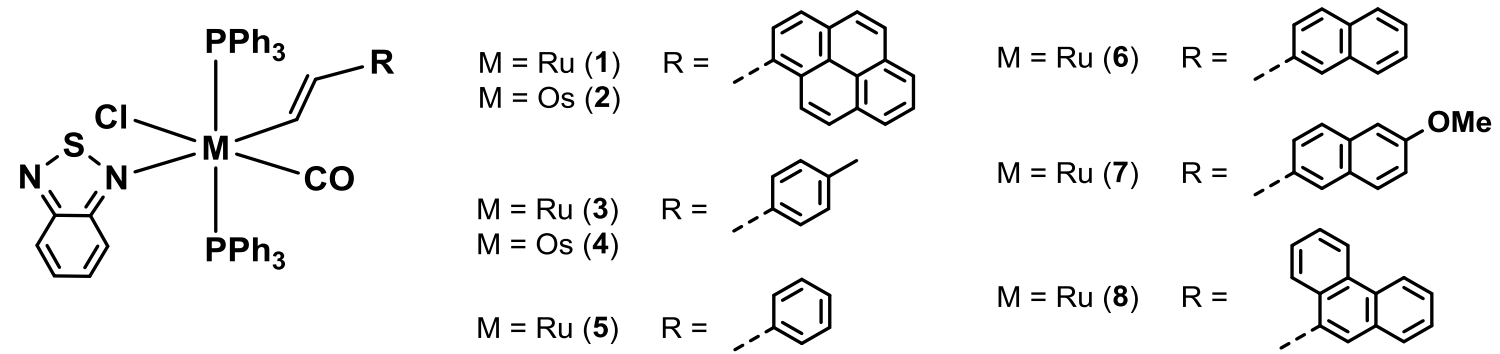

\section{$\left[\mathrm{Ru}(\mathrm{CH}=\mathrm{CHPyr}-1) \mathrm{Cl}(\mathrm{CO})(\mathrm{BTD})\left(\mathrm{PPh}_{3}\right)_{2}\right]$ (1)}

2,1,3-benzothiadiazole $(25 \mathrm{mg}, 0.184 \mathrm{mmol})$ was added to a dichloromethane $(10 \mathrm{~mL})$ solution of $\left[\mathrm{RuHCl}(\mathrm{CO})\left(\mathrm{PPh}_{3}\right)_{3}\right](102 \mathrm{mg}, 0.107 \mathrm{mmol})$ and the resulting orange solution was stirred at room temperature for few minutes. 1-ethynylpyrene $(37 \mathrm{mg}, 0.164 \mathrm{mmol})$ was then added and the reaction mixture was stirred at 
room temperature for $1 \mathrm{~h}$, after which methanol $(25 \mathrm{~mL})$ was added and the dichloromethane slowly removed under reduced pressure (rotary evaporator). The resulting red-orange crystals were isolated by filtration, washed with ethanol $(2 \times 10 \mathrm{~mL})$ and dried in vacuo. Yield: $106 \mathrm{mg}(94 \%)$. IR ( $\left.v_{\max } / \mathrm{cm}^{-1}\right): 1928(\mathrm{CO}), 1432,1232$, 1088, 846, 740, 692. NMR $\delta_{\mathrm{H}}\left(\mathrm{CDCl}_{3}\right) 7.01\left(1 \mathrm{H}, \mathrm{d}, J_{\mathrm{HH}}=15.0 \mathrm{~Hz}, \mathrm{H} \beta\right), 7.64-7.18(30 \mathrm{H}, \mathrm{m}, \mathrm{Ph}), 7.93(2 \mathrm{H}, \mathrm{m}$, BTD), $7.70-7.95\left(9 \mathrm{H}, \mathrm{m}\right.$, pyrenyl), $8.05(2 \mathrm{H}, \mathrm{m}, \mathrm{BTD}), 9.06\left(1 \mathrm{H}, \mathrm{dt}, J_{\mathrm{HH}}=15.0 \mathrm{~Hz}, J_{\mathrm{HP}}\right.$ unresolved, H $\left.\alpha\right) ; \delta_{\mathrm{P}}$ $\left(\mathrm{CDCl}_{3}\right) 29.4\left(\mathrm{~s}, \mathrm{PPh}_{3}\right)$. MS (ES +ve) $m / z 1053\left(\mathrm{M}^{+}, 5 \%\right)$. Elemental analysis: Found: C, 69.4; H, 4.5; N, 2.6. $\mathrm{C}_{61} \mathrm{H}_{45} \mathrm{ClN}_{2} \mathrm{OP}_{2} \mathrm{RuS}$ requires $\mathrm{C}, 69.6 ; \mathrm{H}, 4.3 ; \mathrm{N}, 2.7 \%$.

\section{$\left.\left[\mathrm{Ru}(\mathrm{CH}=\mathrm{CHPyr}-\mathbf{1}) \mathrm{Cl}(\mathrm{CO})_{2}\left(\mathrm{PPh}_{\mathbf{3}}\right)_{2}\right] \mathbf{( 1} \cdot \mathrm{CO}\right)$}

Compound 2 was prepared by treating a dichloromethane solution $(10 \mathrm{~mL})$ of $1(7.0 \mathrm{mg}, 0.007 \mathrm{mmol})$ with a stream of carbon monoxide for 1 minute. Ethanol $(5 \mathrm{~mL})$ was added, forming a yellow precipitate which was filtered, washed with ethanol $(10 \mathrm{~mL})$, and dried in vacuo. Yield: $6.4 \mathrm{mg}(97 \%) . \mathrm{IR}\left(v_{\max } / \mathrm{cm}^{-1}\right): 2031$ (CO), 1874 (CO) 1481, 1433, 1346, 1160, 1091, 847, 740, 691. NMR $\delta_{\mathrm{H}}\left(\mathrm{CDCl}_{3}\right) 7.13\left(1 \mathrm{H}, \mathrm{dt}, J_{\mathrm{HH}}=15.0 \mathrm{~Hz}, J_{\mathrm{HP}}\right.$ unresolved, $\mathrm{H} \beta), 7.76-7.30\left(30 \mathrm{H}, \mathrm{m}, \mathrm{PPh}_{3}\right), 8.10-7.83(9 \mathrm{H}, \mathrm{m}$, pyrenyl $), 8.53\left(1 \mathrm{H}, \mathrm{dt}, J_{\mathrm{HH}}=15.0 \mathrm{~Hz}, J_{\mathrm{HP}}\right.$ unresolved, $\mathrm{H} \alpha) ; \delta_{\mathrm{P}}\left(\mathrm{CDCl}_{3}\right) 23.7\left(\mathrm{~s}, \mathrm{PPh}_{3}\right) . \mathrm{MS}(\mathrm{ES}+\mathrm{ve}) \mathrm{m} / z 945\left(\mathrm{M}^{+}, 10 \%\right)$. Elemental Analysis: Found: C, 70.8; $\mathrm{H}, 4.4 ; \mathrm{C}_{56} \mathrm{H}_{41} \mathrm{ClO}_{2} \mathrm{P}_{2} \mathrm{Ru}$ requires $\mathrm{C}, 71.2 ; \mathrm{H}, 4.4 \%$.

\section{$\left[\mathrm{Os}(\mathrm{CH}=\mathrm{CHPyr}-1) \mathrm{Cl}(\mathrm{CO})(\mathrm{BTD})\left(\mathrm{PPh}_{3}\right)_{2}\right]$ (2)}

A dichloromethane solution $(10 \mathrm{~mL})$ of $\left[\mathrm{OsHCl}(\mathrm{CO})(\mathrm{BTD})\left(\mathrm{PPh}_{3}\right)_{2}\right](70 \mathrm{mg}, 0.076 \mathrm{mmol})$ was treated with 1ethynylpyrene (19 $\mathrm{mg}, 0.084 \mathrm{mmol})$. The resulting dark red solution was stirred for 3 hours at room temperature and then filtered through Celite. Addition of methanol $(15 \mathrm{~mL})$ followed by slow reduction of the solvent volume, resulted in a dark red solid, which was washed with cold methanol $(10 \mathrm{~mL})$, petroleum ether $(10 \mathrm{~mL})$ and dried. Yield: $60 \mathrm{mg}(69 \%)$. IR $\left(v_{\max } / \mathrm{cm}^{-1}\right): 1919$ (CO), 1434, 1183, 1117, 745, 719, 691. NMR $\delta_{\mathrm{H}}\left(\mathrm{CD}_{2} \mathrm{Cl}_{2}\right)$ 7.08-7.21 (18H, m, Ph), $7.46(12 \mathrm{H}, \mathrm{m}, \mathrm{Ph}), 7.80-7.99(9 \mathrm{H}+1 \mathrm{H}, \mathrm{m}$, pyrenyl $+\mathrm{H} \beta), 8.15\left(2 \mathrm{H}, \mathrm{d}, J_{\mathrm{HH}}=7.6 \mathrm{~Hz}\right.$, BTD), 8.15 (2H, m, BTD), $9.70\left(1 \mathrm{H}, \mathrm{dt}, J_{\mathrm{HH}}=16.8 \mathrm{~Hz}, J_{\mathrm{HP}}\right.$ unresolved, $\left.\mathrm{H} \alpha\right) ; \delta_{\mathrm{P}}\left(\mathrm{CD}_{2} \mathrm{Cl}_{2}\right)-1.2\left(\mathrm{~s}, \mathrm{PPh}_{3}\right)$. MS (ES + ve) $m / z 1188\left(\mathrm{M}^{+}+2 \mathrm{Na}, 60 \%\right)$. Elemental Analysis: Found: C, 60.3; H, 3.5; N, 2.5. $\mathrm{C}_{61} \mathrm{H}_{45} \mathrm{ClN}_{2} \mathrm{OOsP}_{2} \mathrm{~S} \cdot \mathrm{CH}_{2} \mathrm{Cl}_{2}$ requires $\mathrm{C}, 60.7 ; \mathrm{H}, 3.9 ; \mathrm{N}, 2.3 \%$.

\section{$\left[\mathrm{Os}(\mathrm{CH}=\mathrm{CHPyr}-1) \mathrm{Cl}(\mathrm{CO})_{2}\left(\mathrm{PPh}_{3}\right)_{2}\right]$ (2 CO)}

Compound 2 CO was prepared by treating a dichloromethane solution ( $3 \mathrm{~mL})$ of 2 (25 mg, $0.022 \mathrm{mmol})$ with a stream of carbon monoxide for 1 minute. Methanol $(5 \mathrm{~mL})$ was added and the resulting mustard yellow precipitate was isolated by filtration. The compound was washed with methanol $(10 \mathrm{~mL})$ and dried. Yield: 19 mg (84\%). IR ( $\left.v_{\max } / \mathrm{cm}^{-1}\right): 2017$ (CO), 1954 (CO), 1434, 1092, 847, 740, 692. NMR $\delta_{\mathrm{H}}\left(\mathrm{CD}_{2} \mathrm{Cl}_{2}\right) 7.25(1 \mathrm{H}, \mathrm{dt}$, $\left.J_{\mathrm{HH}}=18.1 \mathrm{~Hz}, J_{\mathrm{HP}}=2.3 \mathrm{~Hz}, \mathrm{H} \beta\right), 7.33-7.43(18 \mathrm{H}, \mathrm{m}, \mathrm{Ph}), 7.58\left(1 \mathrm{H}, \mathrm{d}, J_{\mathrm{HH}}=8.1 \mathrm{~Hz}\right.$, pyrenyl), $7.68-7.73$ $(12 \mathrm{H}, \mathrm{m}, \mathrm{Ph}), 7.87\left(2 \mathrm{H}, \mathrm{s}\right.$, pyrenyl), $7.92-8.00(4 \mathrm{H}, \mathrm{m}$, pyrenyl $), 8.06\left(1 \mathrm{H}, \mathrm{dt}, 1 \mathrm{H}, J_{\mathrm{HH}}=18.1 \mathrm{~Hz}, J_{\mathrm{HP}}=3.0 \mathrm{~Hz}\right.$, $\mathrm{H} \alpha), 8.07-8.12\left(2 \mathrm{H}, \mathrm{m}\right.$, pyrenyl); $\delta_{\mathrm{P}}\left(\mathrm{CD}_{2} \mathrm{Cl}_{2}\right)-7.3\left(\mathrm{~s}, \mathrm{PPh}_{3}\right)$. MS (ES +ve) $m / z 1034\left(\mathrm{M}^{+}, 100 \%\right)$. Found: C, 65.0; $\mathrm{H}, 4.2$. $\mathrm{C}_{56} \mathrm{H}_{41} \mathrm{ClO}_{2} \mathrm{OsP}_{2}$ requires $\mathrm{C}, 65.1 ; \mathrm{H}, 4.0 \%$. 


\section{$\left[\mathrm{Ru}\left(\mathrm{CH}=\mathrm{CHC}_{6} \mathrm{H}_{4} \mathrm{Me}-4\right) \mathrm{Cl}(\mathrm{CO})(\mathrm{BTD})\left(\mathrm{PPh}_{3}\right)_{2}\right](3)$}

4-ethynyltoluene ( $26 \mu \mathrm{l}, 0.236 \mathrm{mmol})$ was added to a dichloromethane solution $(10 \mathrm{~mL})$ of $\left[\mathrm{RuHCl}(\mathrm{CO})\left(\mathrm{PPh}_{3}\right)_{3}\right]$ $(150 \mathrm{mg}, 0.158 \mathrm{mmol})$ to give a dark red solution. BTD (32 $\mathrm{mg}, 0.235 \mathrm{mmol})$ was then added and the solution was stirred for 1 hour at room temperature. EtOH $(20 \mathrm{~mL})$ was added and the dichloromethane was slowly removed under vacuum to yield a bright orange crystalline product. This was filtered and washed with EtOH (2 x $10 \mathrm{~mL})$ and petroleum ether $(20 \mathrm{~mL})$ and dried under vacuum. Yield: $131 \mathrm{mg}(88 \%)$. IR $\left(v_{\max } / \mathrm{cm}^{-1}\right): 1914$ (CO), 1482, 1434, 1091, 979, 837, 741, 693. NMR $\delta_{\mathrm{H}}\left(\mathrm{CD}_{2} \mathrm{Cl}_{2}\right) 2.29\left(3 \mathrm{H}, \mathrm{s}, \mathrm{CH}_{3}\right), 5.75\left(1 \mathrm{H}, \mathrm{dt}, J_{\mathrm{HH}}=16.0 \mathrm{~Hz}\right.$, $J_{\mathrm{HP}}=$ unresolved, $\left.\mathrm{H} \beta\right), 6.77,6.79\left(2 \times 2 \mathrm{H}, \mathrm{AB}, J_{\mathrm{AB}}=7.9 \mathrm{~Hz}, \mathrm{C}_{6} \mathrm{H}_{4} \mathrm{Me}\right), 7.12\left(12 \mathrm{H}, \mathrm{t}, J_{\mathrm{HH}}=7.0 \mathrm{~Hz}, \mathrm{Ph}\right), 7.23$ $\left(6 \mathrm{H}, \mathrm{t}, J_{\mathrm{HH}}=7.0 \mathrm{~Hz}, \mathrm{Ph}\right), 7.50-7.44(12 \mathrm{H}, \mathrm{m}, \mathrm{Ph}), 7.72-7.67$ (2H, m, BTD), $7.91(2 \mathrm{H}, \mathrm{s} b r, \mathrm{BTD}), 8.63(1 \mathrm{H}$, $\left.\mathrm{dt}, J_{\mathrm{HH}}=16.0 \mathrm{~Hz}, J_{\mathrm{HP}}=3.2 \mathrm{~Hz}, \mathrm{H \alpha}\right) ; \delta_{\mathrm{P}}\left(\mathrm{CD}_{2} \mathrm{Cl}_{2}\right) 26.7\left(\mathrm{~s}, \mathrm{PPh}_{3}\right)$. MS (ES +ve) $m / z 943\left(\mathrm{M}^{+}, 40 \%\right)$. Elemental Analysis: Found: $\mathrm{C}, 62.1 ; \mathrm{H}, 4.7 ; \mathrm{N}, 2.9 . \mathrm{C}_{52} \mathrm{H}_{43} \mathrm{ClN}_{2} \mathrm{OP}_{2} \mathrm{RuS} \cdot \mathrm{CH}_{2} \mathrm{Cl}_{2}$ requires C, 62.0; H, 4.4; N, $2.7 \%$.

\section{$\left[\mathrm{Ru}\left(\mathrm{CH}=\mathrm{CHC}_{6} \mathrm{H}_{4} \mathrm{Me}-4\right) \mathrm{Cl}(\mathrm{CO})_{2}\left(\mathrm{PPh}_{3}\right)_{2}\right](3 \mathrm{CO})$}

Compound $3 \mathbf{C O}$ was prepared by treating a dichloromethane solution $(3 \mathrm{~mL})$ of $\mathbf{3}(30 \mathrm{mg}, 0.032 \mathrm{mmol})$ with a stream of carbon monoxide for 1 minute. Methanol $(5 \mathrm{~mL})$ was added and the resulting precipitate was isolated by filtration. The pale pink compound was washed with methanol $(10 \mathrm{~mL})$ and dried. Yield: $25 \mathrm{mg}(94 \%)$. IR $\left(v_{\max } / \mathrm{cm}^{-1}\right): 2030(\mathrm{CO}), 1968(\mathrm{CO}), 1481,1434,1091,990,741,733,690 . \mathrm{NMR} \delta_{\mathrm{H}}\left(\mathrm{CD}_{2} \mathrm{Cl}_{2}\right) 2.31\left(3 \mathrm{H}, \mathrm{s}, \mathrm{CH}_{3}\right)$, $5.85\left(1 \mathrm{H}, \mathrm{dt}, J_{\mathrm{HH}}=18.0 \mathrm{~Hz}, J_{\mathrm{HP}}\right.$ unresolved, $\left.\mathrm{H} \beta\right), 6.80,7.01\left(2 \times 2 \mathrm{H}, \mathrm{AB}, J_{\mathrm{AB}}=7.9 \mathrm{~Hz}, \mathrm{C}_{6} \mathrm{H}_{4} \mathrm{Me}\right), 7.37-7.47$ $(18 \mathrm{H}, \mathrm{m}, \mathrm{Ph}), 7.52\left(1 \mathrm{H}, \mathrm{dt}, J_{\mathrm{HH}}=18.0 \mathrm{~Hz}, J_{\mathrm{HP}}=3.5 \mathrm{~Hz}, \mathrm{H \alpha}\right), 7.69-7.74(12 \mathrm{H}, \mathrm{m}, \mathrm{Ph}) ; \delta_{\mathrm{P}}\left(\mathrm{CD}_{2} \mathrm{Cl}_{2}\right) 23.8(\mathrm{~s}$, $\left.\mathrm{PPh}_{3}\right)$. MS (ES +ve) $m / z 853\left(\mathrm{M}^{+}+\mathrm{H}_{2} \mathrm{O}\right.$, 9\%). Elemental analysis: Found: $\mathrm{C}, 63.7 ; \mathrm{H}, 4.6$. $\mathrm{C}_{47} \mathrm{H}_{39} \mathrm{ClO}_{2} \mathrm{P}_{2} \mathrm{Ru} \cdot 0.75 \mathrm{CH}_{2} \mathrm{Cl}_{2}$ requires $\mathrm{C}, 63.9 ; \mathrm{H}, 4.5 \%$.

\section{$\left[\mathrm{Ru}\left(\mathrm{CH}=\mathrm{CHC}_{6} \mathrm{H}_{5}\right) \mathrm{Cl}(\mathrm{CO})(\mathrm{BTD})\left(\mathrm{PPh}_{3}\right)_{2}\right]$ (5)}

Ethynylbenzene $(25 \mu \mathrm{l}, 0.236 \mathrm{mmol})$ was added to a dichloromethane solution $(10 \mathrm{~mL})$ of $\left[\mathrm{RuHCl}(\mathrm{CO})\left(\mathrm{PPh}_{3}\right)_{3}\right]$ $(150 \mathrm{mg}, 0.158 \mathrm{mmol})$ to give a dark red solution. BTD $(32 \mathrm{mg}, 0.235 \mathrm{mmol})$ was then added and the solution was left to stir for 1 hour at room temperature. EtOH $(20 \mathrm{~mL})$ was added and dichloromethane was slowly removed under vacuum to yield a bright red crystalline product, which was filtered and washed with EtOH $(2 \mathrm{x}$ $10 \mathrm{~mL}$ ) and petroleum ether $(20 \mathrm{~mL})$. Yield: $125 \mathrm{mg}(85 \%)$. IR $\left(\nu_{\max } / \mathrm{cm}^{-1}\right): 1917(\mathrm{CO}), 1481,1433,1090,738$, 689. NMR $\delta_{\mathrm{H}}\left(\mathrm{CD}_{2} \mathrm{Cl}_{2}\right): 5.82\left(1 \mathrm{H}, \mathrm{d}, J_{\mathrm{HH}}=16.0 \mathrm{~Hz}, \mathrm{H} \beta\right), 6.91\left(2 \mathrm{H}, \mathrm{d}, J_{\mathrm{HH}}=7.3 \mathrm{~Hz}, \mathrm{CPh}\right), 6.98\left(1 \mathrm{H}, \mathrm{t}, J_{\mathrm{HH}}=7.3\right.$ $\mathrm{Hz}, \mathrm{CPh}), 7.14-7.20(12 \mathrm{H}+2 \mathrm{H}, \mathrm{m}, \mathrm{PPh}+\mathrm{CPh}), 7.30(6 \mathrm{H}, \mathrm{m}, \mathrm{PPh}), 7.46-7.51(12 \mathrm{H}, \mathrm{m}, \mathrm{PPh}), 7.54(2 \mathrm{H}, \mathrm{m}$, BTD), $7.95(2 \mathrm{H}, \mathrm{m}, \mathrm{BTD}), 8.70\left(1 \mathrm{H}, \mathrm{dt}, J_{\mathrm{HH}}=16.0 \mathrm{~Hz}, J_{\mathrm{HP}}=3.0 \mathrm{~Hz}, \mathrm{H \alpha}\right) ; \delta_{\mathrm{P}}\left(\mathrm{CD}_{2} \mathrm{Cl}_{2}\right) 27.0\left(\mathrm{~s}, \mathrm{PPh}_{3}\right)$. MS (ES + ve) $m / z 839\left(\mathrm{M}^{+}-\mathrm{BTD}+2 \mathrm{Na}, 34 \%\right)$. Elemental analysis. Found: $\mathrm{C}, 65.9 ; \mathrm{H}, 4.5 . \mathrm{C}_{51} \mathrm{H}_{41} \mathrm{ClN}_{2} \mathrm{OP}_{2} \mathrm{RuS}$ requires C, $66.0 ; \mathrm{H}, 4.5 \%$.

\section{$\left[\mathrm{Ru}(\mathrm{CH}=\mathrm{CHNap}-2) \mathrm{Cl}(\mathrm{CO})(\mathrm{BTD})\left(\mathrm{PPh}_{3}\right)_{2}\right]$ (6)}

$\left[\mathrm{RuHCl}(\mathrm{CO})\left(\mathrm{PPh}_{3}\right)_{3}\right](117 \mathrm{mg}, 0.123 \mathrm{mmol})$ and 2-ethynylnaphthalene (21 mg, $\left.0.138 \mathrm{mmol}\right)$ were dissolved in dichloromethane $(15 \mathrm{~mL})$ and a dichloromethane solution $(5 \mathrm{~mL})$ of 2,1,3-benzothiadiazole $(25 \mathrm{mg}, 0.184$ mmol) was added. The resulting orange solution was stirred for 1 hour at room temperature. Addition of methanol $(20 \mathrm{~mL})$ followed by slow reduction of the solvent volume, resulted in a bright orange crystalline solid, which was washed with cold methanol $(10 \mathrm{~mL})$ and petroleum ether $(10 \mathrm{~mL})$ and dried. Yield: $87 \mathrm{mg}$ 
(72\%). IR $\left(v_{\max } / \mathrm{cm}^{-1}\right) 1925(\mathrm{CO}), 1550,1483,1433(\mathrm{C}-\mathrm{N}), 1090,979,923 \mathrm{~cm}^{-1} ;{ }^{1} \mathrm{H}$ NMR $\delta_{\mathrm{H}}\left(\mathrm{CD}_{2} \mathrm{Cl}_{2}\right) 6.00(1 \mathrm{H}$, $\left.\mathrm{d}, J_{\mathrm{HH}}=16.3 \mathrm{~Hz}, \mathrm{H} \beta\right), 7.13-7.56\left(30 \mathrm{H}+4 \mathrm{H}, \mathrm{m}, \mathrm{PPh}_{3}+\mathrm{Nap}\right), 7.64\left(1 \mathrm{H}, \mathrm{d}, J_{\mathrm{HH}}=8.6 \mathrm{~Hz}, \mathrm{Nap}\right), 7.70(1 \mathrm{H}, \mathrm{d}$, $\left.J_{\mathrm{HH}}=8.6 \mathrm{~Hz}, \mathrm{Nap}\right), 7.73\left(1 \mathrm{H}, \mathrm{d}, J_{\mathrm{HH}}=8.6 \mathrm{~Hz}, \mathrm{Nap}\right), 7.96(2 \mathrm{H}, \mathrm{m}, \mathrm{BTD}), 8.89\left(1 \mathrm{H}, \mathrm{dt}, J_{\mathrm{HH}}=16.3, J_{\mathrm{HP}}=3.1 \mathrm{~Hz}\right.$, $\mathrm{H} \alpha) ; \delta_{\mathrm{P}}\left(\mathrm{CD}_{2} \mathrm{Cl}_{2}\right) 26.9\left(\mathrm{~s}, \mathrm{PPh}_{3}\right)$ ppm. MS (ES +ve) $m / z 889\left(\mathrm{M}^{+}-\mathrm{BTD}+2 \mathrm{Na}, 80 \%\right)$; Elemental analysis. Found: C 67.4, H 4.5, N 3.0. $\mathrm{C}_{55} \mathrm{H}_{43} \mathrm{ClN}_{2} \mathrm{OP}_{2} \mathrm{RuS}$ requires C 67.5, H 4.4, N $2.9 \%$.

\section{$\left[\mathrm{Ru}(\mathrm{CH}=\mathrm{CHNap}-2) \mathrm{Cl}(\mathrm{CO})_{2}\left(\mathrm{PPh}_{3}\right)_{2}\right](6 \mathrm{CO})$}

Carbon monoxide was bubbled through a dichloromethane solution $(10 \mathrm{~mL})$ of $6(30 \mathrm{mg}, 0.031 \mathrm{mmol})$ until the solution became colourless. Addition of methanol $(7 \mathrm{~mL})$ followed by slow reduction of the solvent volume, resulted in the precipitation of a colourless solid, which was washed with cold methanol (10 $\mathrm{mL})$ and petroleum ether $(10 \mathrm{~mL})$ and dried. Yield: $25 \mathrm{mg}(93 \%)$. IR ( $\left.v_{\max } / \mathrm{cm}^{-1}\right) 2026$ (CO), 1963 (CO), $1481(\mathrm{C}-\mathrm{N}), 1433,1187$, 1091, 998, 859. NMR $\delta_{\mathrm{H}}\left(\mathrm{CD}_{2} \mathrm{Cl}_{2}\right) 6.09\left(1 \mathrm{H}, \mathrm{d}, J_{\mathrm{HH}}=18.0 \mathrm{~Hz}, \mathrm{H} \beta\right), 7.19(1 \mathrm{H}, \mathrm{s}, \mathrm{Nap}), 7.53-7.47,7.73(30 \mathrm{H}+$ $\left.5 \mathrm{H}, \mathrm{m} \times 2, \mathrm{PPh}_{3}+\mathrm{Nap}\right), 7.66\left(1 \mathrm{H}, \mathrm{d}, J_{\mathrm{HH}}=8.2 \mathrm{~Hz}, \mathrm{Nap}\right), 7.79\left(1 \mathrm{H}, \mathrm{dt}, J_{\mathrm{HH}}=18.0 \mathrm{~Hz}, J_{\mathrm{HP}}=3.5 \mathrm{~Hz}, \mathrm{H} \alpha\right) ; \delta_{\mathrm{P}}$ $\left(\mathrm{CD}_{2} \mathrm{Cl}_{2}\right) 24.1\left(\mathrm{~s}, \mathrm{PPh}_{3}\right)$ ppm. MS (ES +ve): $\mathrm{m} / z 871\left(\mathrm{M}^{+}, 100 \%\right)$; Elemental analysis. Found: C 65.1, H 4.0. $\mathrm{C}_{50} \mathrm{H}_{39} \mathrm{ClO}_{2} \mathrm{P}_{2} \mathrm{Ru} \cdot 0.75 \mathrm{CH}_{2} \mathrm{Cl}_{2}$ requires $\mathrm{C} 65.3, \mathrm{H} 4.4 \%$.

\section{[Ru(CH=CHNap-2-OMe-6)Cl(CO)(BTD) $\left.\left(\mathrm{PPh}_{3}\right)_{2}\right]$ (7)}

$\left[\mathrm{RuHCl}(\mathrm{CO})\left(\mathrm{PPh}_{3}\right)_{3}\right](100 \mathrm{mg}, 0.105 \mathrm{mmol})$ and 2-ethynyl-6-methoxynaphthalene $(21 \mathrm{mg}, 0.115 \mathrm{mmol})$ were dissolved in dichloromethane $(10 \mathrm{~mL})$ and a dichloromethane solution $(5 \mathrm{~mL})$ of 2,1,3-benzothiadiazole $(21 \mathrm{mg}$, $0.154 \mathrm{mmol}$ ) was added. The resulting purple solution was stirred for 1 hour at room temperature and then filtered through Celite. Addition of ethanol $(15 \mathrm{~mL})$ followed by slow reduction of the solvent volume, resulted in the formation of a purple crystalline solid, which was washed with cold ethanol $(5 \mathrm{~mL})$ and diethyl ether $(5$ $\mathrm{mL}$ ) and dried. Yield: $91 \mathrm{mg}(86 \%)$. IR ( $\left.v_{\max } / \mathrm{cm}^{-1}\right) 1929$ (CO), 1600, 1549, 1432 (C-N), 1197, 1090, $1031,855$. NMR $\delta_{\mathrm{H}}\left(\mathrm{CD}_{2} \mathrm{Cl}_{2}\right) 3.92(3 \mathrm{H}, \mathrm{s}, \mathrm{OMe}), 5.95\left(1 \mathrm{H}, \mathrm{d}, J_{\mathrm{HH}}=15.8 \mathrm{~Hz}, \mathrm{H} \beta\right), 7.08(2 \mathrm{H}, \mathrm{s}, \mathrm{Nap}), 7.20,7.31,7.51(30 \mathrm{H}$ $+3 \mathrm{H}, \mathrm{mx}$ 3, $\left.\mathrm{PPh}_{3}+\mathrm{Nap}\right), 7.56(2 \mathrm{H}, \mathrm{m}, \mathrm{BTD}), 7.60\left(1 \mathrm{H}, \mathrm{d}, J_{\mathrm{HH}}=9.8 \mathrm{~Hz}, \mathrm{Nap}\right), 7.96$ (2H, m, BTD), 8.75 (1H, $\left.\mathrm{dt}, J_{\mathrm{HH}}=15.8 \mathrm{~Hz}, J_{\mathrm{HP}}=3.1 \mathrm{~Hz}, \mathrm{H \alpha}\right) ; \delta_{\mathrm{P}}\left(\mathrm{CD}_{2} \mathrm{Cl}_{2}\right) 27.0\left(\mathrm{~s}, \mathrm{PPh}_{3}\right)$. MS $(\mathrm{ES}+\mathrm{ve}): m / z 873\left(\mathrm{M}^{+}-\mathrm{BTD}, 100 \%\right), 974$ $\left(\mathrm{M}^{+}-\mathrm{Cl}, 50 \%\right)$; Elemental analysis. Found: $\mathrm{C} 61.5, \mathrm{H} 4.6, \mathrm{~N}$ 2.7. $\mathrm{C}_{56} \mathrm{H}_{45} \mathrm{ClN}_{2} \mathrm{O}_{2} \mathrm{P}_{2} \mathrm{RuS} \cdot 1.25 \mathrm{CH}_{2} \mathrm{Cl}_{2}$ requires $\mathrm{C}$ $61.7, \mathrm{H} 4.3$, N $2.5 \%$.

\section{$\left[\mathrm{Ru}(\mathrm{CH}=\mathrm{CHNap}-2-\mathrm{OMe}-6) \mathrm{Cl}(\mathrm{CO})_{2}\left(\mathrm{PPh}_{3}\right)_{2}\right](\mathbf{C O})$}

Carbon monoxide was bubbled through a dichloromethane solution $(10 \mathrm{~mL})$ of $7(45 \mathrm{mg}, 0.045 \mathrm{mmol})$ until the initial purple solution becomes pale yellow. Addition of ethanol $(20 \mathrm{~mL})$ followed by slow reduction of the solvent volume, resulted in the precipitation of a yellow solid, which was washed with cold ethanol (10 mL) and diethyl ether $(10 \mathrm{~mL})$ and dried. Yield: $38 \mathrm{mg}(94 \%)$. IR ( $\left.v_{\max } / \mathrm{cm}^{-1}\right) 2025$ (CO), 1965 (CO), 1596, 1480, 1433, 1263, 1236, 1160, 1091, 1031, 998. NMR $\delta_{\mathrm{H}}\left(\mathrm{CD}_{2} \mathrm{Cl}_{2}\right) 3.93(3 \mathrm{H}, \mathrm{s}, \mathrm{OMe}), 6.05\left(1 \mathrm{H}, \mathrm{d}, J_{\mathrm{HH}}=18.0 \mathrm{~Hz}, \mathrm{H} \beta\right), 7.08$ $-7.18(4 \mathrm{H}, \mathrm{m}, \mathrm{Nap}), 7.37-7.47\left(18 \mathrm{H}+1 \mathrm{H}, \mathrm{m}, \mathrm{PPh}_{3}+\mathrm{Nap}\right), 7.57\left(1 \mathrm{H}, J_{\mathrm{HH}}=8.5 \mathrm{~Hz}, \mathrm{Nap}\right), 7.63\left(1 \mathrm{H}, J_{\mathrm{HH}}=8.5\right.$ $\mathrm{Hz}$, Nap), $7.68\left(1 \mathrm{H}, \mathrm{dt}, J_{\mathrm{HH}}=18.0 \mathrm{~Hz}, J_{\mathrm{HP}}=3.6 \mathrm{~Hz}, \mathrm{H \alpha}\right), 7.72-7.76\left(12 \mathrm{H}, \mathrm{m}, \mathrm{PPh}_{3}\right) . \delta_{\mathrm{P}}\left(\mathrm{CD}_{2} \mathrm{Cl}_{2}\right) 24.0\left(\mathrm{~s}, \mathrm{PPh}_{3}\right)$. MS (ES +ve): $m / z 921\left(\mathrm{M}^{+}+\mathrm{Na}, 8 \%\right)$. Elemental analysis. Found: $\mathrm{C} 67.9, \mathrm{H}$ 4.7. $\mathrm{C}_{51} \mathrm{H}_{41} \mathrm{ClO}_{3} \mathrm{P}_{2} \mathrm{Ru}$ requires $\mathrm{C}$ $68.0, \mathrm{H} 4.6 \%$. 


\section{$\left[\mathrm{Ru}(\mathrm{CH}=\mathrm{CHPhen}-9) \mathrm{Cl}(\mathrm{CO})(\mathrm{BTD})\left(\mathrm{PPh}_{3}\right)_{2}\right](8)$}

$\left[\mathrm{RuHCl}(\mathrm{CO})\left(\mathrm{PPh}_{3}\right)_{3}\right](500 \mathrm{mg}, 0.525 \mathrm{mmol})$ and 9-ethynylphenanthrene $(120 \mathrm{mg}, 0.593 \mathrm{mmol})$ were dissolved in dichloromethane $(15 \mathrm{~mL})$ and treated with a dichloromethane solution $(5 \mathrm{~mL})$ of 2,1,3-benzothiadiazole (143 $\mathrm{mg}, 1.050 \mathrm{mmol})$. The resulting red solution was stirred for 2 hours at room temperature. Addition of ethanol $(20 \mathrm{~mL})$ followed by slow reduction of the solvent volume resulted in a dark orange crystalline solid, which was washed with cold ethanol $(10 \mathrm{~mL})$ and diethyl ether $(10 \mathrm{~mL})$ and dried. Yield: $455 \mathrm{mg}(84 \%)$. IR $\left(v_{\max } / \mathrm{cm}^{-1}\right)$ $1911(\mathrm{CO}), 1545,1481,1431(\mathrm{C}-\mathrm{N}), 1092,833,740 . \mathrm{NMR} \delta_{\mathrm{H}}\left(\mathrm{CD}_{2} \mathrm{Cl}_{2}\right) 6.71\left(1 \mathrm{H}, \mathrm{d}, J_{\mathrm{HH}}=15.4 \mathrm{~Hz}, \mathrm{H} \beta\right), 7.12$ (1H, s, Phen), $7.21\left(12 \mathrm{H}, \mathrm{m}, \mathrm{PPh}_{3}\right), 7.33\left(6 \mathrm{H}, \mathrm{m}, \mathrm{PPh}_{3}\right), 7.44(1 \mathrm{H}, \mathrm{m}, \mathrm{Phen}), 7.53-7.58(12 \mathrm{H}+5 \mathrm{H}+2 \mathrm{H}, \mathrm{m}$, $\mathrm{PPh}_{3}+$ Phen + BTD), $7.98(2 \mathrm{H}, \mathrm{s}, \mathrm{BTD}), 8.59-8.62(1 \mathrm{H}, \mathrm{m}, \mathrm{Phen}), 8.67\left(1 \mathrm{H}, \mathrm{d}, J_{\mathrm{HH}}=8.1 \mathrm{~Hz}\right.$, Phen $), 8.91(1 \mathrm{H}$, $\left.\mathrm{dt}, J_{\mathrm{HH}}=15.4 \mathrm{~Hz}, J_{\mathrm{HP}}=2.9 \mathrm{~Hz}, \mathrm{H \alpha}\right) . \delta_{\mathrm{P}}\left(\mathrm{CD}_{2} \mathrm{Cl}_{2}\right) 27.0\left(\mathrm{~s}, \mathrm{PPh}_{3}\right) \mathrm{ppm}$. MS (ES +ve): $m / z 939\left(\mathrm{M}^{+}-\mathrm{BTD}+2 \mathrm{Na}\right.$, 42\%). Elemental analysis. Found: $\mathrm{C} 68.8, \mathrm{H} 4.3, \mathrm{~N} 2.7 . \mathrm{C}_{59} \mathrm{H}_{45} \mathrm{ClN}_{2} \mathrm{OP}_{2} \mathrm{RuS}$ requires $\mathrm{C} 68.9, \mathrm{H} 4.4, \mathrm{~N} 2.7 \%$.

\section{$\left[\mathrm{Ru}(\mathrm{CH}=\mathrm{CHPhen}-9) \mathrm{Cl}(\mathrm{CO})_{2}\left(\mathrm{PPh}_{3}\right)_{2}\right](\mathbf{C} \mathrm{CO})$}

Carbon monoxide was bubbled through a dichloromethane solution $(10 \mathrm{~mL})$ of $8(100 \mathrm{mg}, 0.097 \mathrm{mmol})$ until the dark orange solution became yellow. Addition of methanol $(7 \mathrm{~mL})$ followed by slow reduction of the solvent volume resulted in the precipitation of a colourless solid, which was washed with cold methanol $(10 \mathrm{~mL})$ and diethyl ether $(10 \mathrm{~mL})$ and dried. Yield: $87 \mathrm{mg}(98 \%)$. IR $\left(v_{\max } / \mathrm{cm}^{-1}\right) 2038$ (CO), $1972(\mathrm{CO}), 1547,1483,1435$ $(\mathrm{C}-\mathrm{N}), 1190,1170,1090,1000,801 . \mathrm{NMR} \delta_{\mathrm{H}}\left(\mathrm{CD}_{2} \mathrm{Cl}_{2}\right) 6.84\left(1 \mathrm{H}, \mathrm{dt}, 1 \mathrm{H}, J_{\mathrm{HH}}=17.5 \mathrm{~Hz}, J_{\mathrm{HP}}=2.1 \mathrm{~Hz}, \mathrm{H} \beta\right), 7.01$ (1H, s, Phen), $7.38-7.50\left(18 \mathrm{H}+1 \mathrm{H}, \mathrm{m}, \mathrm{PPh}_{3}+\mathrm{Phen}\right), 7.57-7.73(5 \mathrm{H}, \mathrm{m}, \mathrm{Phen}), 7.80-7.84\left(12 \mathrm{H}, \mathrm{m}, \mathrm{PPh}_{3}\right)$, $7.96\left(1 \mathrm{H}, \mathrm{dt}, J_{\mathrm{HH}}=17.5 \mathrm{~Hz}, J_{\mathrm{HP}}=3.6 \mathrm{~Hz}, \mathrm{H \alpha}\right), 8.63-8.65(1 \mathrm{H}, \mathrm{m}, \mathrm{Phen}), 8.71\left(1 \mathrm{H}, \mathrm{d}, J_{\mathrm{HH}}=8.1 \mathrm{~Hz}, \mathrm{Phen}\right) . \delta_{\mathrm{P}}$ $\left(\mathrm{CD}_{2} \mathrm{Cl}_{2}\right) 23.1\left(\mathrm{~s}, \mathrm{PPh}_{3}\right)$. MS (ES +ve): $m / z 942\left(\mathrm{M}^{+}+\mathrm{Na}, 6 \%\right), 926\left(\mathrm{M}^{+}-\mathrm{Cl}+\mathrm{Na}, 100 \%\right)$. Elemental analysis. Found: $\mathrm{C}$ 66.2, $\mathrm{H}$ 4.6. $\mathrm{C}_{54} \mathrm{H}_{41} \mathrm{ClO}_{2} \mathrm{P}_{2} \mathrm{Ru} \cdot \mathrm{CH}_{2} \mathrm{Cl}_{2}$ requires $\mathrm{C} 65.7, \mathrm{H} 4.3 \%$.

\section{Silica gel immobilisation of the vinyl compounds 1-8}

Each vinyl complex $(0.007-0.022 \mathrm{mmol})$ was dissolved in a minimum volume of $\mathrm{CHCl}_{3}$. An excess $(5 \mathrm{mmol})$ of silica (particle size $40-63 \mu \mathrm{m}$ ) was added to the coloured solution and the resulting mixture was stirred at room temperature for five minutes. After removal of the solvent on a rotary evaporator, the solid was left to stand for one hour at room temperature prior to its use (see Figure S4).

\section{Crystallography}

The dichloromethane solvent molecule included in the structure of $\mathbf{5} \cdot \mathbf{C O}$ was found to be disordered. Two orientations were identified of approximately 86 and 14\% occupancy. The geometries of these orientations were optimized, the thermal parameters of adjacent atoms were restrained to be similar, and only the non-hydrogen atoms of the major occupancy orientation were refined anisotropically (those of the minor occupancy orientation were refined isotropically). 
Crystal data for 4: $\mathrm{C}_{52} \mathrm{H}_{43} \mathrm{ClN}_{2} \mathrm{OOsP}_{2} \mathrm{~S} \cdot \mathrm{CH}_{2} \mathrm{Cl}_{2}, M=1116.46$, triclinic, $P-1$ (no. 2), $a=11.8215(3), b=$ 13.0465(4), $c=15.3904(4) \AA, \alpha=92.606(2), \beta=99.286(2), \gamma=91.790(2)^{\circ}, V=2338.33(11) \AA^{3}, Z=2, D_{\mathrm{c}}=$ $1.586 \mathrm{~g} \mathrm{~cm}^{-3}, \mu(\mathrm{Mo}-\mathrm{K} \alpha)=3.053 \mathrm{~mm}^{-1}, T=173 \mathrm{~K}$, red blocky needles, Oxford Diffraction Xcalibur 3 diffractometer; 10837 independent measured reflections $\left(R_{\text {int }}=0.0201\right), F^{2}$ refinement, ${ }^{\mathrm{S} 6} R_{1}(\mathrm{obs})=0.0232$, $w R_{2}($ all $)=0.0501,9915$ independent observed absorption-corrected reflections $\left[\left|F_{\mathrm{o}}\right|>4 \sigma\left(\left|F_{\mathrm{o}}\right|\right), 2 \theta_{\max }=59^{\circ}\right], 570$ parameters. CCDC 1011581.

Crystal data for 6: $\mathrm{C}_{55} \mathrm{H}_{43} \mathrm{ClN}_{2} \mathrm{OP}_{2} \mathrm{RuS} \cdot \mathrm{CHCl}_{3}, M=1097.80$, monoclinic, $P 2_{1} / n$ (no. 14), $a=16.1844(4), b$ $=15.5180(4), c=19.9196(5) \AA, \beta=96.285(3)^{\circ}, V=4972.8(2) \AA^{3}, Z=4, D_{\mathrm{c}}=1.466 \mathrm{~g} \mathrm{~cm}^{-3}, \mu(\mathrm{Mo}-\mathrm{K} \alpha)=0.679$ $\mathrm{mm}^{-1}, T=173 \mathrm{~K}$, red blocks, Agilent Xcalibur 3E diffractometer; 9846 independent measured reflections $\left(R_{\mathrm{int}}=\right.$ $0.0287), F^{2}$ refinement, ${ }^{\mathrm{S} 6} R_{1}$ (obs) $=0.0452, w R_{2}$ (all) $=0.1199,7621$ independent observed absorption-corrected reflections $\left[\left|F_{\mathrm{o}}\right|>4 \sigma\left(\left|F_{\mathrm{o}}\right|\right), 2 \theta_{\max }=56^{\circ}\right], 604$ parameters. CCDC 1048863.

Crystal data for 5. CO: $\mathrm{C}_{46} \mathrm{H}_{37} \mathrm{ClO}_{2} \mathrm{P}_{2} \mathrm{Ru} \cdot \mathrm{CH}_{2} \mathrm{Cl}_{2}, M=905.14$, monoclinic, $P 2_{1} / n$ (no. 14), $a=$ $10.13508(17), b=18.4651(3), c=22.6080(5) \AA, \beta=97.2599(18)^{\circ}, V=4197.06(14) \AA^{3}, Z=4, D_{\mathrm{c}}=1.432 \mathrm{~g} \mathrm{~cm}$ ${ }^{3}, \mu(\mathrm{Cu}-\mathrm{K} \alpha)=5.798 \mathrm{~mm}^{-1}, T=173 \mathrm{~K}$, colourless needles, Oxford Diffraction Xcalibur PX Ultra diffractometer; 8157 independent measured reflections $\left(R_{\text {int }}=0.0479\right), F^{2}$ refinement, ${ }^{\mathrm{S} 6} R_{1}(\mathrm{obs})=0.0625, w R_{2}($ all $)=0.1657$, 7081 independent observed absorption-corrected reflections $\left[\left|F_{\mathrm{o}}\right|>4 \sigma\left(\left|F_{\mathrm{o}}\right|\right), 2 \theta_{\max }=145^{\circ}\right], 509$ parameters. CCDC 1011582.

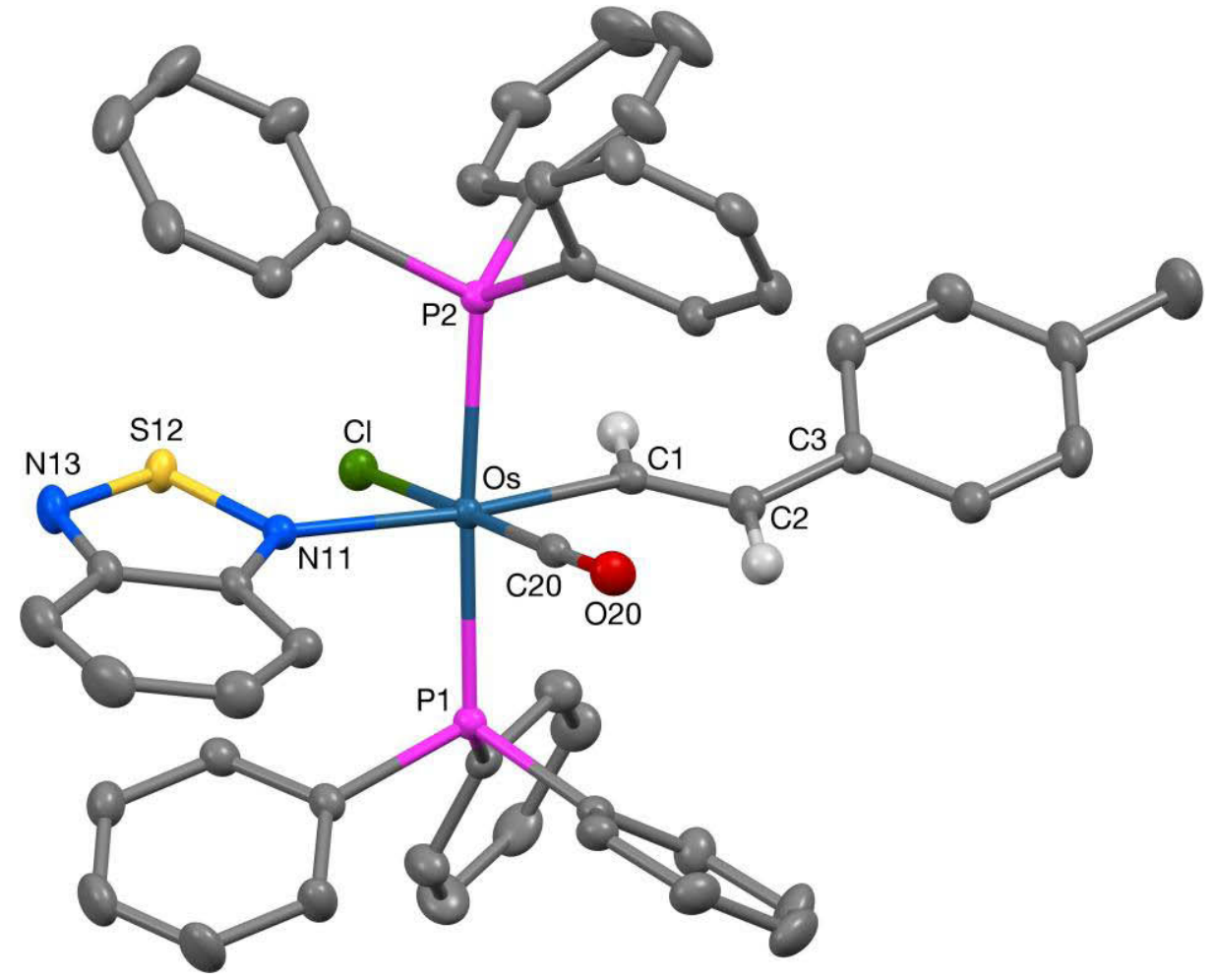

Figure S1. Crystal structure of $\left[\mathrm{Os}\left(\mathrm{CH}=\mathrm{CHC}_{6} \mathrm{H}_{4} \mathrm{Me}-4\right) \mathrm{Cl}(\mathrm{CO})(\mathrm{BTD})\left(\mathrm{PPh}_{3}\right)_{2}\right](4)$ with $50 \%$ probability ellipsoids. 


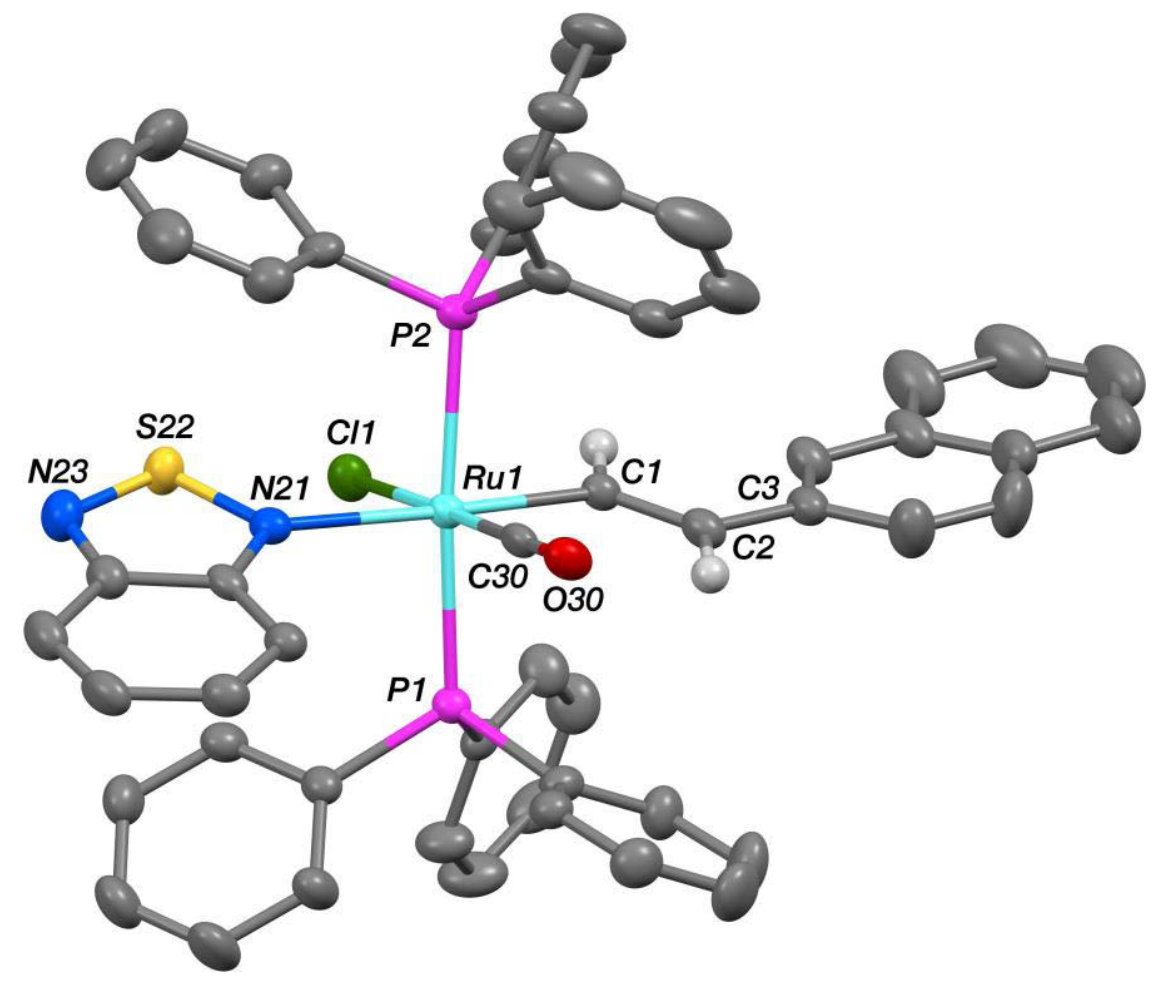

Figure S2. Crystal structure of $\left[\mathrm{Ru}(\mathrm{CH}=\mathrm{CHNap}-2) \mathrm{Cl}(\mathrm{CO})(\mathrm{BTD})\left(\mathrm{PPh}_{3}\right)_{2}\right](\mathbf{6})$ with $50 \%$ probability ellipsoids.

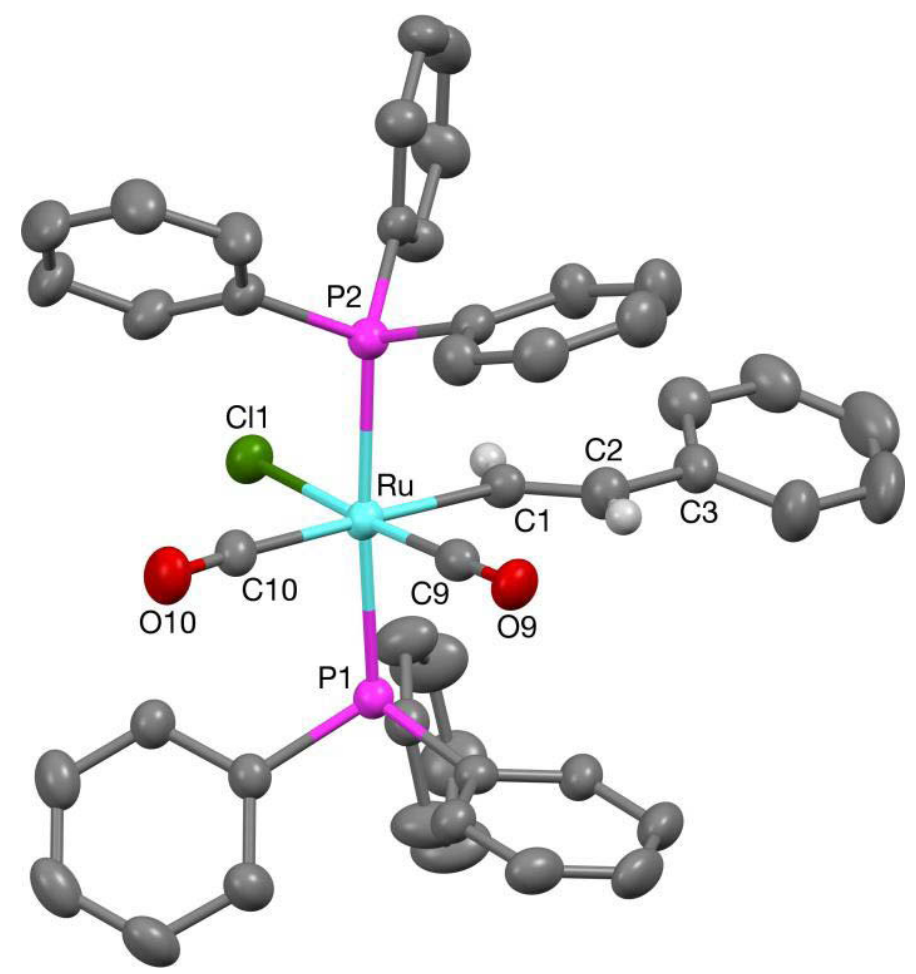

Figure S3. Crystal structure of $\left[\mathrm{Ru}\left(\mathrm{CH}=\mathrm{CHC}_{6} \mathrm{H}_{5}\right) \mathrm{Cl}(\mathrm{CO})_{2}\left(\mathrm{PPh}_{3}\right)_{2}\right](\mathbf{5} \cdot \mathbf{C O})$ with $50 \%$ probability ellipsoids. 


\section{Carbon monoxide sensing studies}

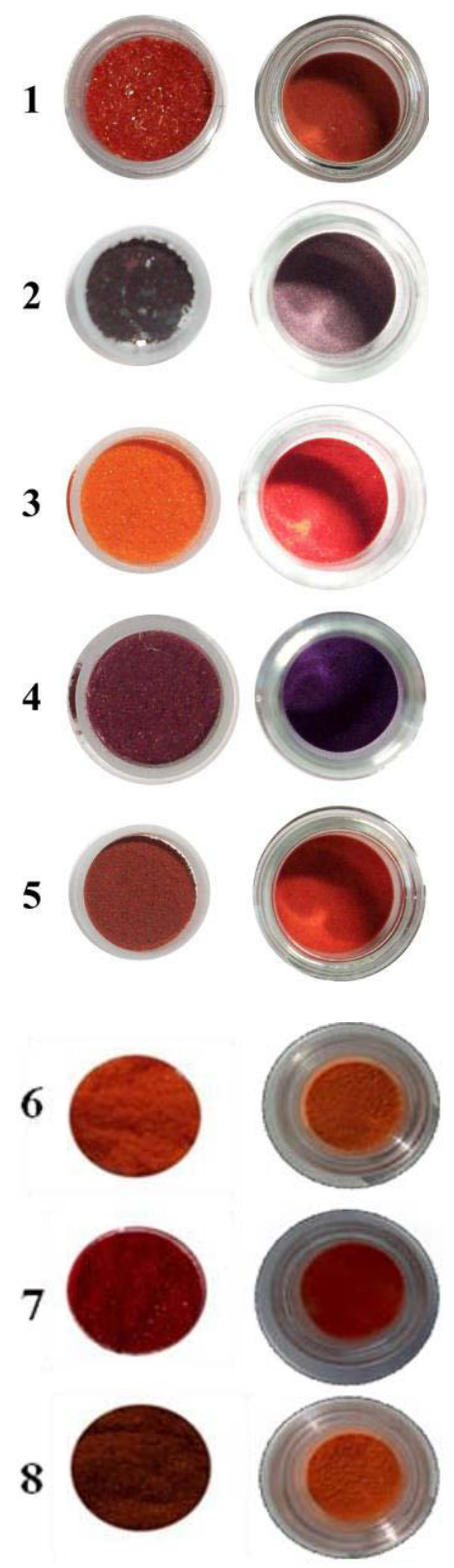

Figure S4. Left: the colour of ruthenium and osmium complexes 1-8; right: the colour of 1-8 on silica. 

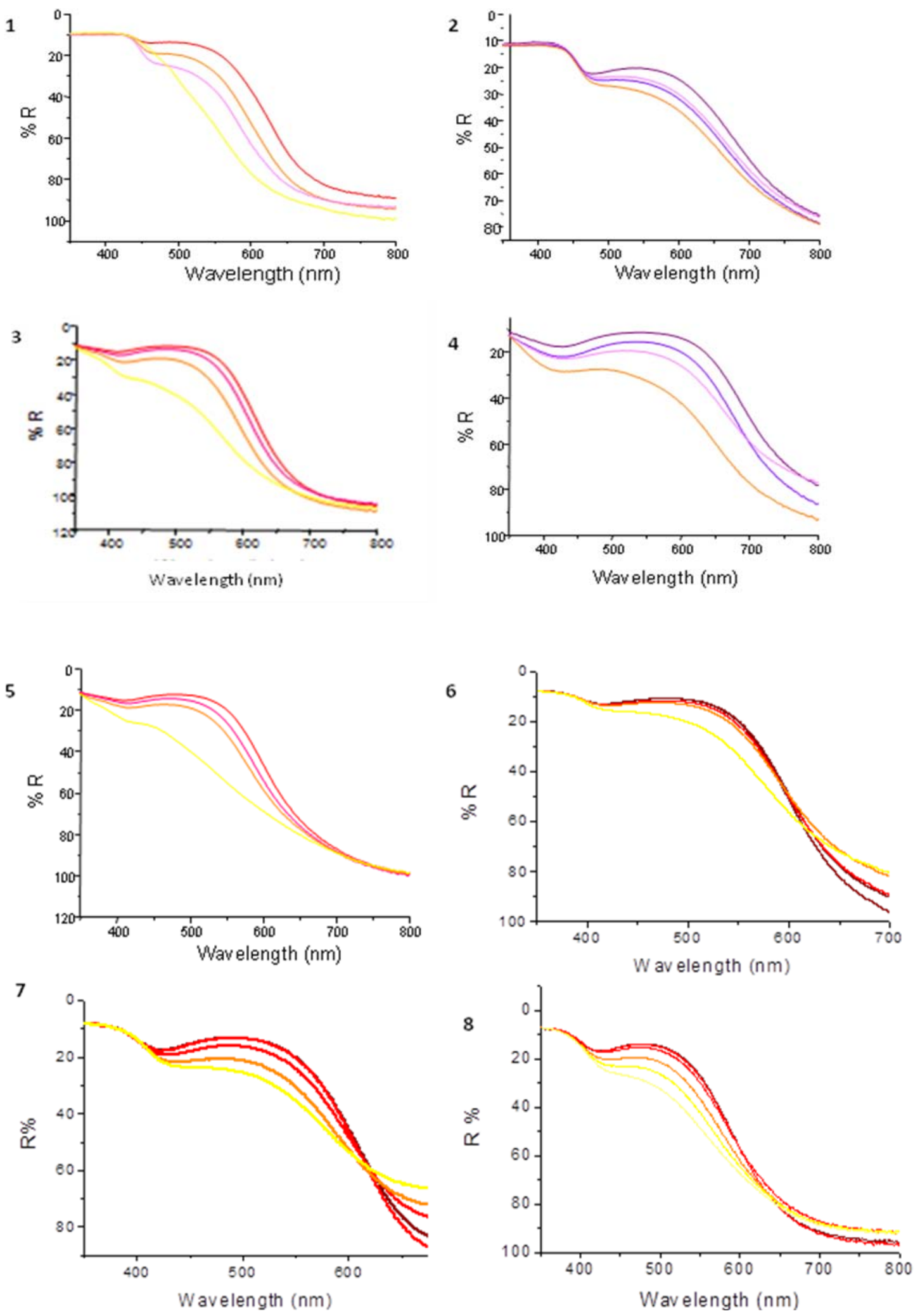

Figure S5. Spectroscopic changes of complexes 1-8 on silica upon exposure to increasing concentrations of CO (0.0001 to $250 \mathrm{ppm})$. 


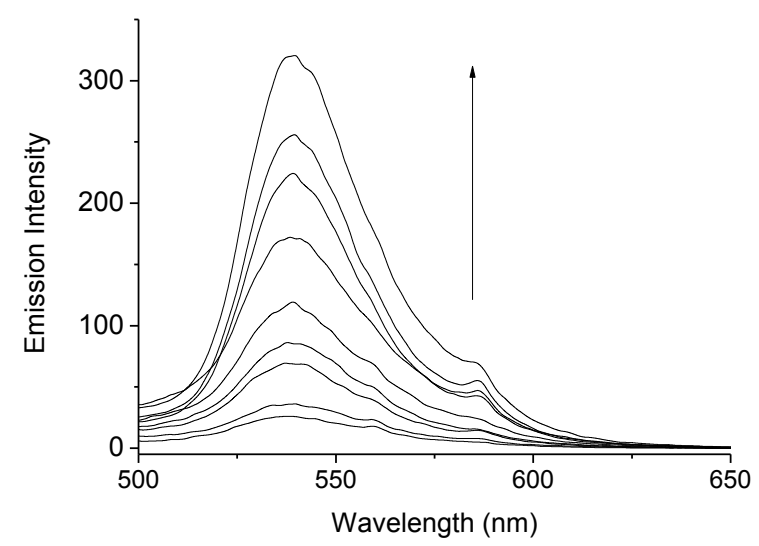

Figure S6. Emission response of complex 8 in chloroform solution upon exposure to increasing concentrations of $\mathrm{CO}\left(1.0 \times 10^{-7}\right.$ to $\left.500 \mathrm{ppm}\right)$.

\section{DFT Studies}

Table S1. Calculated bond lengths in $\AA$ for complexes $\mathbf{1}, \mathbf{1} \cdot \mathbf{C O}, \mathbf{5}$ and $\mathbf{5} \cdot \mathbf{C O}$.

\begin{tabular}{llllllll}
\hline Model & $\begin{array}{l}\text { Ru-N or } \\
\text { Ru-CO(added Co) }\end{array}$ & Ru-P(3) & Ru-P(4) & Ru-Cl & Ru-CO & Ru-C $_{\mathbf{1}}$ & C $_{\mathbf{1}}-\mathbf{C}_{\mathbf{2}}$ \\
\hline $\mathbf{1}$ & 2.28483 & 2.45321 & 2.43757 & 2.54494 & 1.82511 & 2.05145 & 1.34432 \\
$\mathbf{5}$ & 2.28418 & 2.44656 & 2.43375 & 2.54531 & 1.82544 & 2.05911 & 1.34255 \\
$\mathbf{6}$ & 2.28459 & 2.44885 & 2.43105 & 2.54620 & 1.82519 & 2.05455 & 1.34265 \\
$\mathbf{1 \cdot C O}$ & 1.96983 & 2.46679 & 2.44448 & 2.53908 & 1.85638 & 2.11228 & 1.34186 \\
$\mathbf{5 \cdot C O}$ & 1.96822 & 2.46190 & 2.44099 & 2.54352 & 1.85638 & 2.11463 & 1.33957 \\
$\mathbf{6 . C O}$ & 1.96849 & 2.46320 & 2.44023 & 2.54344 & 1.85637 & 2.11296 & 1.33987 \\
\hline
\end{tabular}

Table S2. Molecular orbitals for Compound 1

Wavelength (nm)

624.16

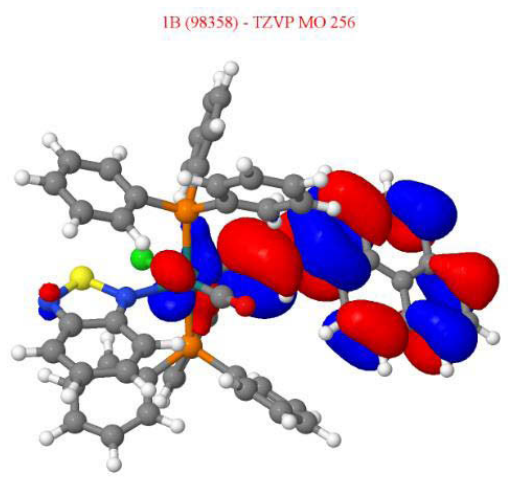

256
MO

Transition

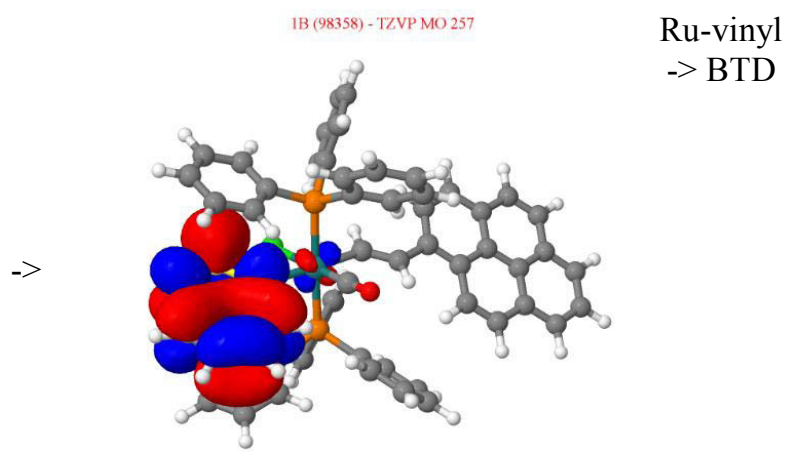

257 
420.79

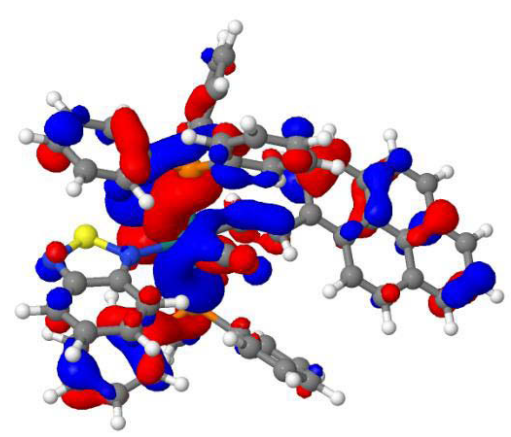

254

414.86

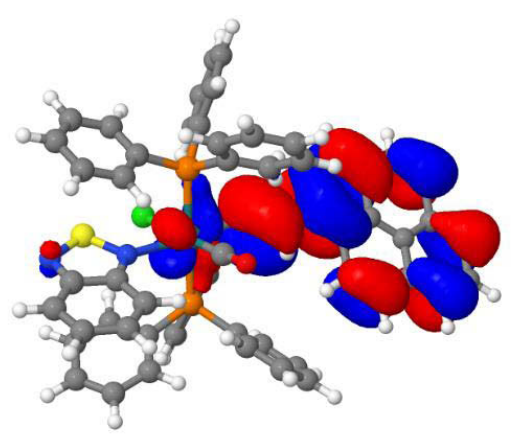

256

320.65

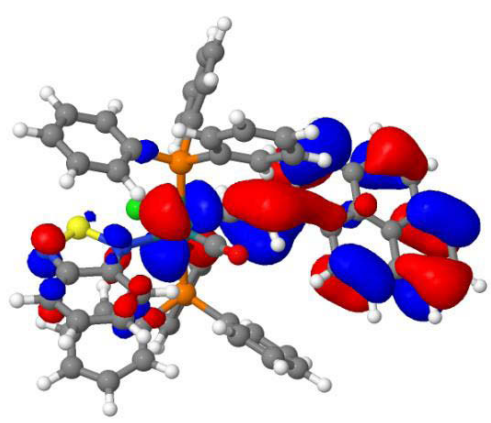

255

302.90

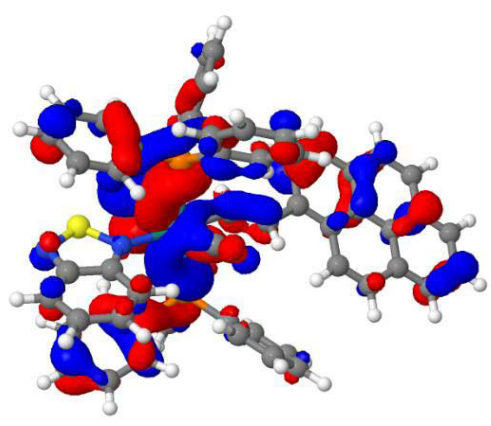

254

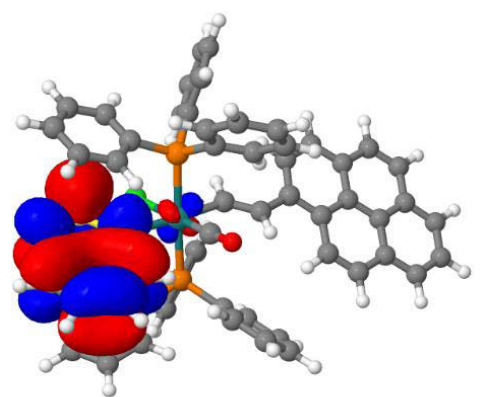

257

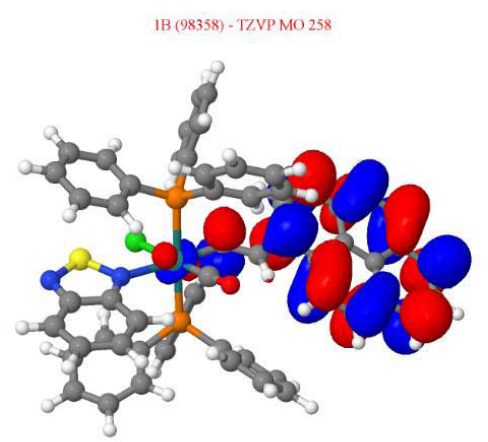

258

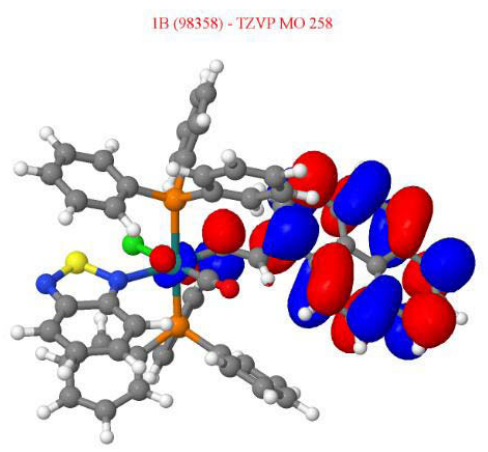

258

IB (98358) - TZVP MO 258

$\mathrm{Ru}-$

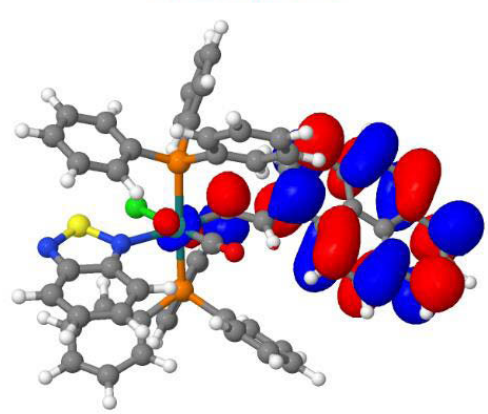

phosphine

-> Ru-

vinyl 


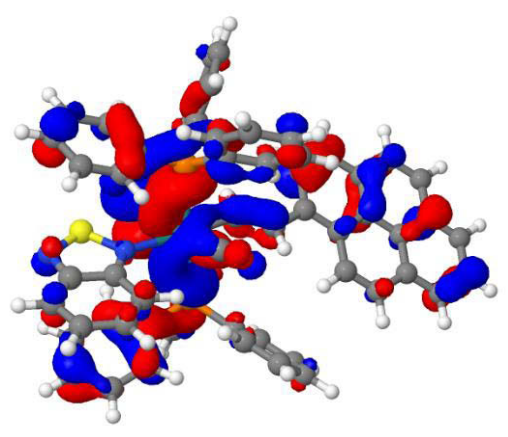

254

272.83

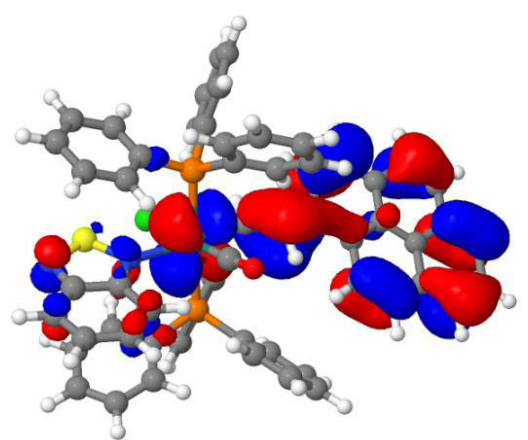

255

250.11

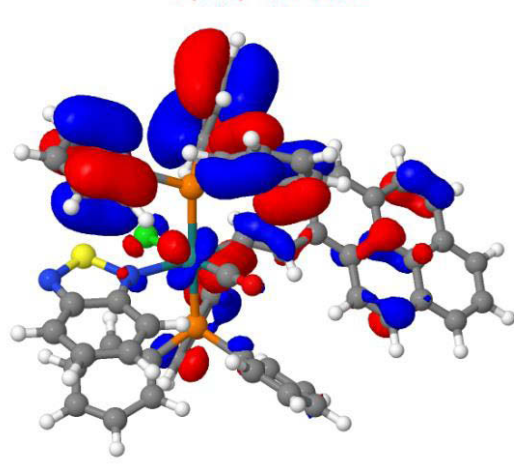

245

Table S3. Molecular orbitals for Compound 5

Wavelength (nm)

575.57

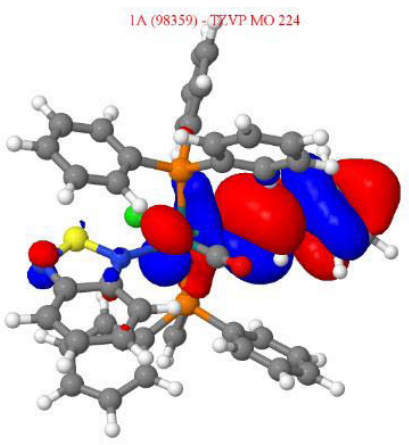

224

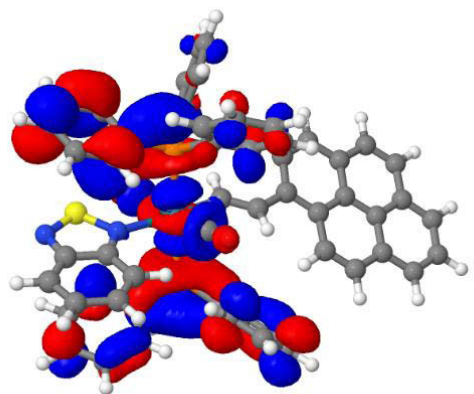

259

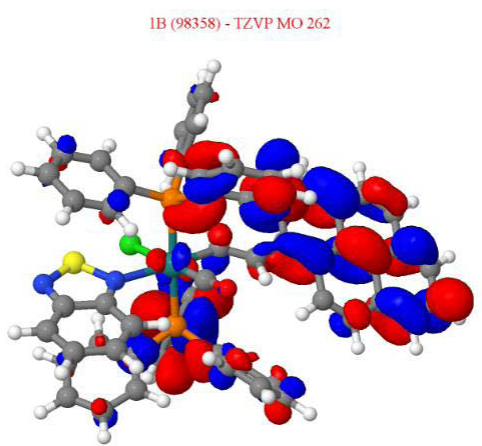

262

Ru-vinyl $->$ vinyl $\pi^{*}$

Ru-vinyl

-> Ru-

phosphine

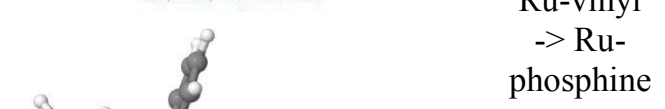

MO

Transition

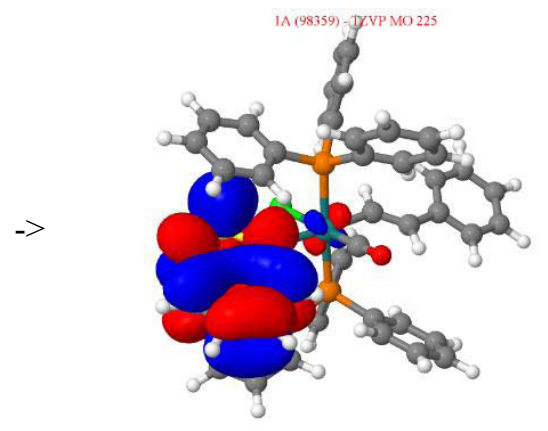

Ru-vinyl

-> BTD 


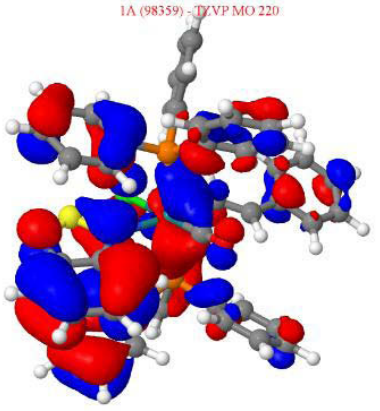

220

329.74

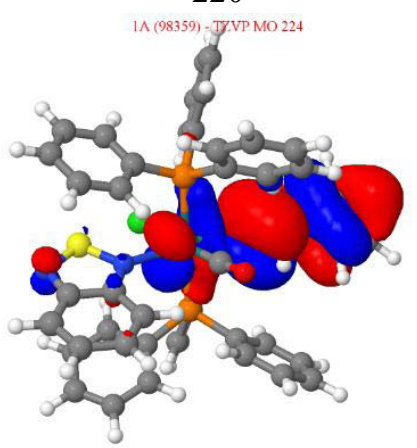

307.82

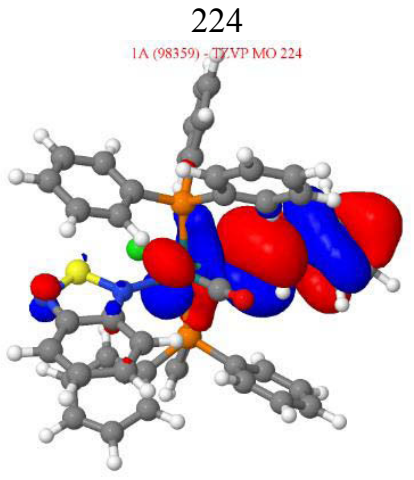

299.95

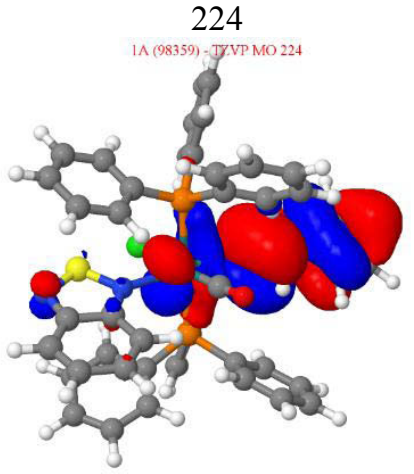

285.99

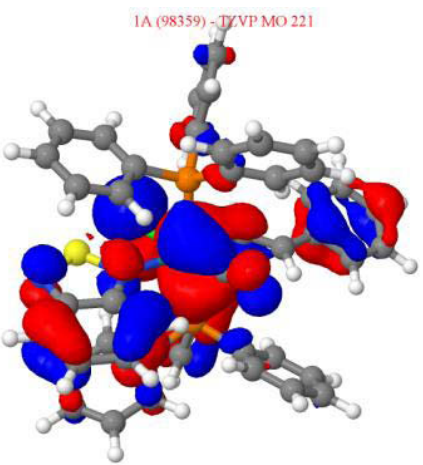

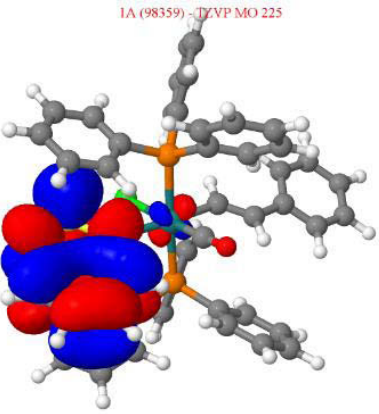

BTD $\pi$

$->\pi^{*}$

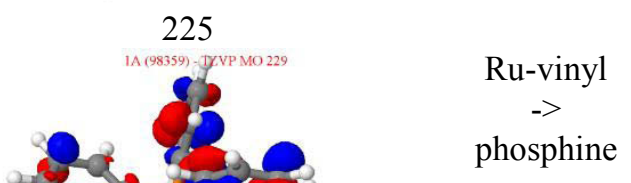

229

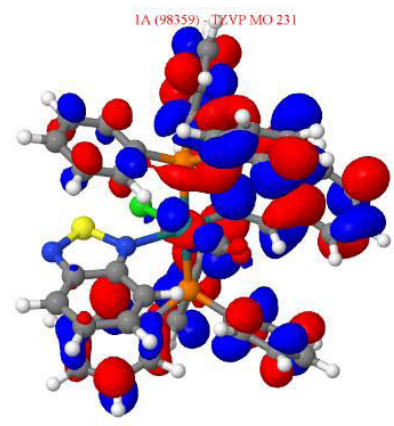

Ru-vinyl phosphine

231

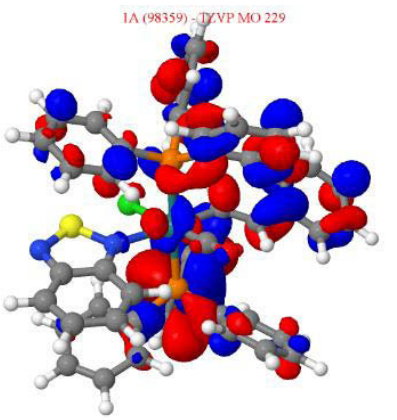

Ru-vinyl phosphine

229

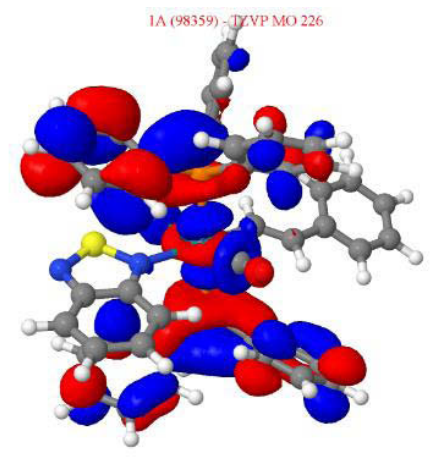

Ru-BTD

phosphine 
259.66

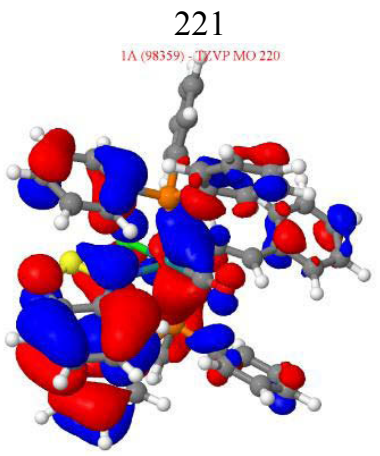

220

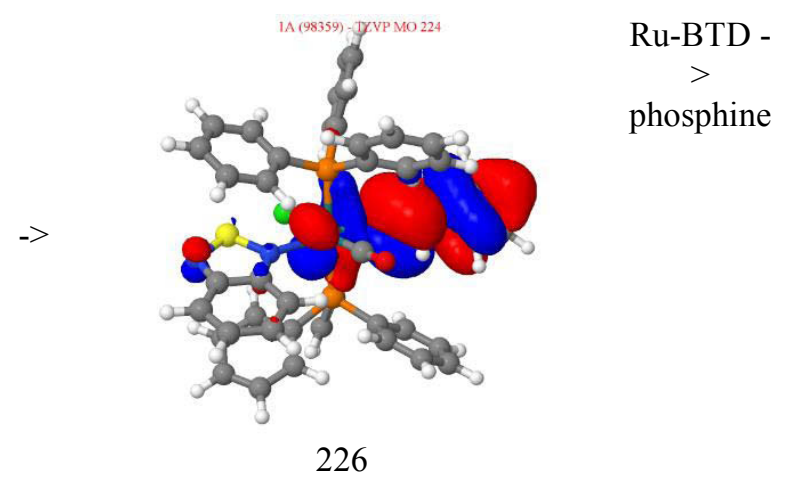

Table S4: Molecular orbitals for Compound 6

Wavelength (nm)

584.72

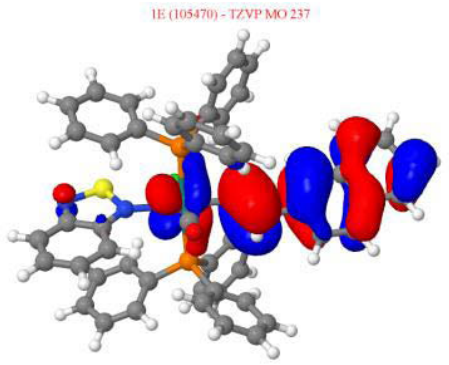

237

417.69

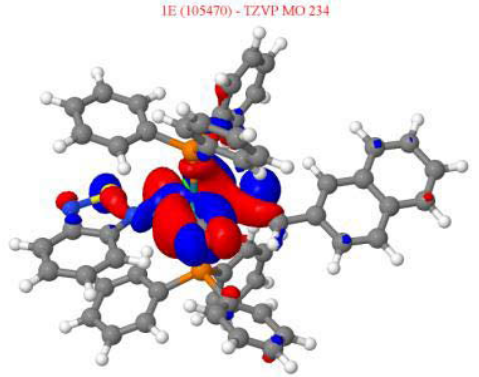

234

359.20

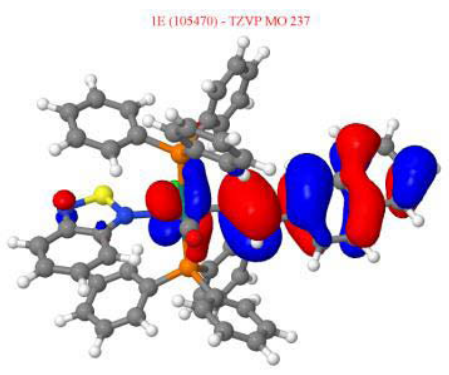

237
MO

Transition

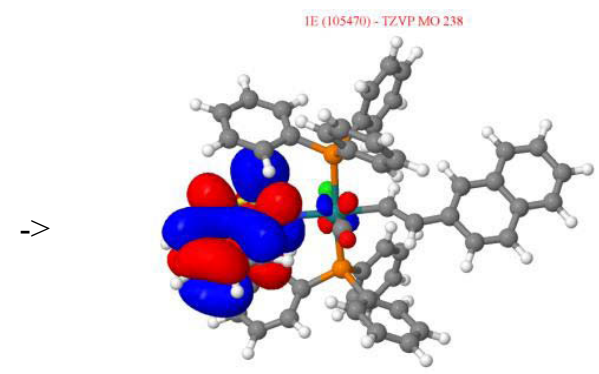

Ru-vinyl -

$>$ BTD

$\mathrm{Ru}->$

BTD

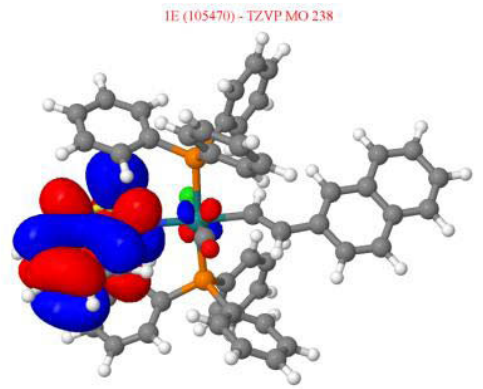

238

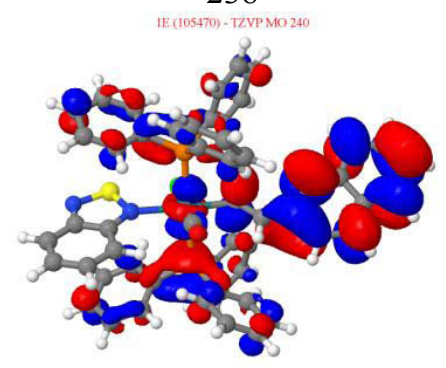

240
Ru-vinyl $\pi$ $->$ Vinyl $\pi^{*}$ 


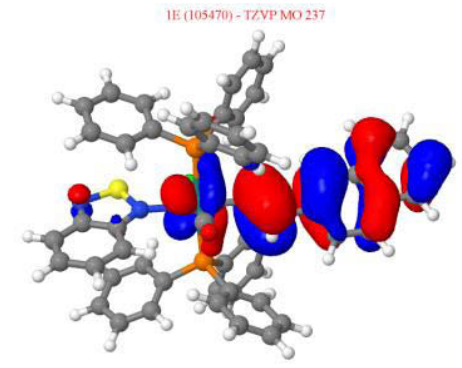

237

286.45

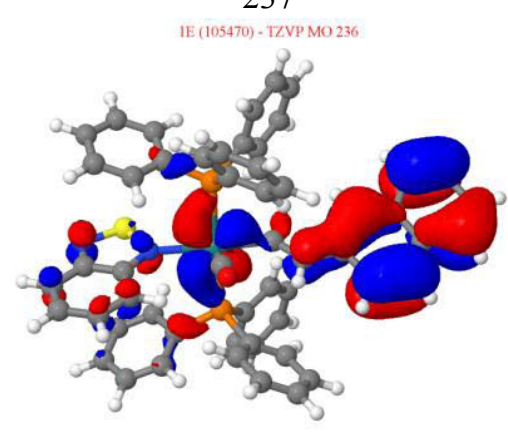

236

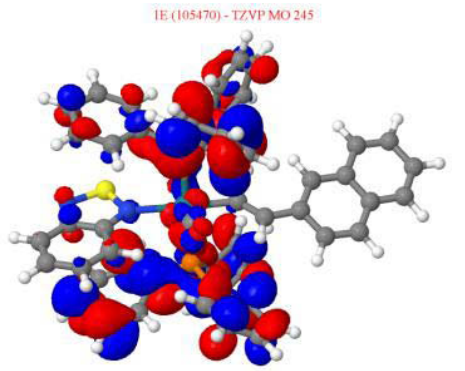

Ru-vinyl -

$>$ Metal P

(LMTC)

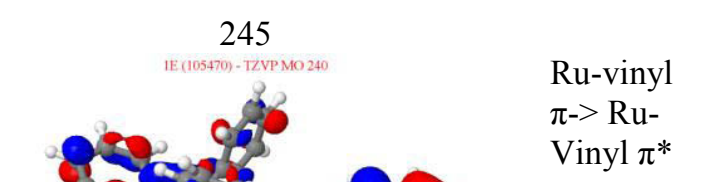

240

Table S5. Molecular orbitals for Compound 1.CO

Wavelength (nm)

409.53

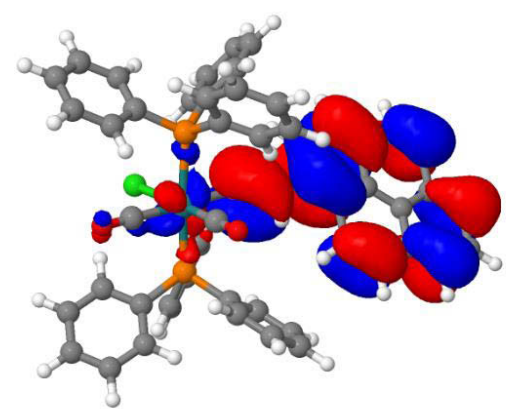

228

398.18

2B (92190) - TZVP MO 228

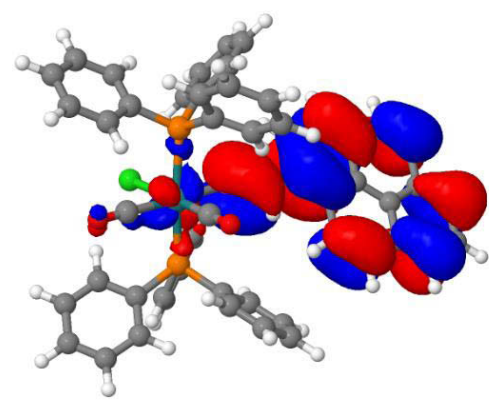

MO

Transition

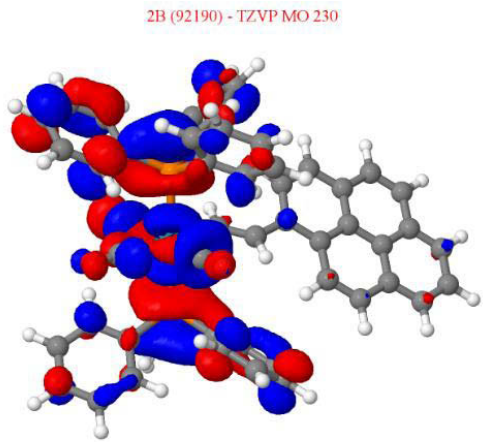

Ligand

metal P

(LMCT)

230

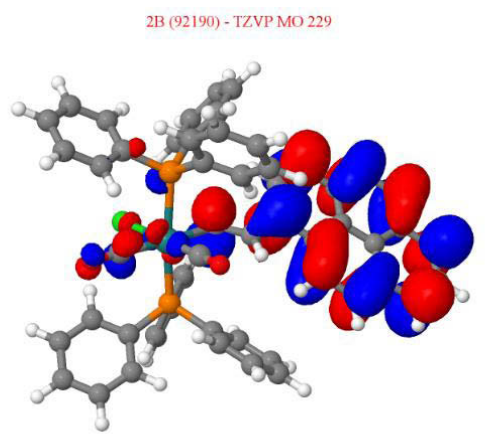

Ligand $\pi$

$->\pi^{*}$ 
323.76

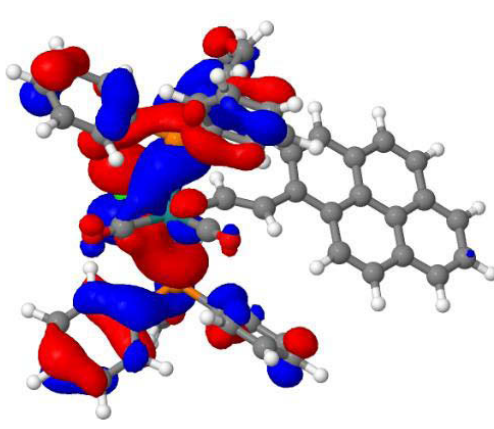

226

301.57

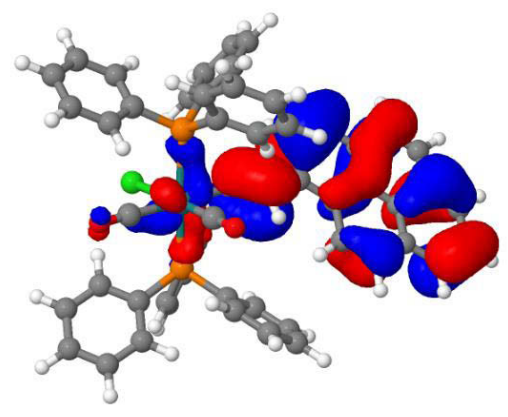

227

291.64

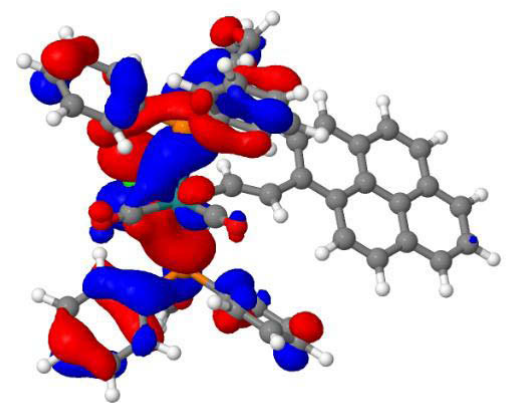

226
2B (92190) - TZVP MO 230

Metal P

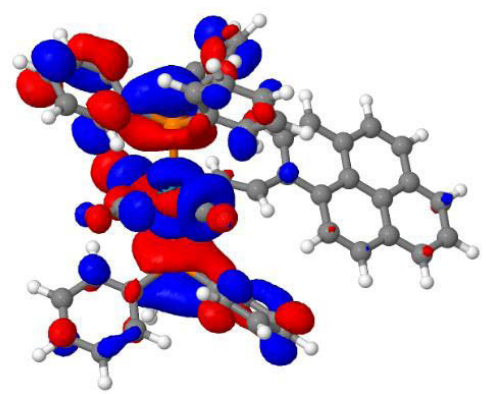

230

$->$

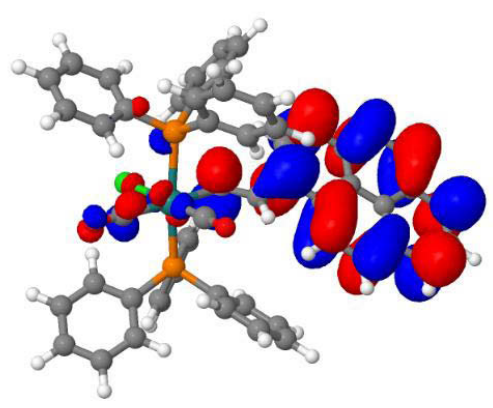

229

2B (92190) - TZVP MO 229

Ligand

$->$

Metal P

(LMCT)

$\underset{->\pi^{*}}{\operatorname{Ligand}} \pi$

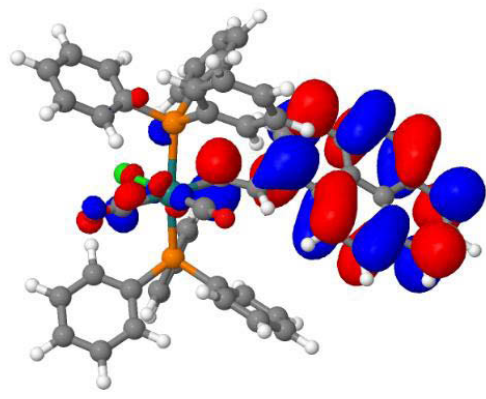

229 
Table S6. Molecular orbitals for Compound 5.CO

Wavelength (nm)

322.38

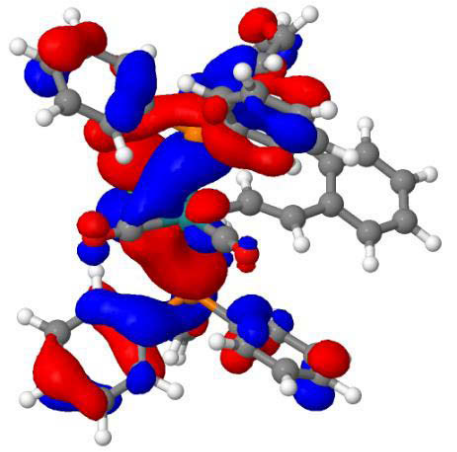

195

313.9

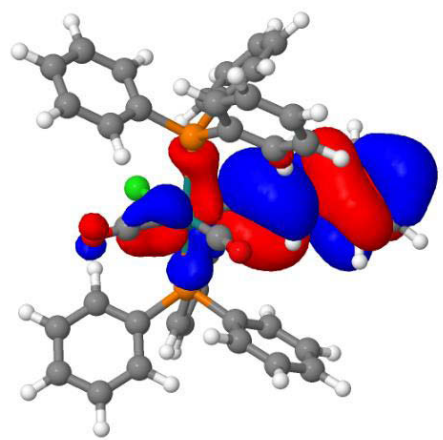

196

310.6

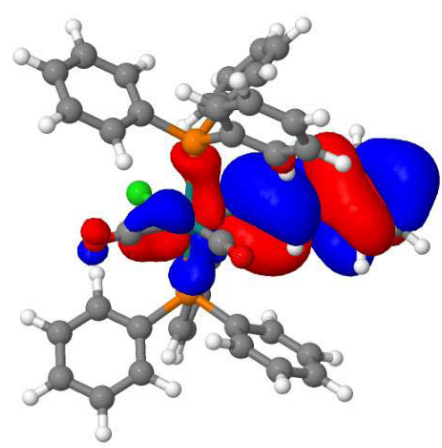

196

291.34
MO

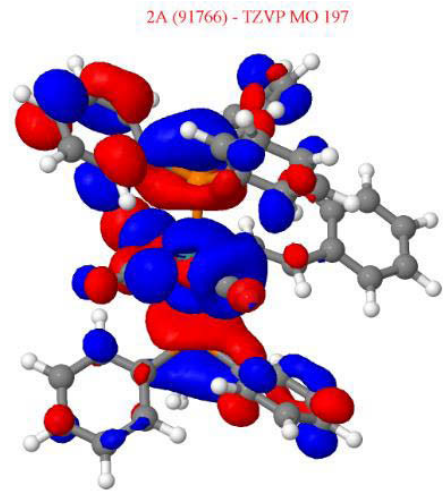

197

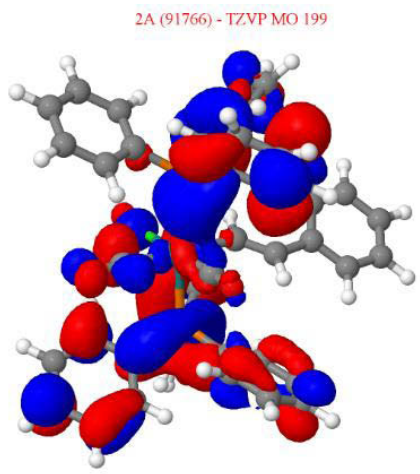

199

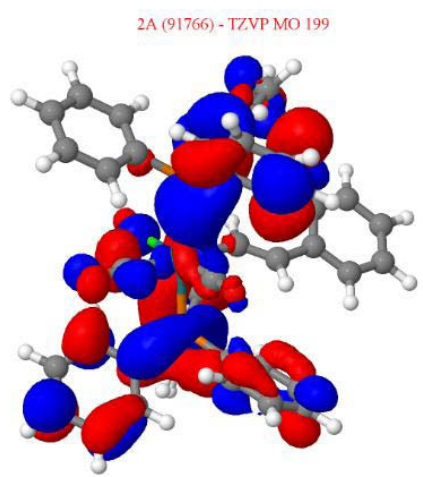

199

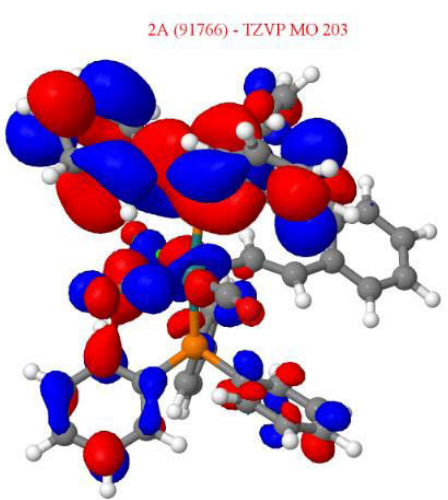

Transition

Metal P

Metal P

Metal

ligand ->

Metal P

Metal

ligand

$->$

Metal P

Metal

ligand<smiles>[LiH]</smiles>

Metal P 
278.46

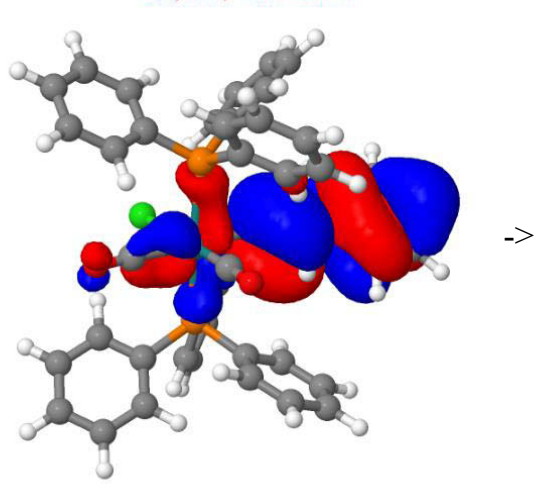

196

267.77

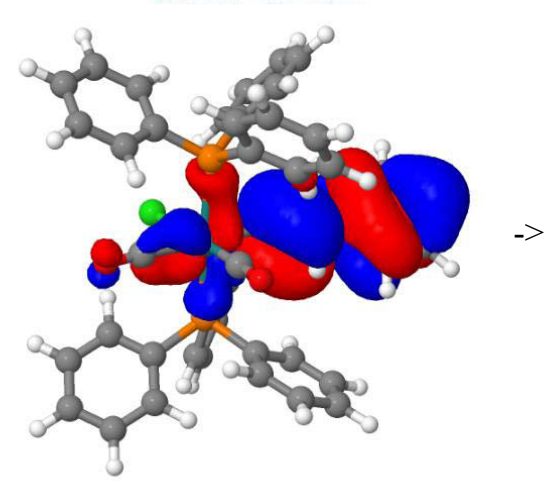

196

252.22

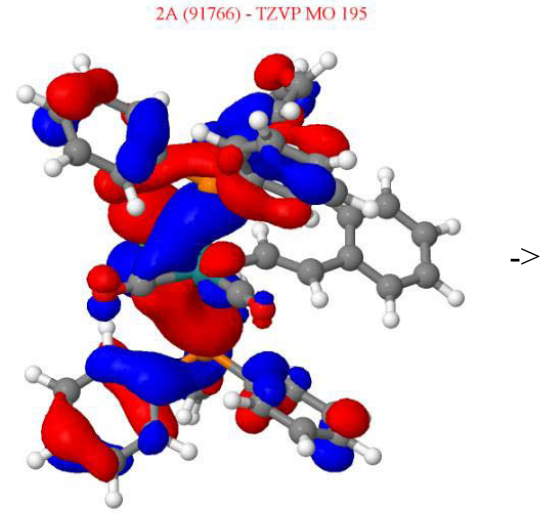

195

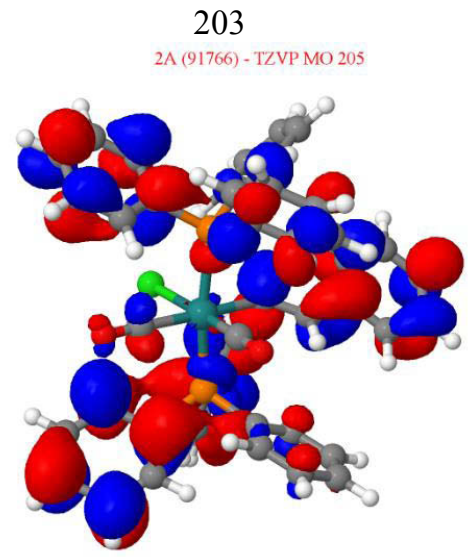

Metal ligand Metal P

205

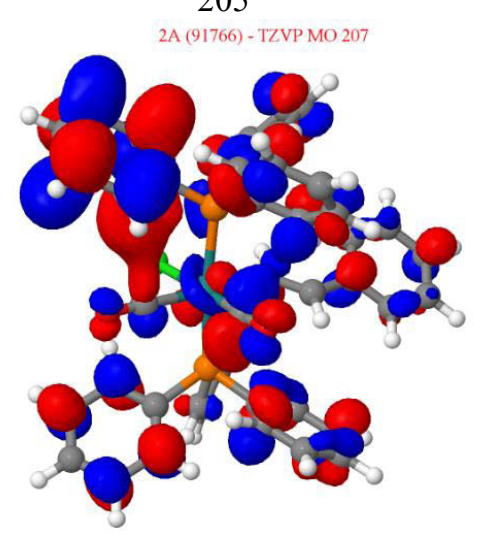

Metal

ligand Metal P

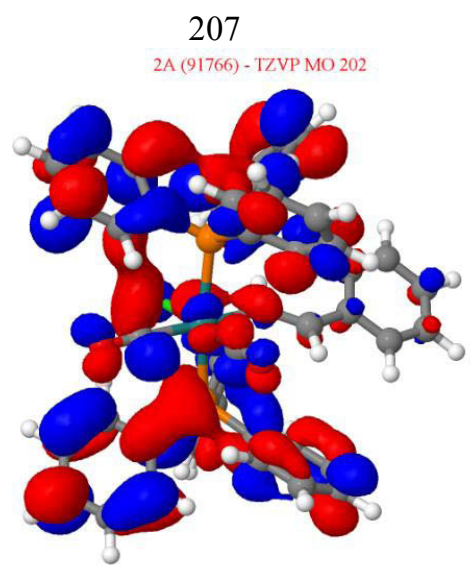

Metal ligand Metal P 
Table S7: Molecular orbitals for Compound 6.CO

Wavelength (nm)

337.85

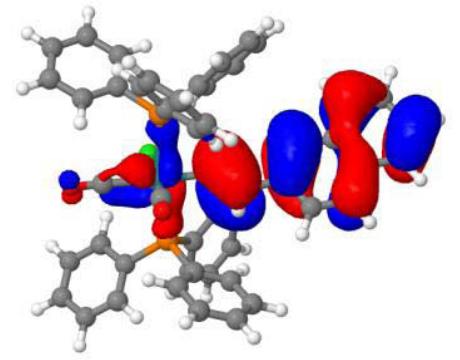

209

323.15

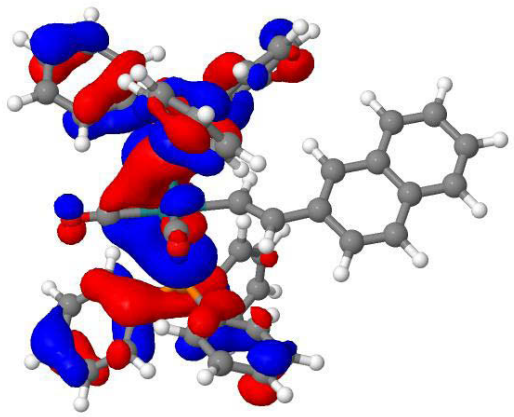

207

291.82

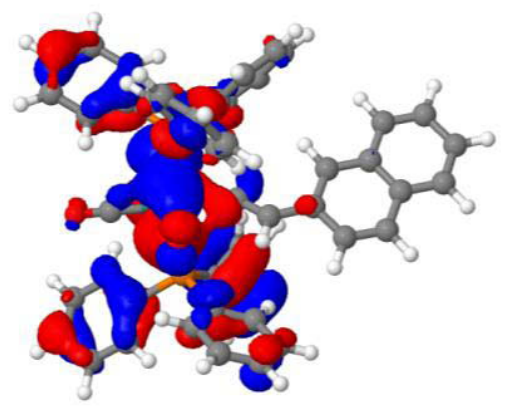

205

277.03

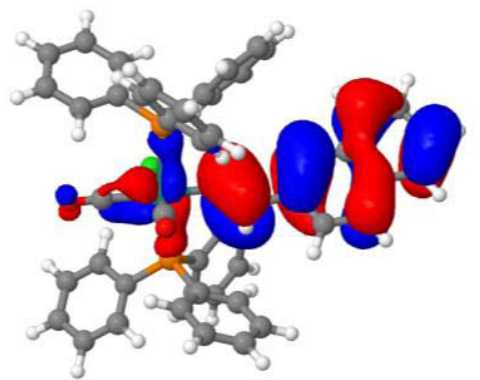

209
MO

Transition

Ligand $\pi$ -

$>\pi^{*}$

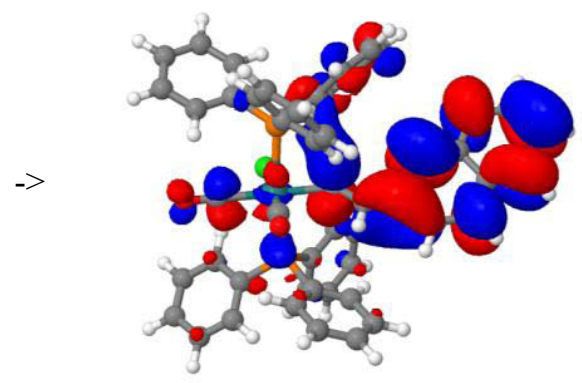

211

2E (104805) - TZVP MO 210

Metal P

(LMTC) -

$>$ Metal P

(LMTC)

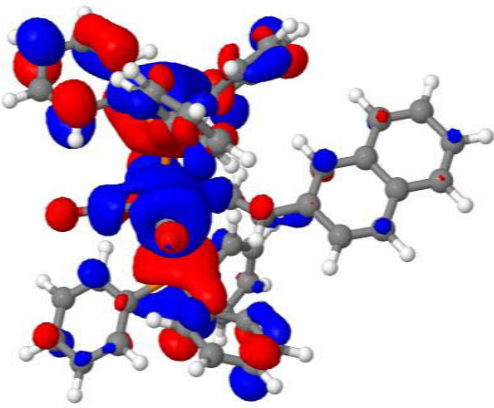

210

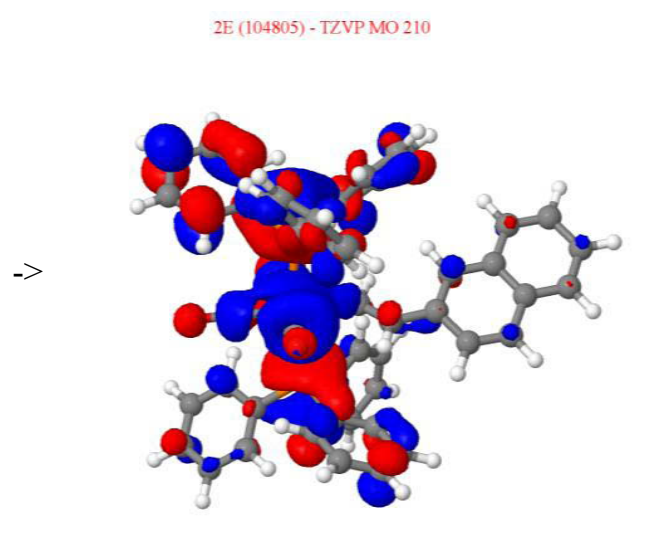

210

2E (104805) - TZVP MO 219

Ligand $\pi$ -

$>$ Metal P

(LMTC)

Metal P

(LMTC) -

$>$ Metal P

(LMTC)

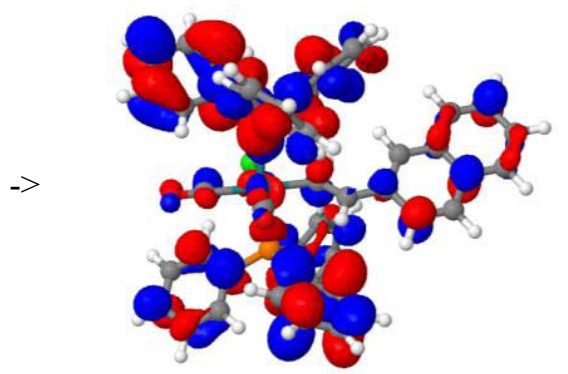

219 
274.37

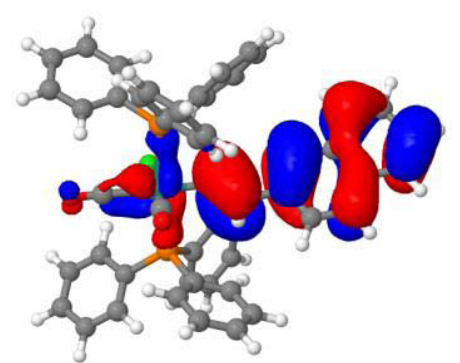

209

270.63

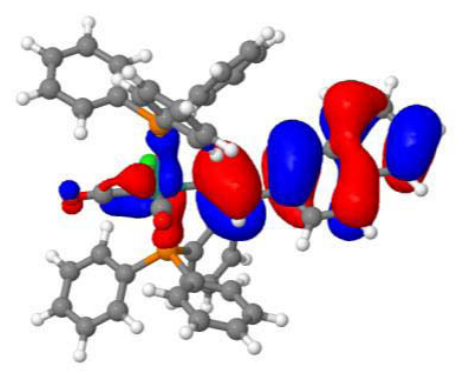

209

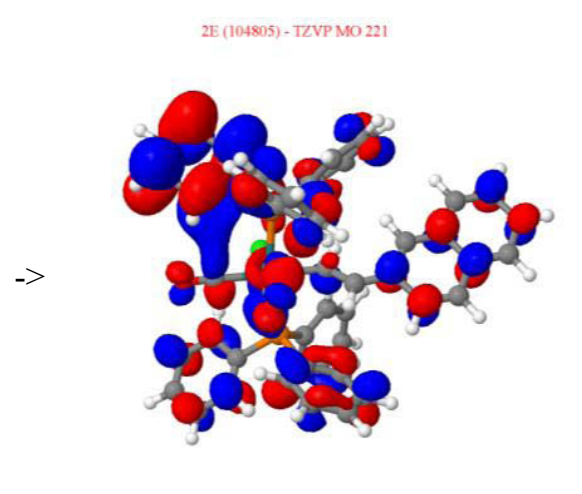

Ligand $\pi$ -

$>$ Metal P

(LMTC)

221

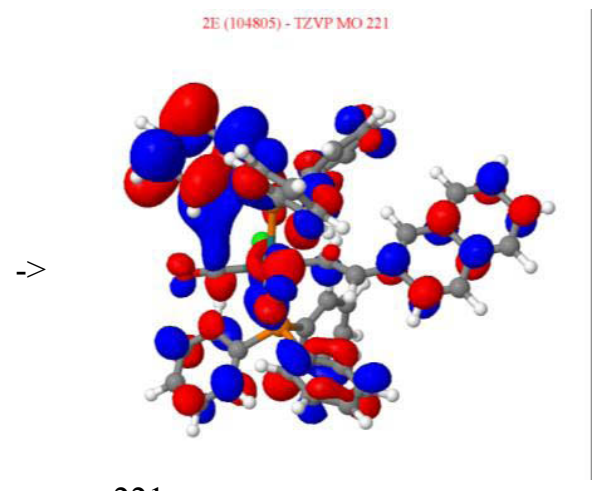

Ligand $\pi$ -

$>$ Metal P

(LMTC) 


\section{Calculated UV-Vis Spectra}

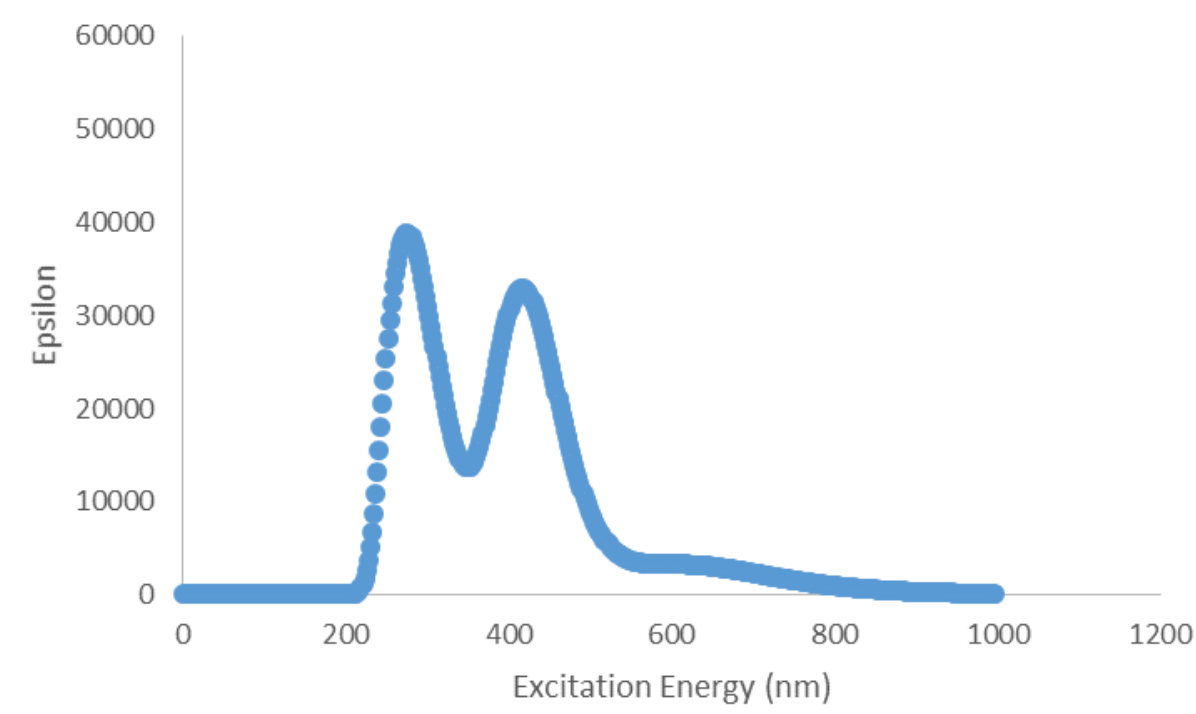

Figure S7. Calculated UV-Vis spectrum for compound 1

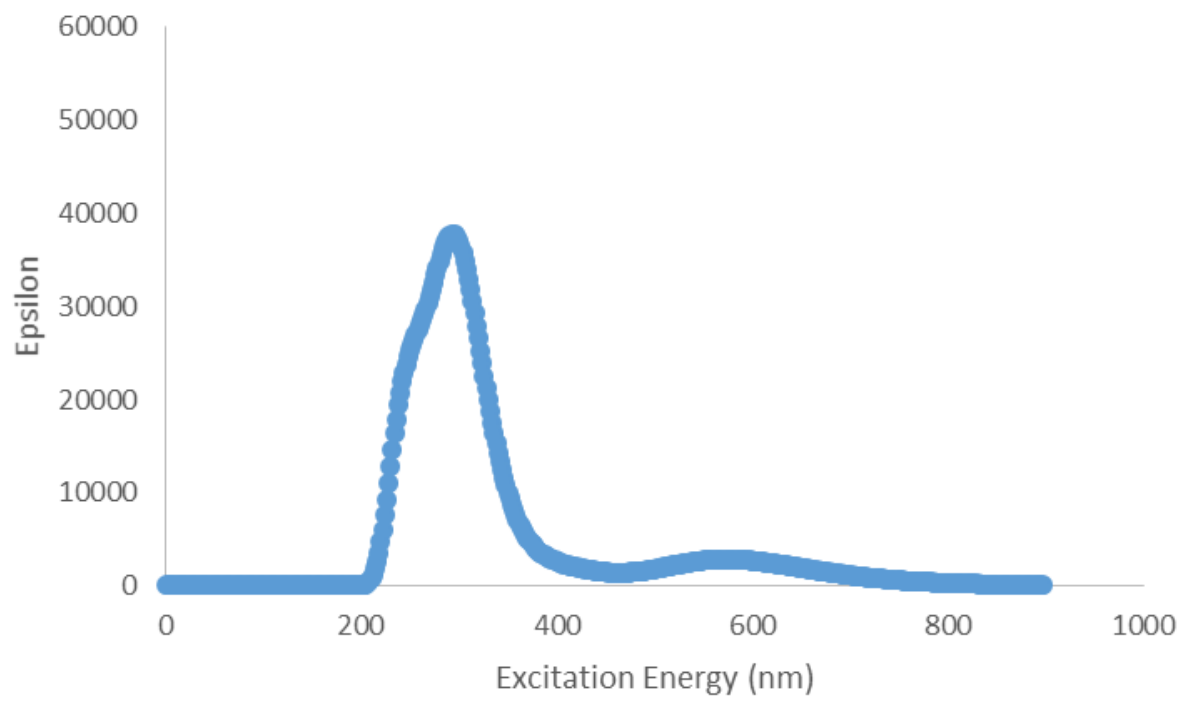

Figure S8. Calculated UV-Vis spectrum for compound 5 


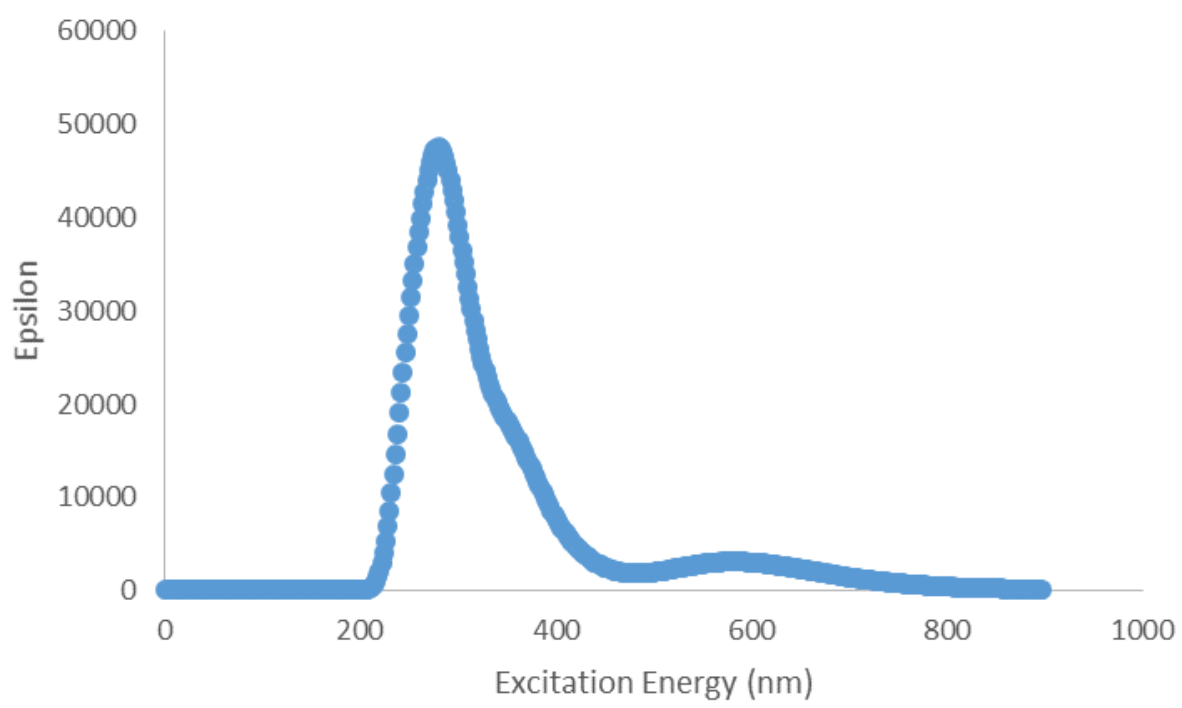

Figure S9: Calculated UV-Vis spectrum for compound 6

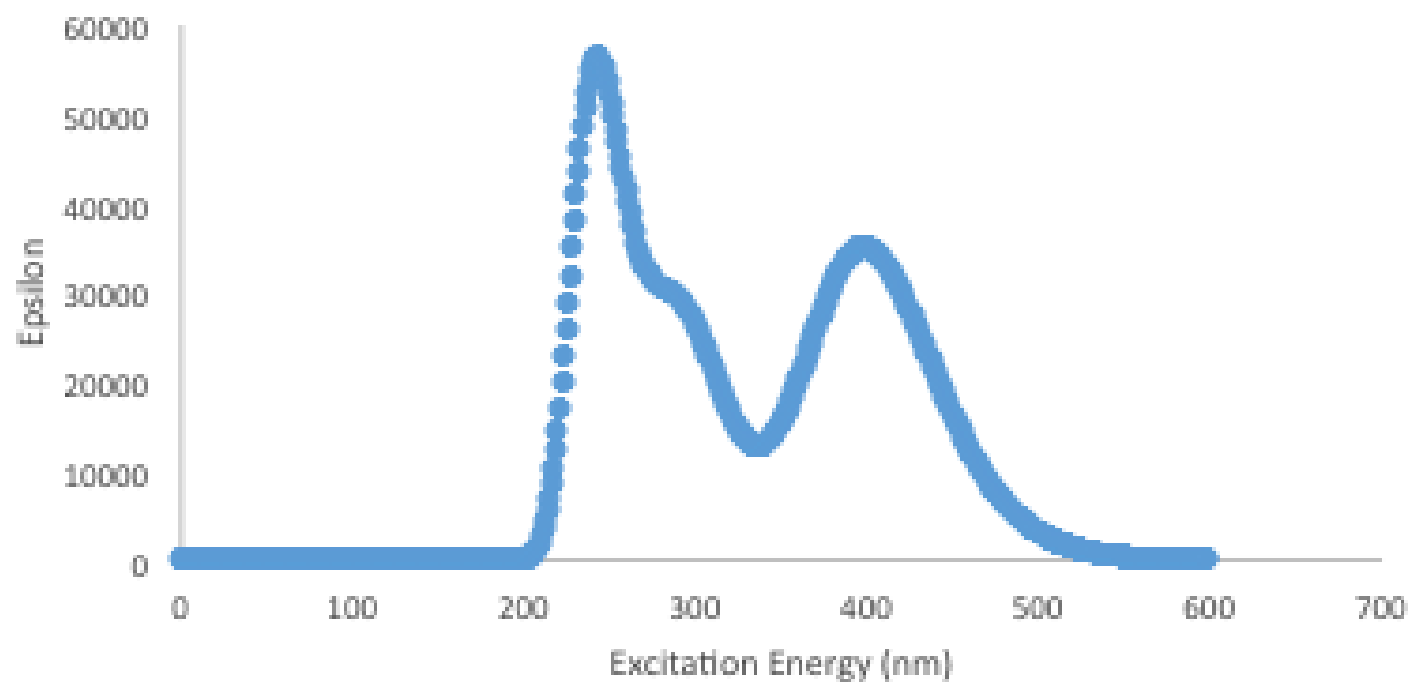

Figure S10. Calculated UV-Vis spectrum for compound $\mathbf{1} \cdot \mathbf{C O}$ 


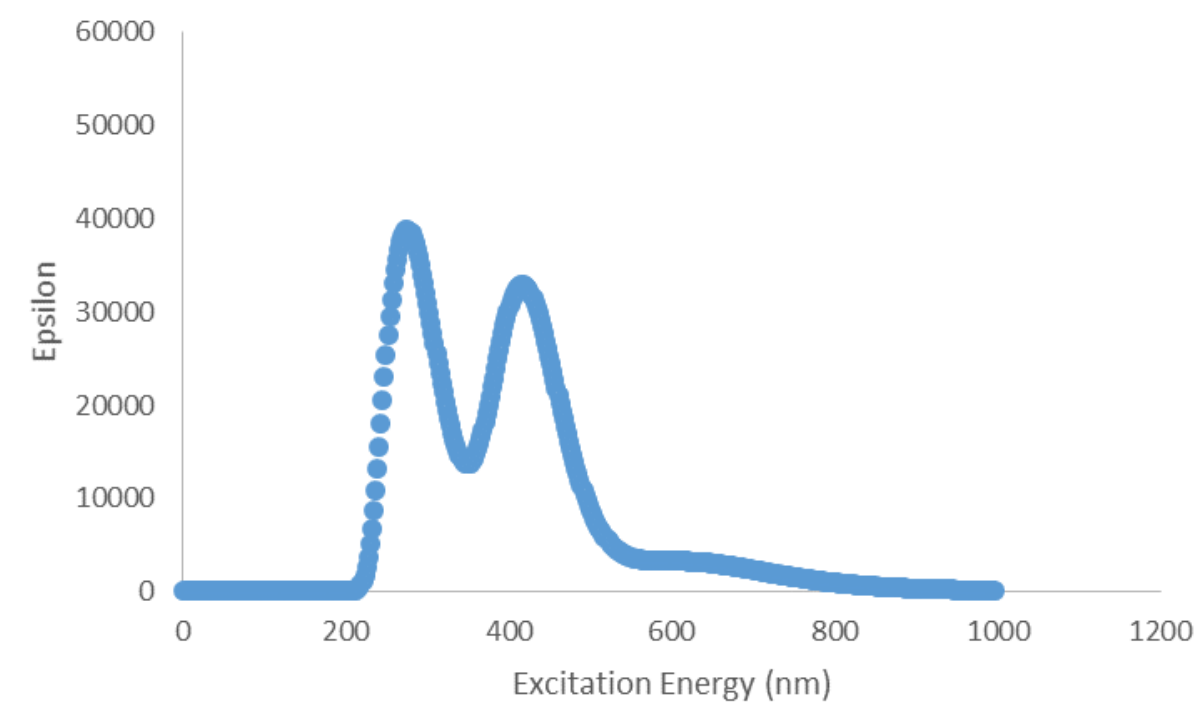

Figure S11. Calculated UV-Vis spectrum for compound $\mathbf{5} \cdot \mathbf{C O}$

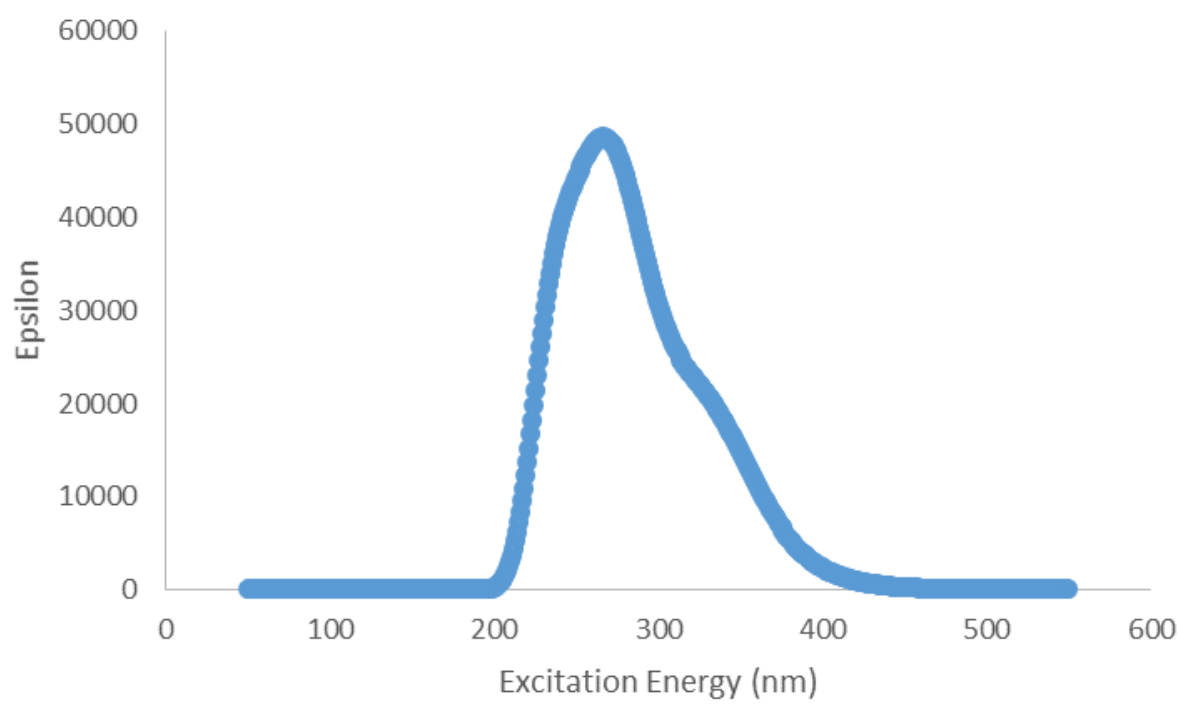

Figure S12: Calculated UV-Vis spectrum for compound $\mathbf{6} \cdot \mathbf{C O}$ 


\section{Comparisons of calculated spectra}

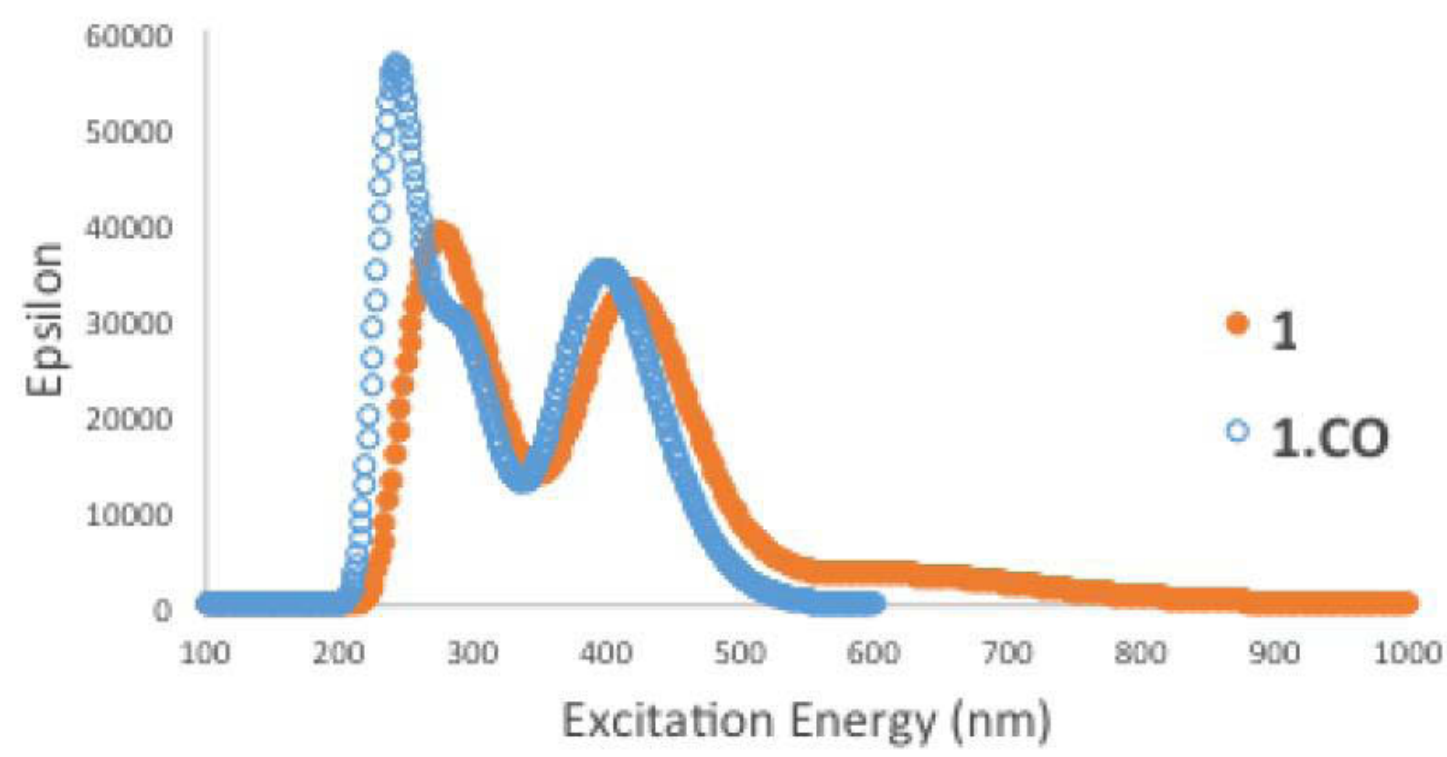

Figure S13. Comparison of calculated UV-Vis spectra for compounds $\mathbf{1}$ and $\mathbf{1} \cdot \mathbf{C O}$

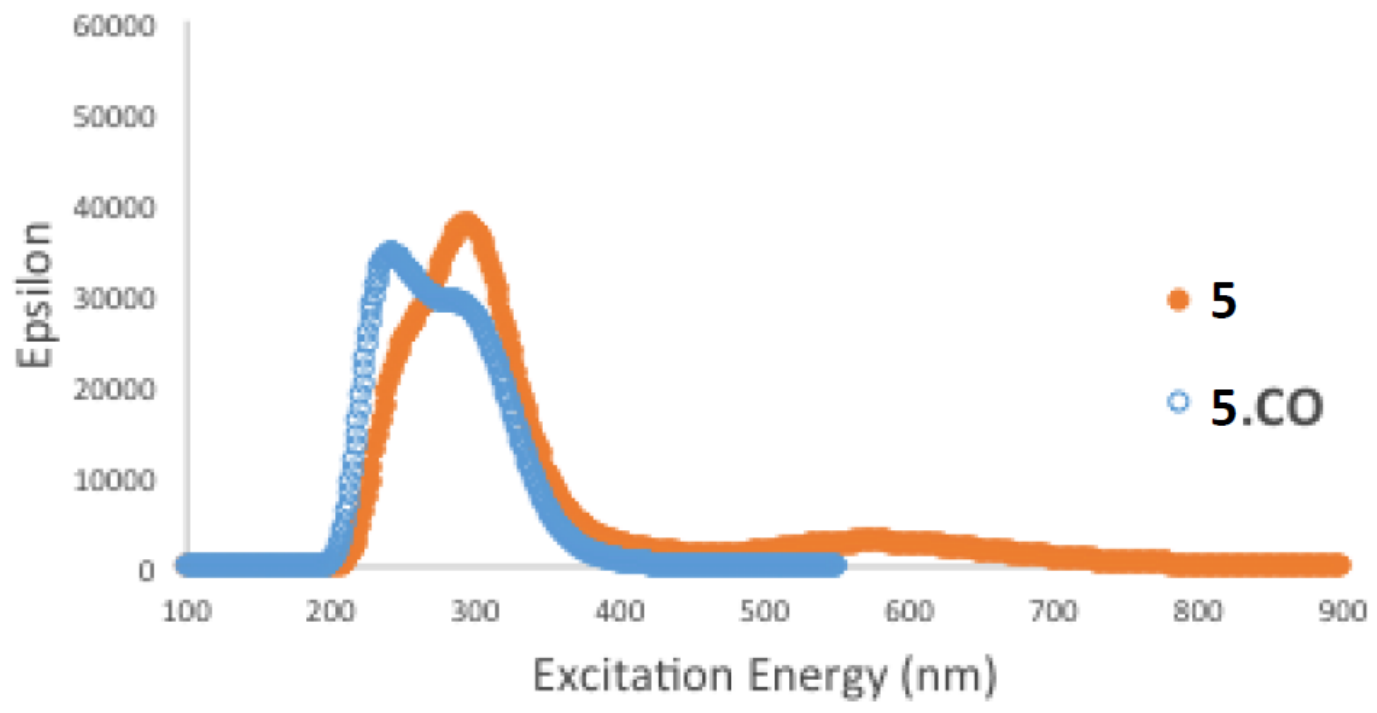

Figure S14. Comparison of calculated UV-Vis spectra for compounds $\mathbf{5}$ and $\mathbf{5} \cdot \mathbf{C O}$ 


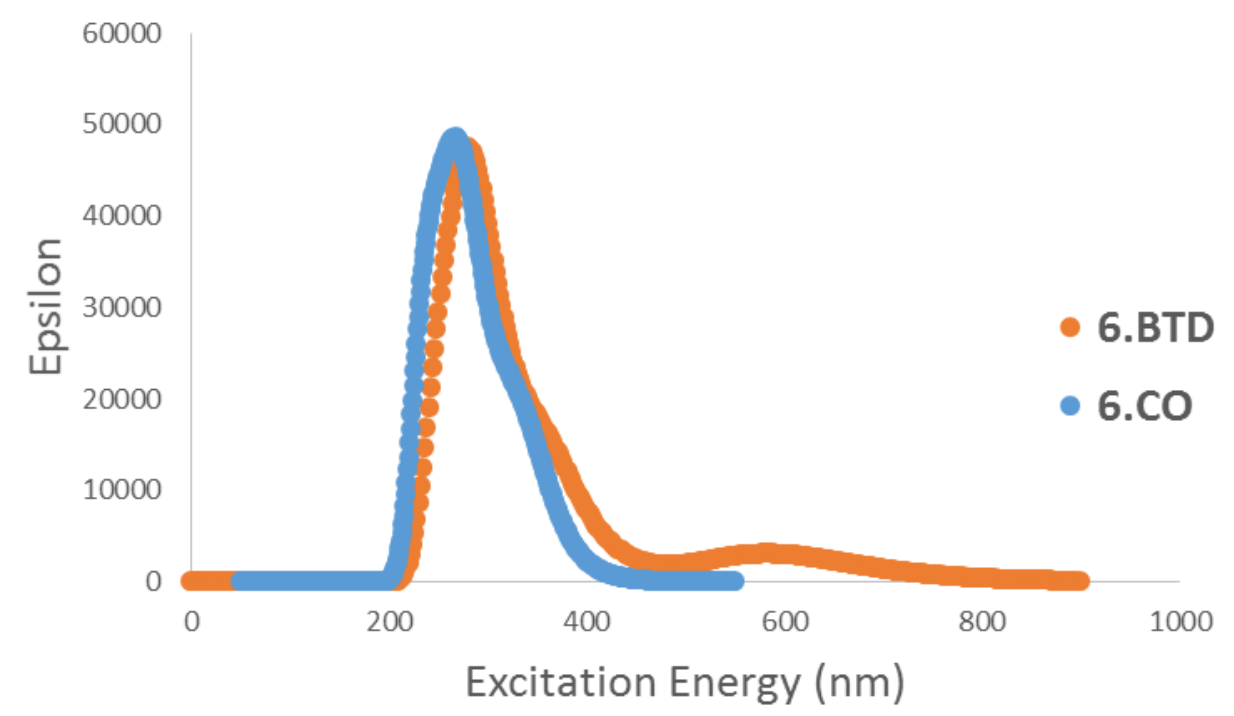

Figure S15. Comparison of calculated UV-Vis spectra for compounds $\mathbf{6}$ and $\mathbf{6} \cdot \mathbf{C O}$

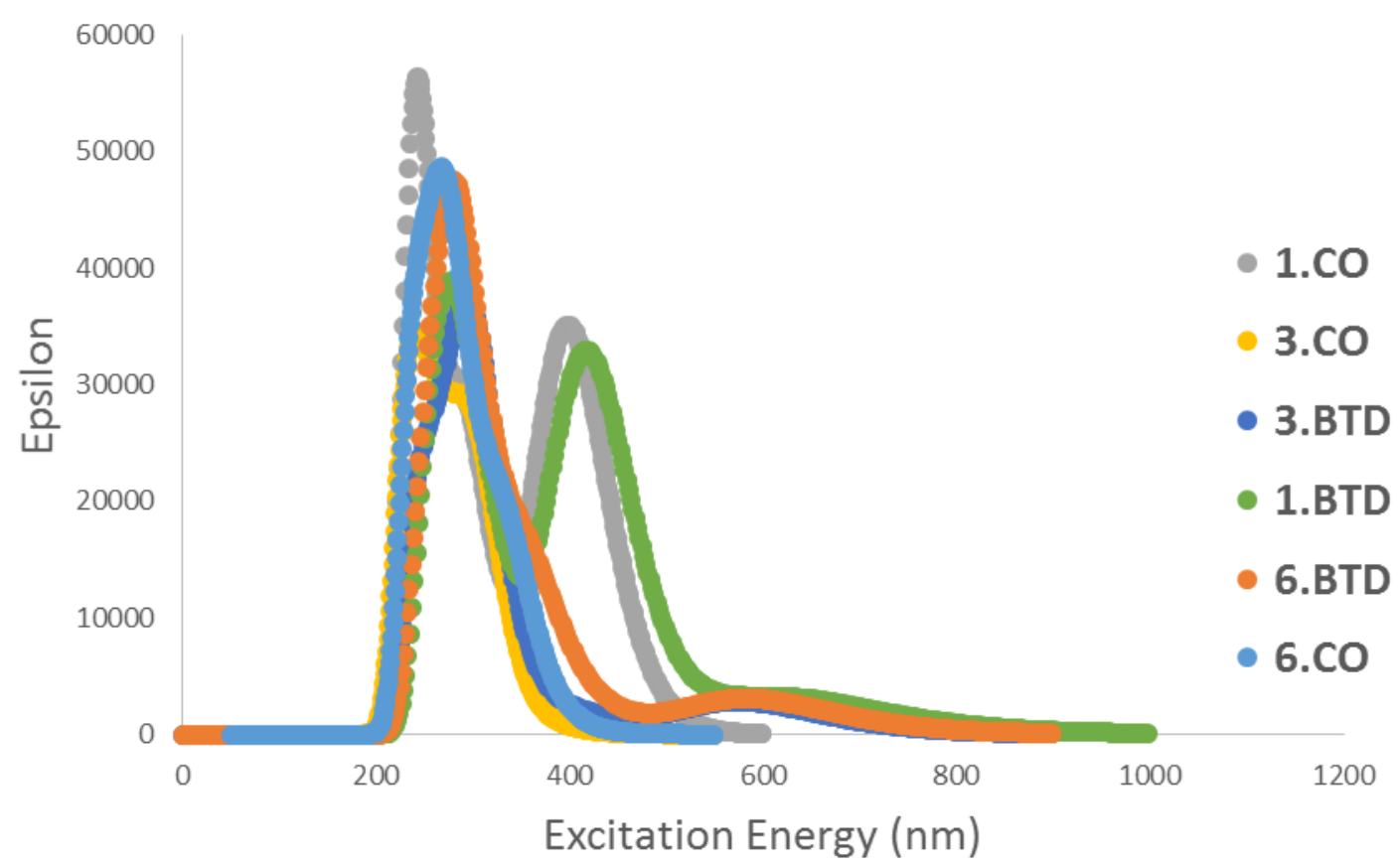

Figure S16. Comparison of calculated UV-Vis spectra for compounds $\mathbf{1}, \mathbf{1} \cdot \mathbf{C O}, \mathbf{5}$ and $\mathbf{5} \cdot \mathbf{C O}$. 


\section{Interferents}

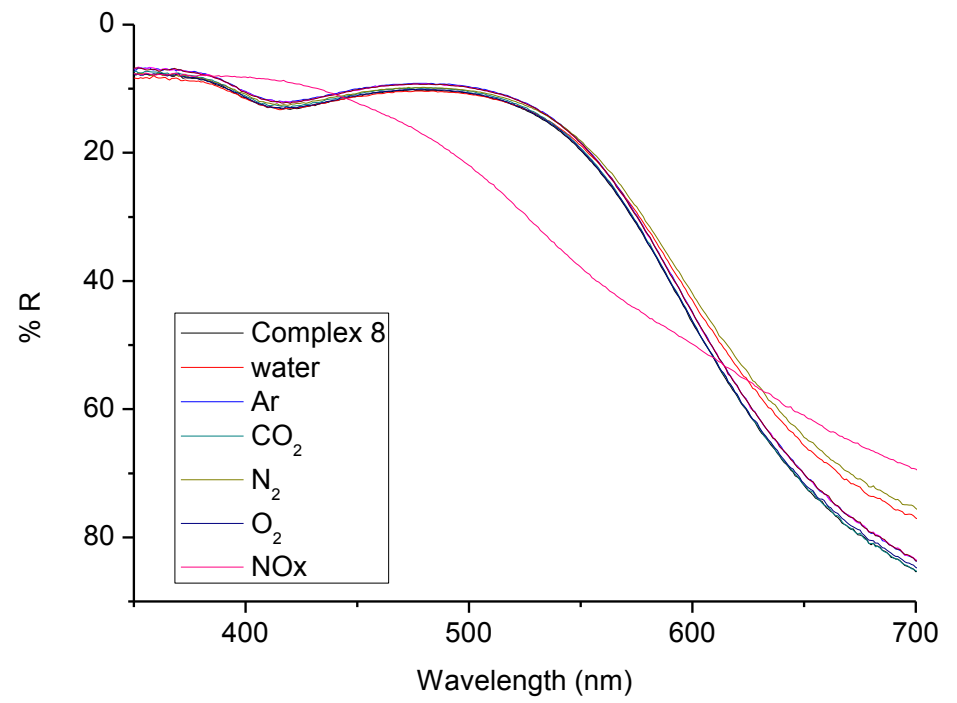

Figure S17. Diffuse reflectance spectra of compound $\mathbf{8}$ recorded in presence of water vapour (steam) and other gases at exceptionally high concentrations (5000 ppm). The only species which causes a change in the spectrum is NOx, at a concentration ten thousand times higher than that permitted by EU air quality standards.

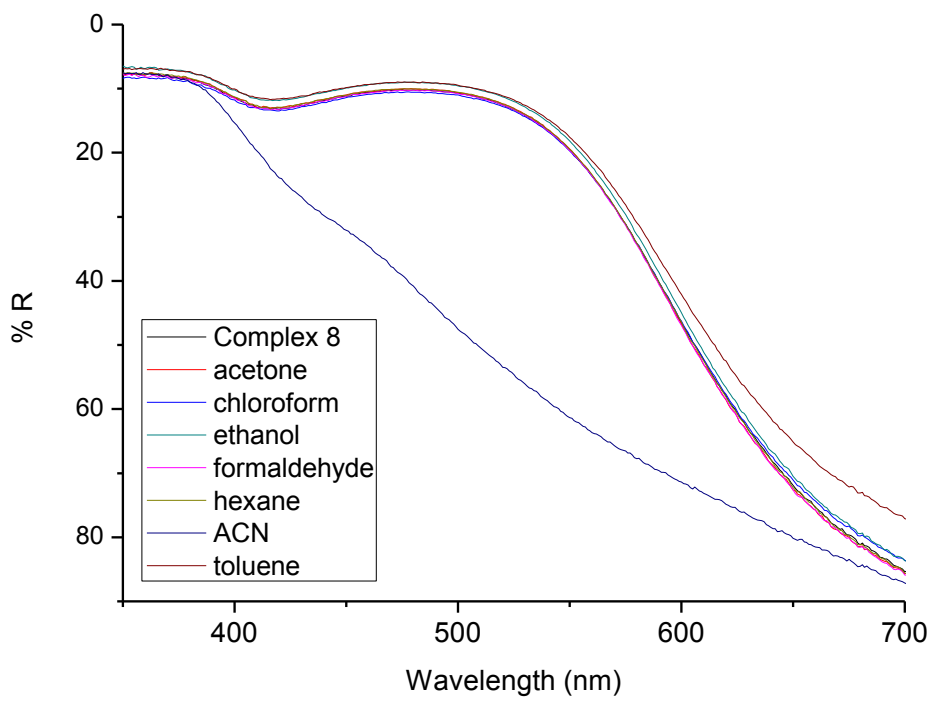

Figure S18. Diffuse reflectance spectra of compound $\mathbf{8}$ recorded in the presence of different solvent vapours at extremely high concentrations $(5000 \mathrm{ppm})$. The only solvent affecting the system is acetonitrile $(\mathrm{ACN})$ when added in very high concentrations (which far exceed any situation in which the sensor will be used). In the main text, the detection limits of the interferents are reported (see Table 5). 


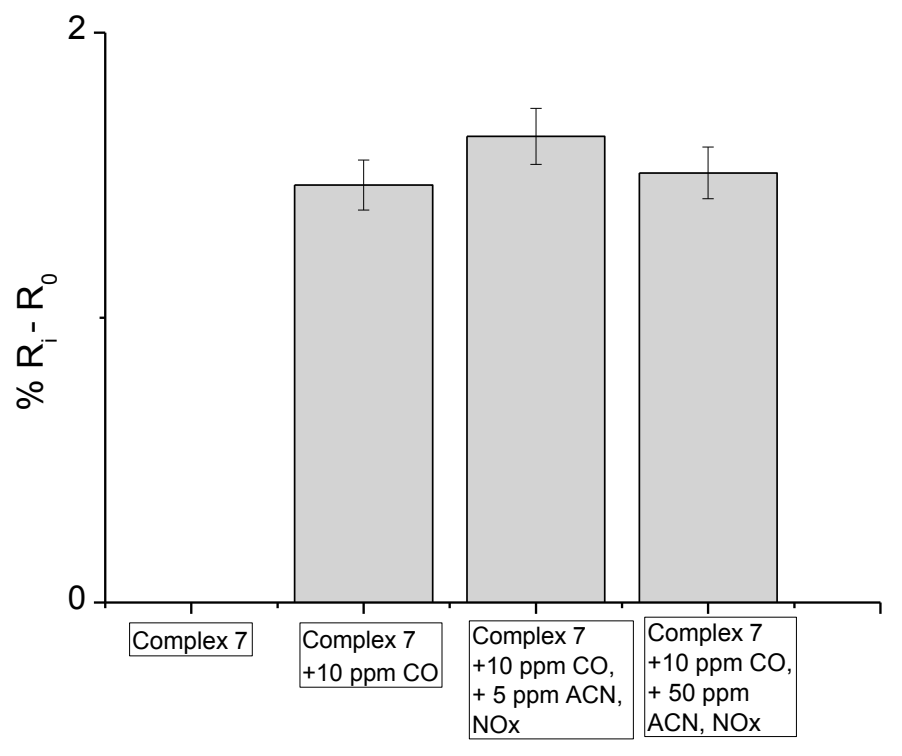

\section{Complex 7}

Figure S19. The graph shows the detection of CO in the presence of low (5 ppm of each interferent) and moderate concentrations (50 ppm of each interferent) of acetonitrile $(\mathrm{ACN})$ and $\mathrm{NO}_{\mathrm{x}}\left(\mathrm{R}_{0}\right.$ is the diffuse reflectance intensity of compound 7 before the experiment; $R_{i}$ is the diffuse reflectance intensity of compound 7 in the presence of the conditions indicated). As shown by the error bars (error $=3 \%$ ), there is no significant difference between the diffuse reflectance intensity of compound 7 with $10 \mathrm{ppm}$ of $\mathrm{CO}$ and in the presence of $10 \mathrm{ppm}$ along with the shown concentrations of the two interferents. 


\section{Detection limits}

The calculation of the detection limits was determined using a graphical method. According to this method, the detection limit is determined by the value at the intersection of the two linear fitting equations obtained by plotting the diffuse reflectance values at a particular wavelength (indicated on yaxis) versus the logarithm of the CO concentration. The results are shown below in Figure S20a-h:

Figure S20a. Compound 1

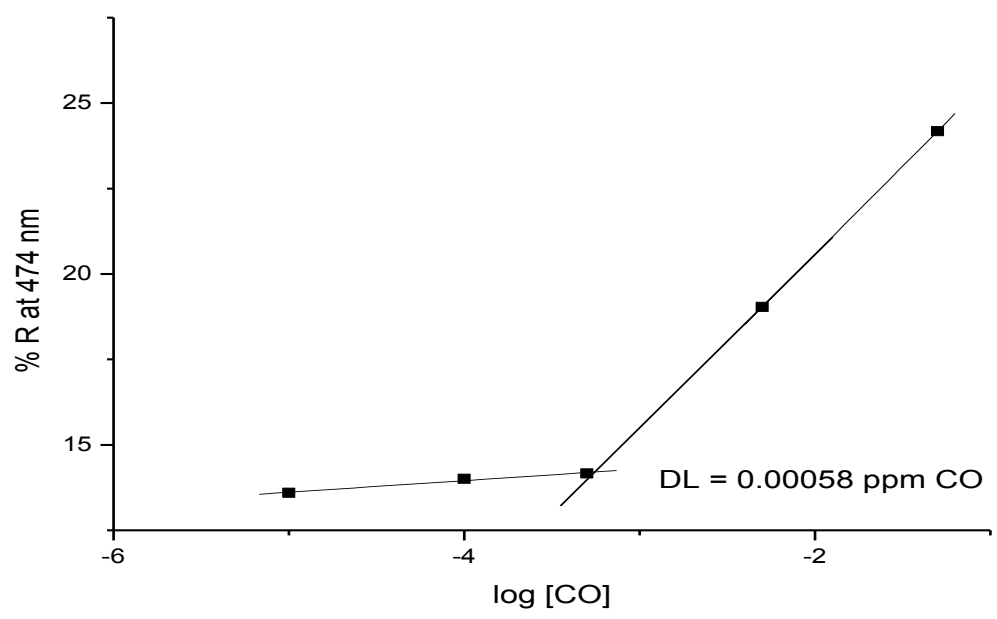

Figure S20b. Compound 2

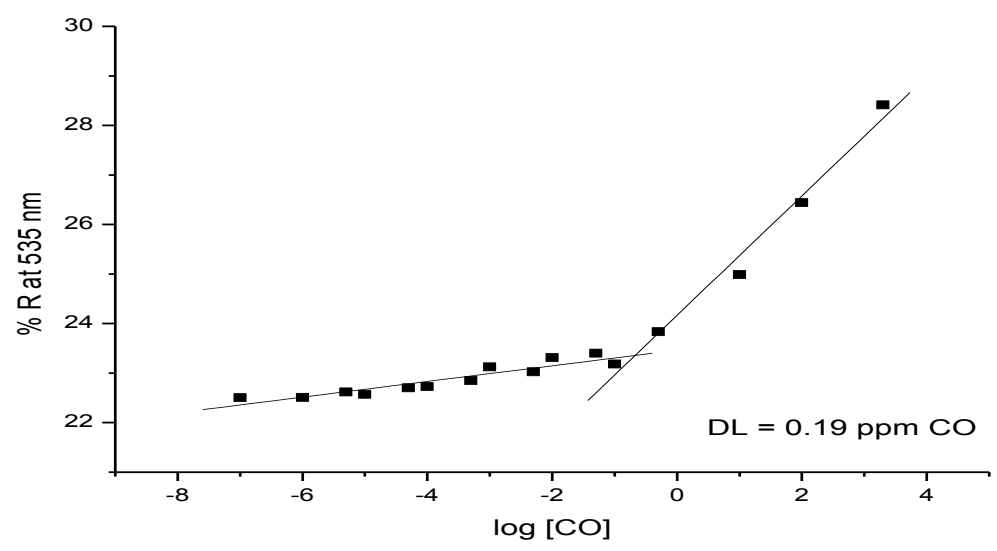


Figure S20c. Compound 3

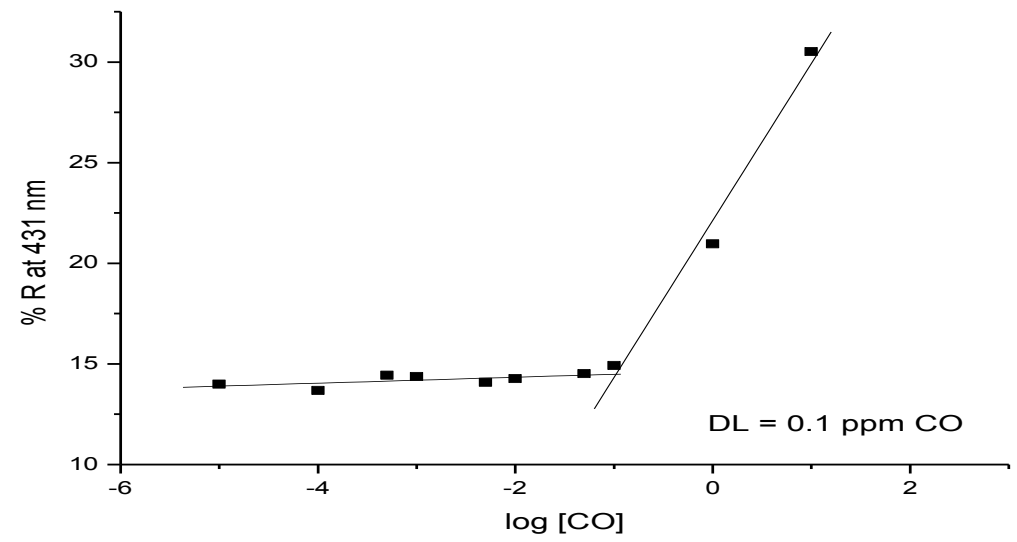

Figure S20d. Compound 4

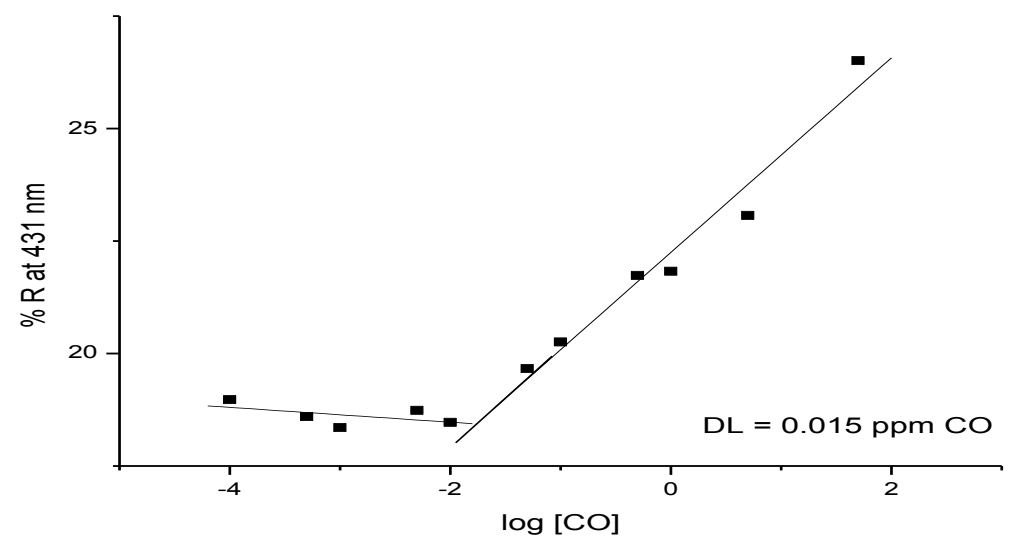

Figure S20e. Compound 5

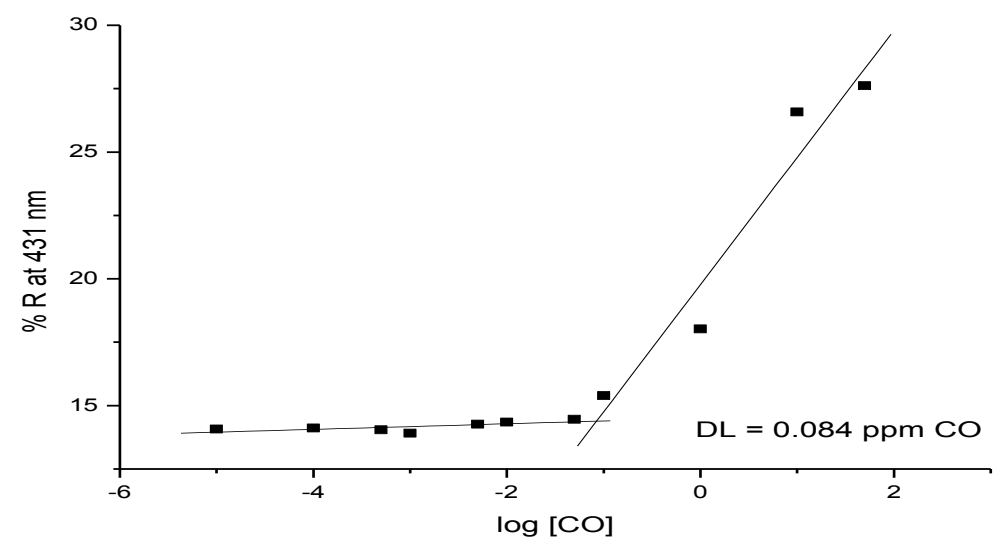


Figure S20f. Compound 6

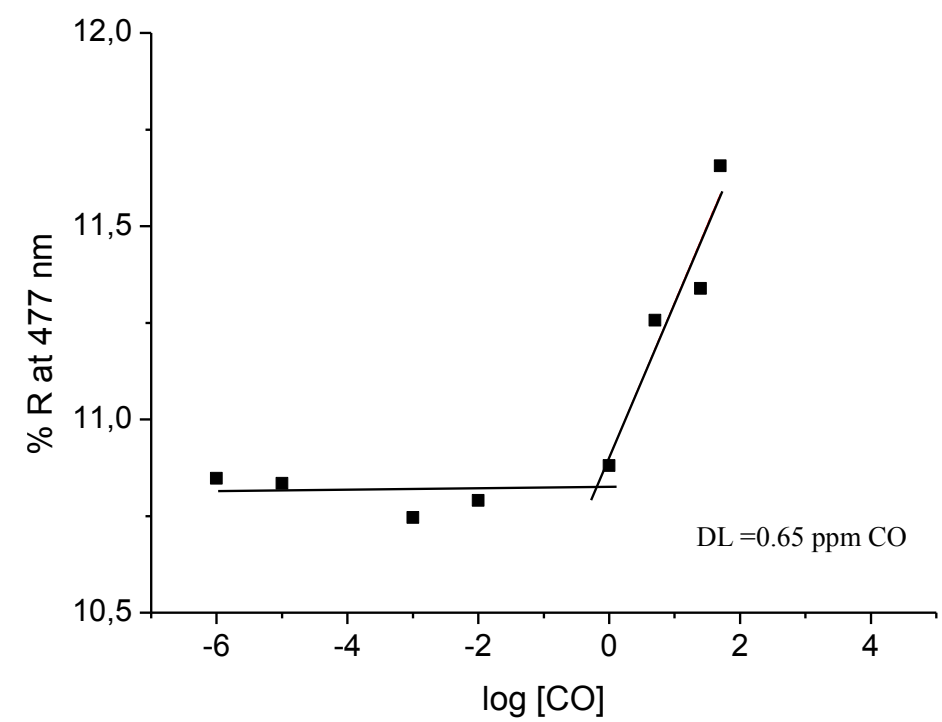

Figure S20g. Compound 7

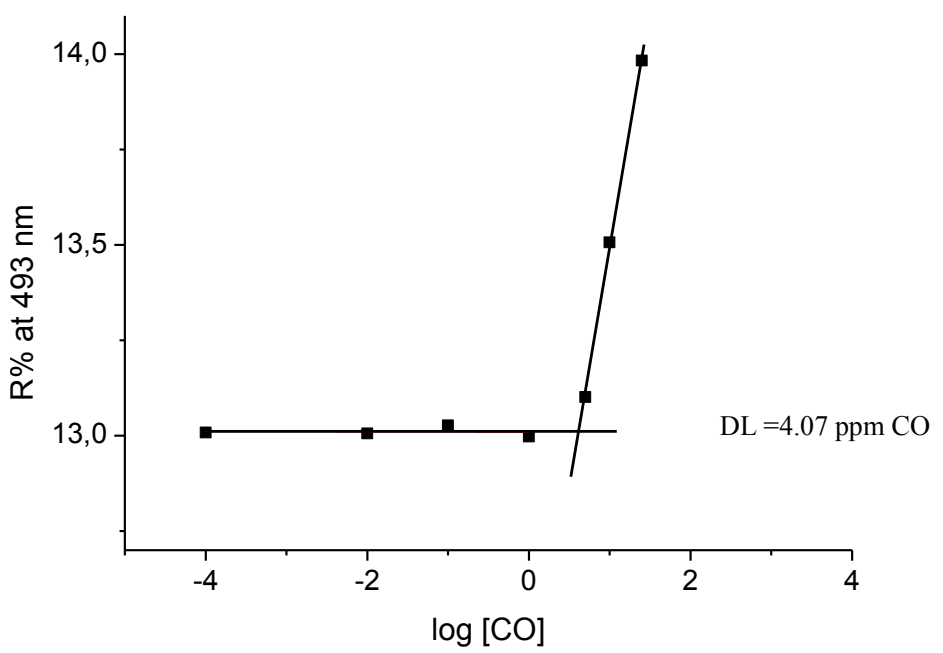


Figure S20h. Compound 8

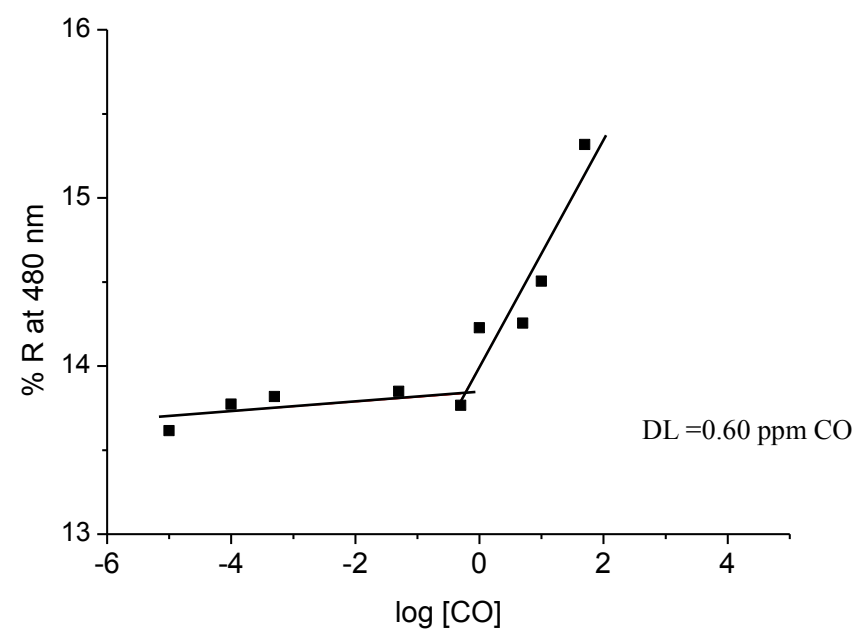

\begin{tabular}{|c|c|c|c|}
\hline Compound & $\begin{array}{c}\text { DL }(\mathrm{ppm}) \\
\text { Graph method }\end{array}$ & $\begin{array}{c}\text { Calculated 3 } \sigma \text { value } \\
\text { using the } 3 \sigma \text { method }\end{array}$ \\
\hline $\mathbf{6}$ & 0.65 & 0.14 & 1.94 \\
\hline $\mathbf{7}$ & 4.07 & 0.03 & 4.46 \\
\hline $\mathbf{8}$ & 0.60 & 0.24 & 1.34 \\
\hline
\end{tabular}

Figure S20i. The detection limits (DL) for the representative compounds $\mathbf{6 , 7}$ and $\mathbf{8}$ were also calculated with the $3 \sigma$ method and these values are reported in the table above. From the data sets, the standard deviation $(\sigma)$ was calculated using the data treatment method with $99 \%$ confidence interval applied by tdistribution. The detection limits (DL) were then determined by extrapolation using the respective $3 \sigma$ deviations. The agreement is found to be good. 


\section{Stoichiometry of the reaction and Job plot}

The titration experiment was performed by adding increasing concentrations of CO gas to a DCM- $\mathrm{d}_{2}$ solution of compound $7(0.008 \mathrm{M})$, until the conversion from 7 to $\mathbf{7} \mathbf{C O}$ was complete. The conversion was monitored via ${ }^{1} \mathrm{H}$ NMR spectroscopy. The concentrations of the two species 7 and $7 \mathbf{C O}$ were determined using tetramethylsilane (TMS) as a reference in a sealed capillary $(0.008 \mathrm{M})$.

A CO/Ar gas mixture containing $700 \mathrm{ppm}\left(863 \mathrm{mg} / \mathrm{m}^{3}\right)$ of CO was prepared and used as a source of $\mathrm{CO}$ for the whole titration. Aliquots of $15 \mathrm{~mL}$ of $\mathrm{CO} / \mathrm{Ar}$ mixture, containing approximately $4.62 \cdot 10^{-7}$ mol of CO, were slowly and carefully bubbled through the solution of compound 7 , so as to ensure that the volume of the solution $(600 \mu \mathrm{L})$ was maintained at a constant level throughout the experiment.

In order to reproduce the same conditions applied during the UV-Vis and fluorescence spectroscopy experiments, it was decided to use a standard NMR tube rather than a Young's Tap NMR tube.

From the ${ }^{1} \mathrm{H}$ NMR spectra, the concentration of $7 \mathbf{C O}$ was calculated as a function of the variation of the respective proton integrations and determine the stoichiometry of the reaction. 

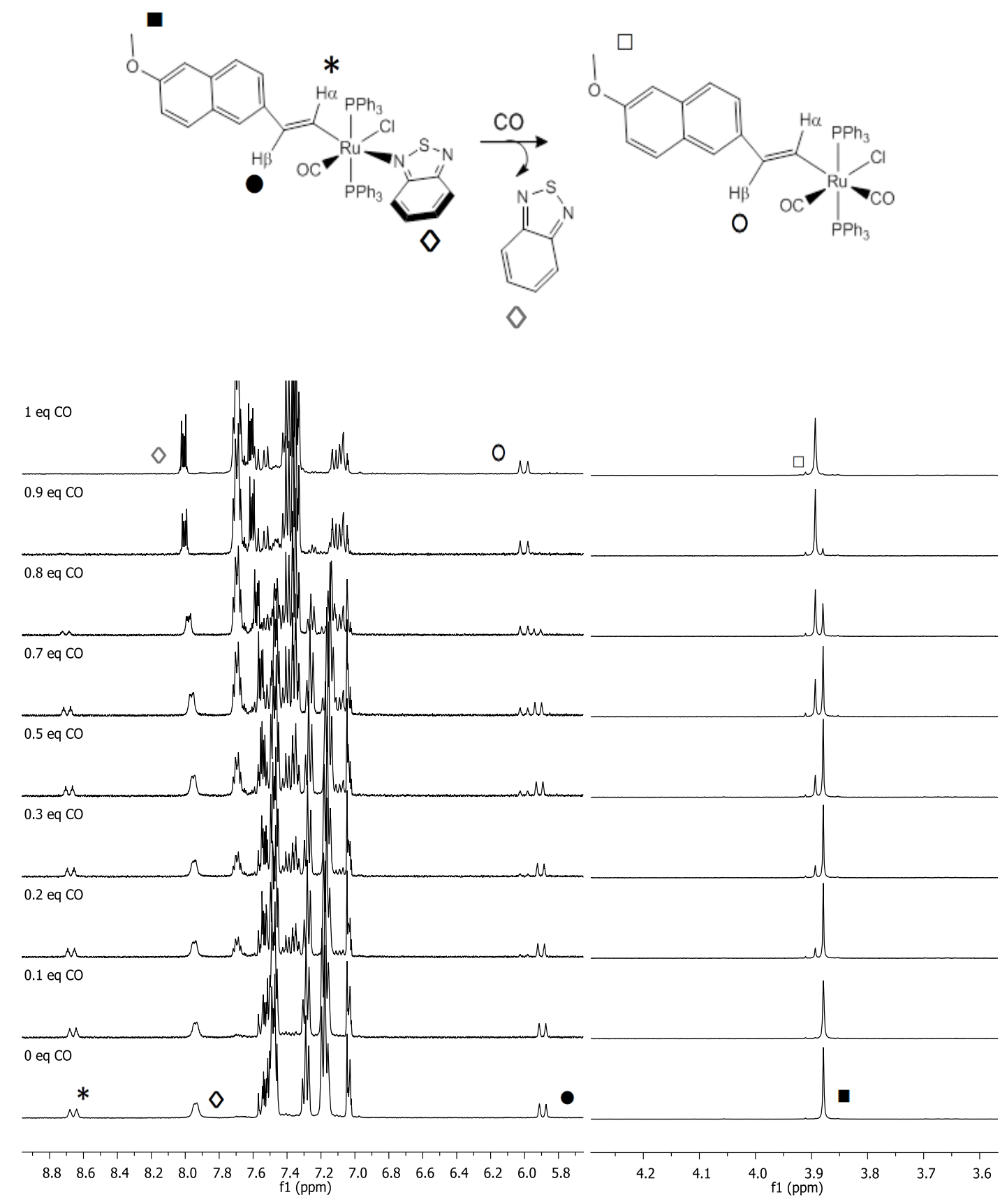

Figure S21. The ${ }^{1} \mathrm{H}$ NMR spectra showing the conversion of compound $\mathbf{7}$ (bottom, 0 eq) to $7 \mathbf{C O}$ (top, 1 eq).

The raw data obtained from the spectra are given below: 


\begin{tabular}{|c|c|c|c|c|}
\hline Compound 7 (mol) & Integral & CO (mol) & Compound 7 CO (mol) & Integral \\
& $\mathbf{0}$ & & 0 & 0 \\
\hline $4.95771 \mathrm{E}-06$ & 1.0353 & 0 & $9.08 \mathrm{E}-08$ & 0.227 \\
$3.7424 \mathrm{E}-07$ & 0.9356 & $4.62 \mathrm{E}-07$ & $1.3804 \mathrm{E}-07$ & 0.3451 \\
$3.4248 \mathrm{E}-07$ & 0.8562 & $9.24 \mathrm{E}-07$ & $1.922 \mathrm{E}-07$ & 0.4805 \\
$2.7948 \mathrm{E}-07$ & 0.6987 & $1.39 \mathrm{E}-06$ & $2.2732 \mathrm{E}-07$ & 0.5683 \\
$2.4404 \mathrm{E}-07$ & 0.6101 & $1.85 \mathrm{E}-06$ & $2.8100 \mathrm{E}-07$ & 0.7025 \\
$1.5388 \mathrm{E}-07$ & 0.3847 & $2.31 \mathrm{E}-06$ & $2.9288 \mathrm{E}-07$ & 0.7322 \\
$8.104 \mathrm{E}-08$ & 0.2026 & $2.77 \mathrm{E}-06$ & $3.8872 \mathrm{E}-07$ & 0.9718 \\
$5.56 \mathrm{E}-08$ & 0.139 & $3.23 \mathrm{E}-06$ & $4.1424 \mathrm{E}-07$ & 1.0356 \\
0 & 0 & $3.70 \mathrm{E}-06$ & & \\
\hline
\end{tabular}

According to the variation method, the stoichiometry of the reaction can be determined by plotting $\frac{n}{(n+m)}[7 \mathbf{C O}]_{\mathrm{t}}$ vs. the molar fraction of $\mathbf{7 \cdot C O}$, where $n$ and $m$ are the integrations of the $\bullet$ and $\circ$ protons of the species $\mathbf{7}$ and $\mathbf{7 \cdot C O}$ respectively. ${ }^{\mathrm{S} 1}$

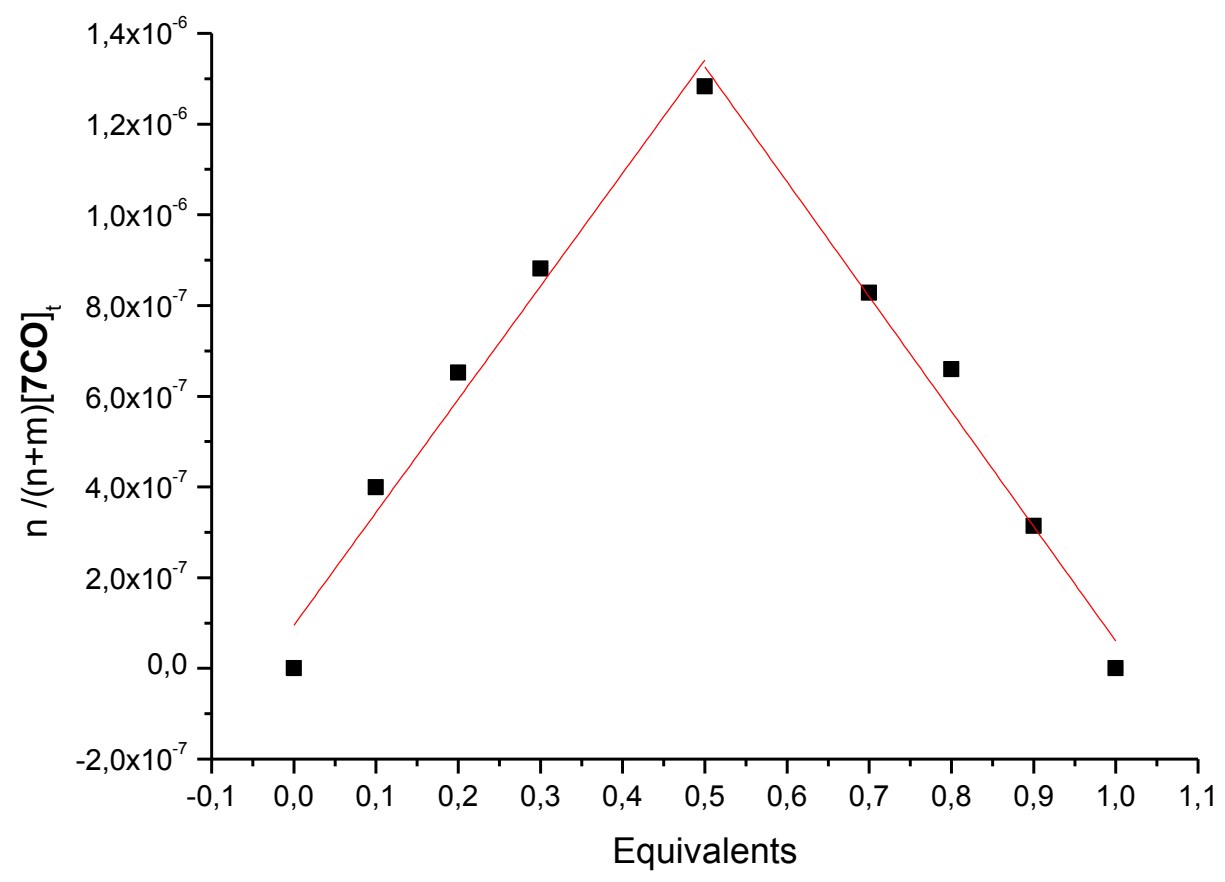

Figure S22. The Job plot confirms the 1:1 stoichiometry of the reaction in which one equivalent of 7 reacts with one equivalent of $\mathrm{CO}$ to afford one equivalent of $7 \mathbf{C O}$. 
The reaction can also be represented by plotting the percentage conversion of species 7 into $7 \mathbf{C O}$ as a function of the equivalents of $\mathrm{CO}$ added:

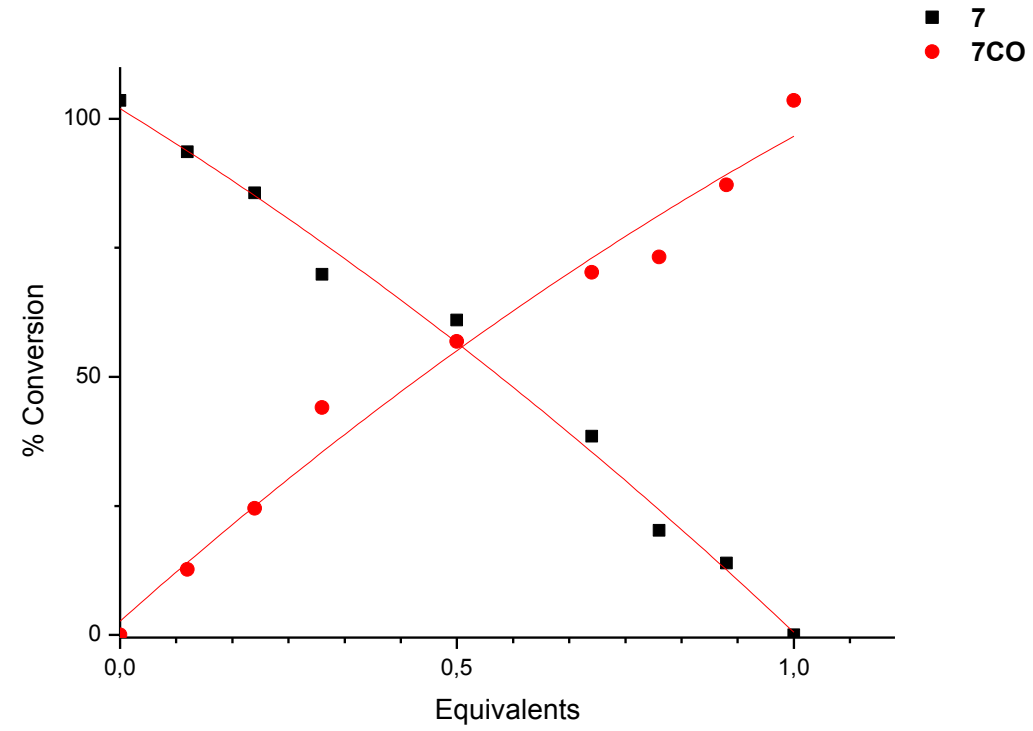

Figure S23. Conversion of 7 into $7 \mathbf{C O}$ as a function of the equivalents of $\mathrm{CO}$ added.

The raw data obtained are given below:

\begin{tabular}{|c|c|c|}
\hline eq & \% conversion 7 & \% conversion 7 CO \\
\hline 0 & 103.53 & 0 \\
0.1 & 93.56 & 22.7 \\
0.2 & 85.62 & 34.51 \\
0.3 & 69.87 & 48.05 \\
0.5 & 61.01 & 56.83 \\
0.7 & 38.47 & 70.25 \\
0.8 & 20.26 & 73.22 \\
0.9 & 13.9 & 97.18 \\
1 & 0 & 103.56 \\
\hline
\end{tabular}


The reaction between the ruthenium(II) or osmium(II) vinyl compounds and carbon monoxide can be considered as a 1:1 displacement reaction described by the general equation:

$$
\mathrm{A}+\mathrm{B} \rightarrow \mathrm{C}+\mathrm{D}
$$

Where, in this case, $\mathrm{A}=\mathbf{7}, \mathrm{B}=\mathrm{CO}, \mathrm{C}=\mathbf{7 \cdot C O}$ and $\mathrm{D}=\mathrm{BTD}$ and the species $\mathrm{C}$ and $\mathrm{D}$ are plotted as function of the mole fraction of either $\mathrm{A}$ or $\mathrm{B}$.

The equilibrium is described by:

$$
\begin{gathered}
\mathrm{K}=\frac{[7 \mathrm{CO}] \cdot[\mathrm{BTD}]}{[7] \cdot[\mathrm{CO}]} \\
\mathrm{C}_{7}^{0}=\mathrm{C}_{7}+\mathrm{C}_{7 \mathrm{CO}} \\
\mathrm{C}_{\mathrm{CO}}^{0}=\mathrm{C}_{\mathrm{BTD}}+\mathrm{C}_{7 \mathrm{CO}} \\
\mathrm{C}_{7 \mathrm{CO}}=\mathrm{C}_{\mathrm{BTD}}
\end{gathered}
$$

\section{Binding constants}

As mentioned in Section 8 of the Supporting Information, the reaction between the ruthenium(II) or osmium(II) vinyl compounds bearing the BTD ligand [PR(BTD)] and carbon monoxide to form [PR(CO)] can be considered as a 1:1 displacement reaction described by equation:

$$
\mathbf{P R}(\mathrm{BTD})+\mathbf{C O} \rightarrow \mathbf{P R}(\mathrm{CO})+\mathrm{BTD}
$$

\begin{tabular}{|c|c|}
\hline Compound & Binding constant (K) \\
\hline $\mathbf{7}$ & $6.56 \pm 0.17$ \\
\hline $\mathbf{8}$ & $6.67 \pm 0.06$ \\
\hline
\end{tabular}

Figure S24. The binding constants calculated for compounds 7 and $\mathbf{8}$. These were determined using HypSpec software, using fluorescence spectroscopic titration data. 


\section{References}

S1 K. R. Laing, W. R. Roper, J. Chem. Soc. A 1970, 2149-2153.

S2 A. F. Hill, J. D. E. T. Wilton-Ely, J. Chem. Soc., Dalton Trans. 1999, 3501-3510.

S3 R. B. Bedford, A. F. Hill, C. Jones, A. J. P. White, D. J. Williams, J. D. E. T. Wilton-Ely, Organometallics 1998, 17, 4744-4753.

S4 H. Loumrhari, J. Ros, M. R. Torres, A. Santos, A. M. Echavarren, J. Organomet. Chem. 1991, $411,255-261$.

S5 M. E. Moragues, A. Toscani, F. Sancenón, R. Martínez-Máñez, A. J. P. White, J. D. E. T. Wilton-Ely, J. Am. Chem. Soc. 2014, 136, 11930-11933.

S6 (a) SHELXTL, Bruker AXS, Madison, WI; (b) SHELX-97, G.M. Sheldrick, Acta Cryst., 2008, A64, 112-122; (c) SHELX-2013, http://shelx.uni-ac.gwdg.de/SHELX/index.php

S7. $\quad$ K. Hirose, J. Incl. Phenom. Macro. 2001, 39, 193 - 209. 